\title{
Opportunities and Barriers for Ontario Teachers in their Delivery of Environmental Education using Information and Communication Technologies
}

\author{
By \\ Courtney Carrier \\ Honours Bachelor of Arts \\ Environment and Urban Sustainability \\ Ryerson University, 2017
}

\author{
A thesis \\ presented to Ryerson University \\ in partial fulfillment of the \\ requirements for the degree of \\ Master of Applied Science \\ in the program of \\ Environmental Applied Science and Management
}

Toronto, Ontario, Canada, 2020

(C) Courtney Carrier, 2020 


\section{AUTHOR'S DECLARATION}

I hereby declare that I am the sole author of this thesis. This is a true copy of the thesis, including any required final revisions, as accepted by my examiners.

I authorize Ryerson University to lend this thesis to other institutions or individuals for the purpose of scholarly research.

I further authorize Ryerson University to reproduce this thesis by photocopying or by other means, in total or in part, at the request of other institutions or individuals for the purpose of scholarly research.

I understand that my thesis may be made electronically available to the public. 


\title{
Opportunities and barriers for Ontario Teachers in their Delivery of Environmental Education using Information and Communication Technologies
}

\author{
Master of Applied Science \\ Environmental Applied Science and Management \\ Courtney Carrier \\ Ryerson University, 2020
}

\begin{abstract}
Teaching and learning about the environment in the present day is filled with possibility, challenge, and urgency. Government-mandated environmental curriculum, where it exists, can provide important pedagogical and content guidance. However, bottom-up and teacher-initiated approaches to the timely delivery of relevant and contemporary environmental education are required. This research identifies and describes barriers and opportunities to the delivery of environmental education in Ontario, Canada. It also explores the receptivity of teachers to the use of information and communication technologies (ICTs) as tools to complement existing instructional methods, and proposes refocusing on local geographies to exemplify humanenvironment interactions. Two methods of data collection were used: an online survey $(n=54)$, a semi-structured focus group $(\mathrm{n}=18)$. Both approaches engaged teachers within the Toronto District School Board (TDSB), Canada's largest school board. Three-quarters of study participants (76\%) identified that teaching about the environment with hands-on assignments (e.g., data collection, field observations, experiments) was beneficial to student learning. A similar majority of teachers (74\%) agreed that environmental education was an afterthought in the Ontario curriculum. A strong positive response from teachers was solicited when they were asked if ICTs were useful teaching tools. Using a Mantel-Haenszel test of trend, teachers' perception of student enjoyment in, and engagement with, subject matter was shown to be significantly positively associated with the frequency of environmental content included in their lessons $(\mathrm{p}<0.000)$. NVivo software was used with content arising from the focus group discussion, and a content analysis was run to identify the frequency with which educators described current environment-related teaching, providing both new details and offering greater context to the online survey responses. While highlighting systemic weaknesses in the delivery of environmental education in Ontario, this study identified tangible avenues that teachers and schools can pursue in order to bridge the gap between environmental rhetoric and action-oriented practice.
\end{abstract}

Keywords: environmental education, place-based learning, Ontario, information and communication technology (ICTs), policy, mixed methods 


\section{LAND ACKNOWLEDGEMENT}

The research described herein was conducted in the City of Toronto, which is in the 'Dish With One Spoon Territory'. The Dish With One Spoon is a treaty between the Anishinaabe, Mississaugas and Haudenosaunee that bound them to share the territory and protect the land. Subsequent Indigenous Nations and peoples, Europeans and all newcomers have been invited into this treaty in the spirit of peace, friendship and respect.

\section{RESEARCH ACKNOWLEDGEMENTS}

Undertaking this research project, as the final requirement of a master's in Environmental Applied Science and Management, has been a whirlwind adventure, filled with so many incredible learning experiences. It would not have been possible without the support and guidance from several organizations and from many people.

Financial support for the project was made possible by the TD Friends of the Environment Fund, Ryerson University's SSHRC Internal Grant (SIG), and Ryerson University's Innovation Circle Prize.

I would like to thank my supervisor, Dr. Andrew Millward, for his continued encouragement, support and guidance, throughout this thesis and master's program. It was with his encouragement that I decided to pursue this study, and I couldn't be more grateful. This project has been a pleasure and privilege to work on. I would also like to thank my committee members, Dr. Sara Edge and Dr. Greg Oulahen, for their guidance, expertise and for taking the time to serve as external readers. As well as Nikesh Bhagat, who provided valuable insights and technical support through this research.

Additionally, this research would not have been possible without the cooperation of Toronto District School Board (TDSB), and especially the support, expertise, and time from Karen Dobrucki and Pam Miller, with the Sustainability Office and EcoSchool's Program, respectively. I am also grateful for the time taken by each of the participants who completed the online survey, and contributed to the focus group.

Finally, I would like to express my utmost gratitude to my family, partner, and friends. I am incredibly fortunate and grateful to have had their love and continued encouragement during my graduate studies. Each of you played an important role in helping shape who I am today, and have always encouraged me to follow my interests and passions, which has led to this incredible milestone. 


\section{TABLE OF CONTENTS}

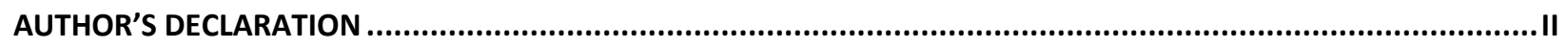

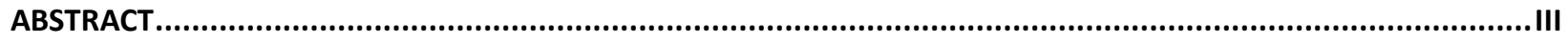

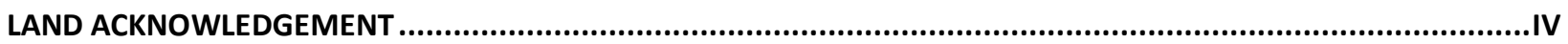

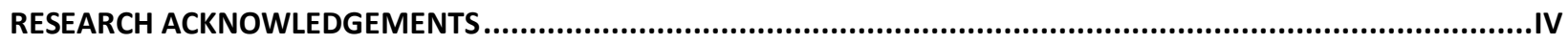

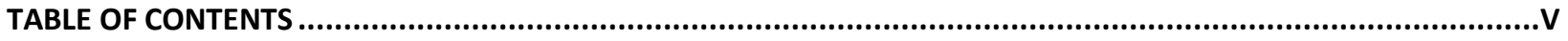

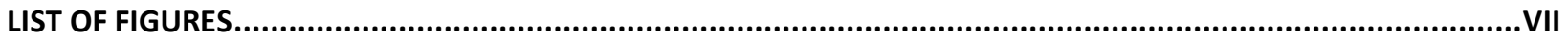

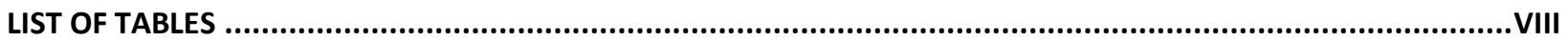

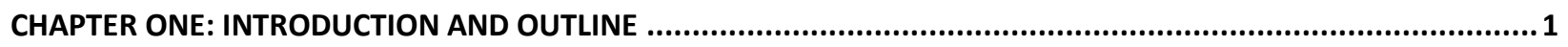

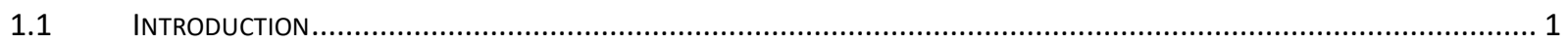

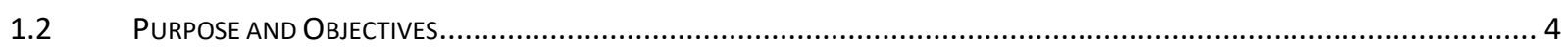

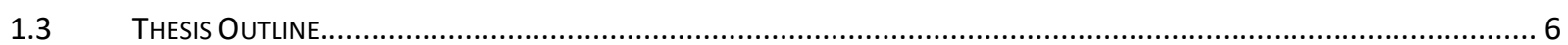

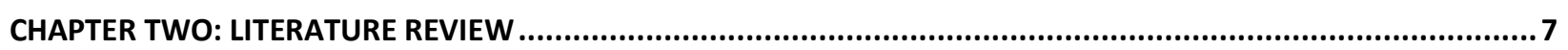

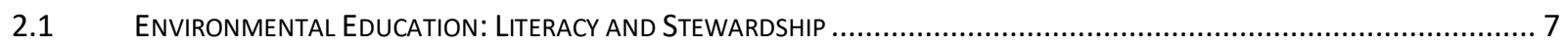

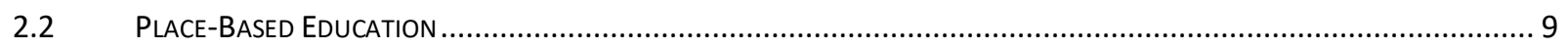

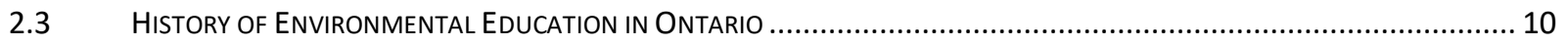

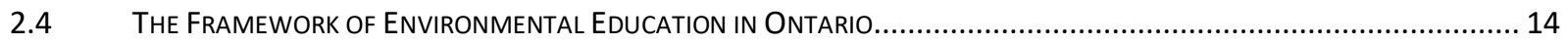

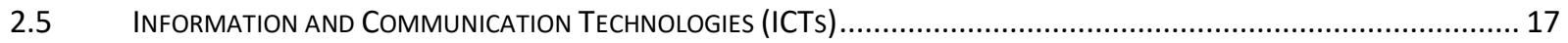

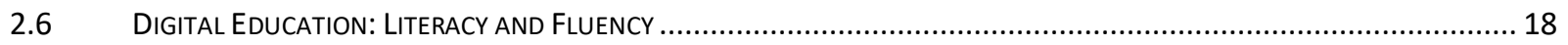

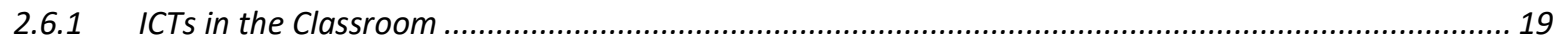

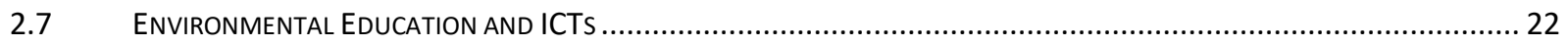

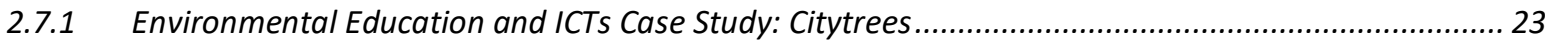

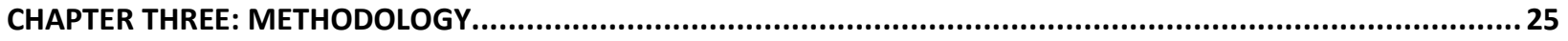

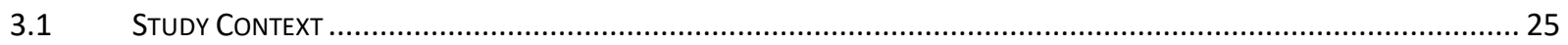

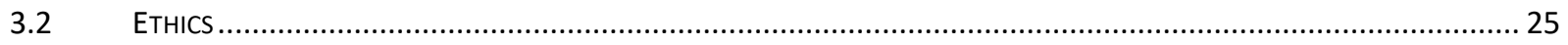

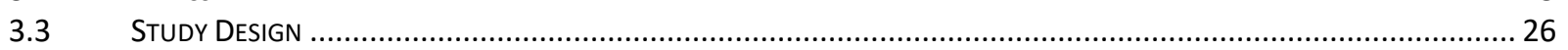

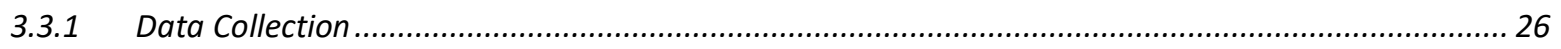

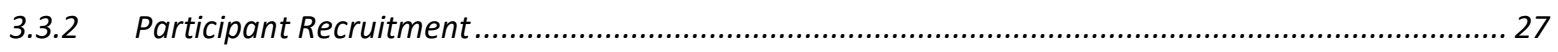

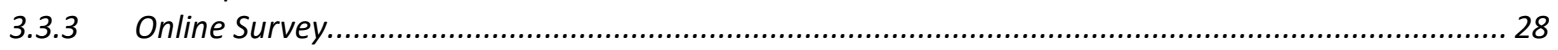

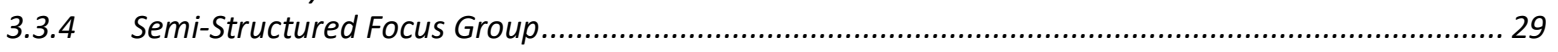

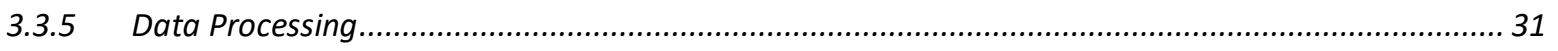

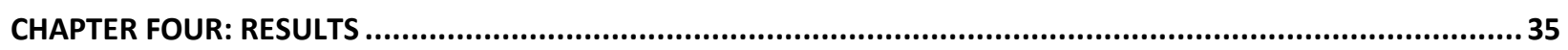

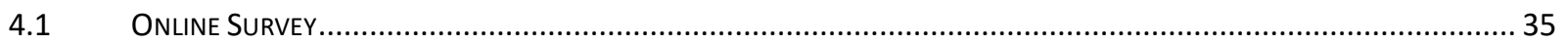

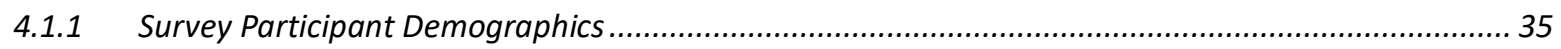

4.1.2 Knowledge and Perceptions of Environmental Education ........................................................... 35

4.1.3 Information and Communication Technology ................................................................................ 43

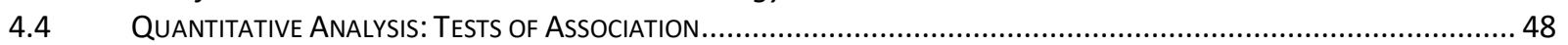

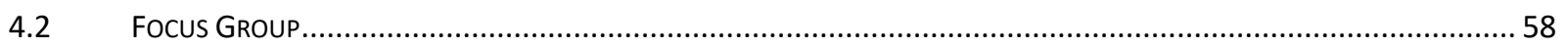

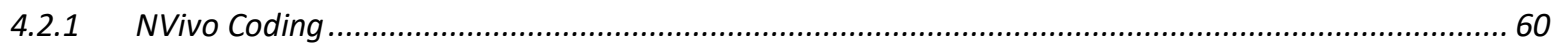

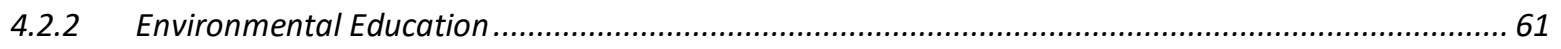

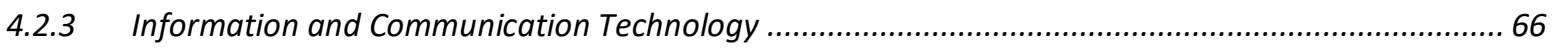

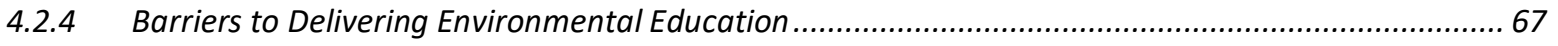

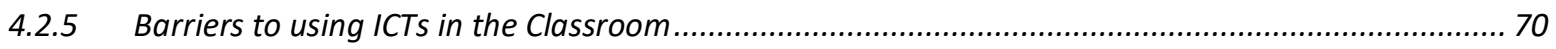

4.2.6 Leveraging ICTs to Teach Environmental Education ............................................................... 71 


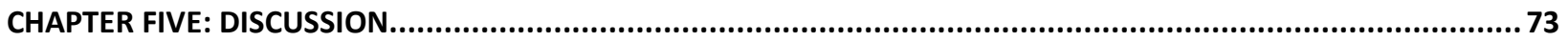

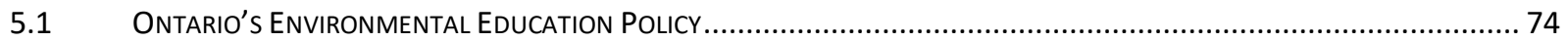

5.2 ENVIRONMENTAL EdUCATION: BARRIERS, THREATS AND SHIFTING APPROACHES................................................ 75

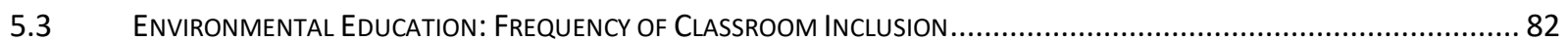

5.4 ENVIRONMENTAL EDUCATION: FORMAL AND INFORMAL EDUCATOR EXPERIENCE ...............................................8 83

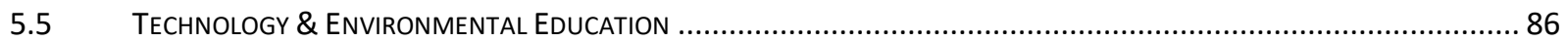

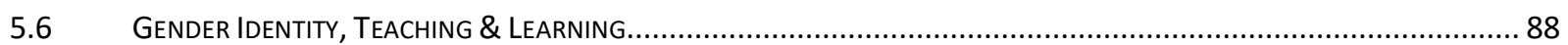

CHAPTER SIX: LIMITATIONS AND RECOMMENDATIONS ...................................................................90

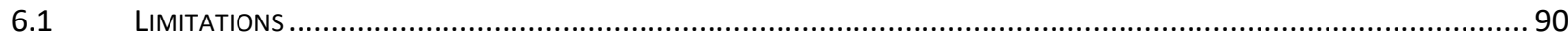

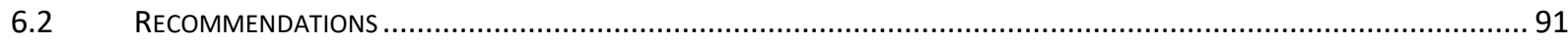

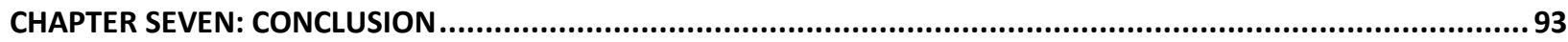

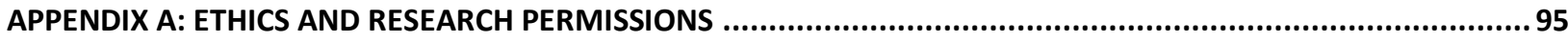

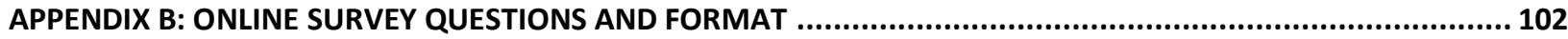

APPENDIX C: SEMI-STRUCTURED FOCUS GROUP QUESTIONS AND FORMAT ............................................112

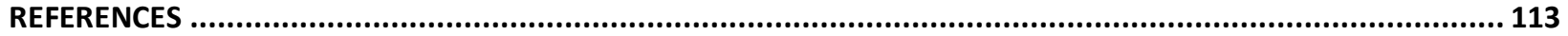




\section{LIST OF FIGURES}

FIGURE 1: DEMOGRAPHIC CHARACTERISTICS OF ONLINE SURVEY PARTICIPANTS ........................................................... 36

FIGURE 2: ONLINE SURVEY PARTICIPANTS' KNOWLEDGE OF ENVIRONMENTAL EDUCATION POLICY AND IMPLEMENTATION................. 37

FIGURE 3: ONLINE SURVEY PARTICIPANTS' PERCEPTION OF ENVIRONMENTAL EDUCATION .................................................. 39

FIGURE 4: BARRIERS TO ENVIRONMENTAL EDUCATION INDENTIFIED BY ONLINE SURVEY PARTICIPANTS.................................. 41

FIGURE 5: ONLINE SURVEY PARTICIPANTS' PERCEPTION OF ENVIRONMENTAL EDUCATION TRAINING ..................................... 42

FIGURE 6: ONLINE SURVEY PARTICIPANTS' PERCEPTION OF TECHNOLOGY USE IN THE CLASSROOM ......................................... 44

FIGURE 7: BARRIERS TO USING TECHNOLOGY IN THE CLASSROOM IDENTIFIED BY ONLINE SURVEY PARTICIPANTS ......................... 46

FIGURE 8: ONLINE SURVEY PARTICIPANTS' PEREPTION OF LEVERAING TECHNOLOGY TO DELIVER ENVIRONMENTAL EDUCATION............ 47

FIGURE 9: FOCUS GROUP PARTICIPANTS' PERCEPTION OF ENVIRONMENTAL EDUCATION ABOUT, THROUGH \& FOR THE ENVIRONMENT 64

FIGURE 10: FOCUS GROUP PARTICIPANTS' PERCEPTION OF ENVIRONMENTAL EDUCATION AND TECHNOLOGY ............................. 65

FIGURE 11: BARRIERS TO ENVIRONMENTAL EDUCATION AND TECHNOLOGY IDENTIFIED BY FOCUS GROUP PARTICIPANTS ................... 69 


\section{LIST OF TABLES}

TABLE 1: FREQUENCY OF ENVIRONMENTAL THEMED EDUCATION AND DEMOGRAPHICS................................................. 49

TABLE 2: PERCEPTION OF BARRIERS TO ENVIRONMENTAL EDUCATON AND DEMOGRAPHICS ................................................ 51

TABLE 3: PERCEPTION OF BARRIERS TO ENVIRONMENTAL EDUCATION AND TEACHING CAREERS..............................................5 53

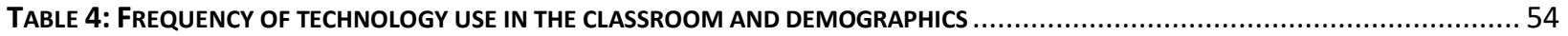

TABLE 5: PERCEPTION OF BARRIERS TO USING TECHNOLOGY IN THE CLASSROOM AND DEMOGRAPHICS.......................................5 56

TABLE 6: PARTICIPANT PERCEPTION OF USING TECHNOLOGY TO FACILITATE ENVIRONMENTAL EDUCATION .................................. 57

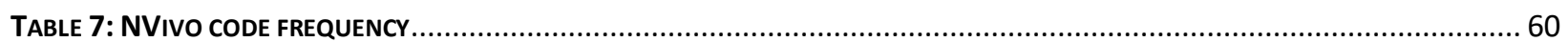




\section{CHAPTER ONE: INTRODUCTION AND OUTLINE}

\subsection{Introduction}

In many western countries, the formal education system is the front-line for teaching children and youth. It is required by law in Canada that children must attend school as of age five or six, and their attendance is required until the age of 16 to 18 , depending on the province or territory (Government of Canada, 2017). According to the Education Act in Ontario, children are legally required to attend school from age six to 18 (Education Act, R.S.O. 1990, c. E.2, s 21). Parents have the option, however, to begin sending their children to start school at the age of four or five to attend one to two years of kindergarten before beginning grade one at the age of six (Government of Ontario, 2019a). According to the Ontario Ministry of Education (OMOE), the regular school year for public education runs from September 1 to June 30, with a minimum of 194 days (OMOE, 2019) with no less than five hours of instruction per day (R.R.O. 1990, Reg. 298, s. 3 (1); O. Reg. 78/14, s. 1 (1)). Furthermore, teaching and learning in the 21st Century has presented educators and students with unique opportunities, and with new challenges. Advances in technology and unprecedented access to information — anywhere and anytime — have provided teachers and students with novel ways to instruct, and to learn. One of many educational themes that may benefit from new technology (i.e., internet, wireless technology, mobile computing) is environmental studies and science (Greenwood \& Hougham, 2015; Schaal \& Lude, 2015; Kalogiannakis \& Papdakis, 2017).

Preparing today's youth with the necessary knowledge and skills to understand, mitigate, and adapt to, a changing climate is a major challenge facing humanity, and one that could be assisted by teaching with technology (Anderson, 2012). At the same time, new technologies have been reported to result in children and youth spending less time outdoors and, in some cases, 
contributing to a disconnect with nature (Louv, 2005; Greenwood \& Hougham, 2015). The present research is interested in the intersection of environmental education and new technologies. Specifically, can Ontario teachers use new technologies to deliver environmental education in a manner that promotes, and perhaps enhances, student connection with the natural environment?

One approach to raising environmental awareness, and to providing tools to youth that can empower them to take stewardship roles in their local environment, is to have environmental education taught across the curriculum (e.g., science, math, social sciences, business, the arts) and throughout kindergarten to grade 12 (K-12) education. This can be through formal education, which refers to learning within a classroom, where attendance and participation are mandated, and based on government created curricula (Government of Canada, 2002; Anderson, 2012; Fazio \& Karrow, 2013). Intra-curricular blending, and inter-annual exposure to environmental themes, is thought to be an important approach to preparing students with the environmental understanding and problem-solving skills that can provide agency and cultivate stewardship potential (Anderson, 2012; Government of Ontario, 2017a, 2017b). In contrast, informal and non-formal learning occurs more as a result of a student's personal interests, family values, and societal influences, and is not necessarily connected to formal education directly (Gerber et al., 2001; Government of Canada, 2002; Eshach, 2007). For example, most informal and non-formal teaching and learning occurs through exposure to media (e.g., social, documentaries, TV, books, newspapers, podcasts/radio), and through public awareness campaigns (e.g., government, NGO) (Gerber et al., 2001; Government of Canada, 2002, Eshach, 2007). While all forms of learning are important, with each appealing to different learning styles and opportunities, the focus of the present research is on the formal delivery of environmental curriculum, as mandated by the Ontario Government (Education 
Act, R.S.O. 1990, c. E.2, s.8 (1), par. 3.; Ontario Ministry of Education, 2019), and implemented by Ontario teachers.

Research has identified that being in outdoor natural spaces can foster a sense of environmental connection, agency, and even stewardship propensity, among youth (Louv, 2005; Gruenewald, 2008; Gruenewald \& Smith, 2008; Smith \& Sobel, 2010; Fazio \& Karrow, 2013; Pedretti \& Nazir, 2014; Fazio \& Karrow, 2015). There is the belief among some educators, however, that to experience nature a person must leave an urban area and travel to a more pristine landscape (less influenced by human activity) (Louv, 2005). This belief presents a challenge to environmental educators working in cities, and urban areas, where travel off school property to places of 'wilderness' can be fraught with barriers (e.g., cost, resources, liability, equity) (Fazio \& Karrow, 2013; Pedretti \& Nazir, 2014; Fazio \& Karrow, 2015). Moreover, the majority of Ontario K-12 students live in, and attend schools in, urban areas; city and suburban areas contain their realworld connections to nature (Gruenewald, 2008; Gruenewald \& Smith, 2008; Smith \& Sobel, 2010). In the present research, nature and natural systems are viewed as being everywhere, with urban ecosystems requiring important attention (Costanza et al., 1997; Tzoulas et al., 2007) and, thus, potentially serving as an essential teaching resource. Schoolyards, to varying degrees, have natural spaces where natural processes can be observed, measured and otherwise interacted with.

New technological innovations are part of human evolution but, as some authors have pointed out (Mooij, 2004; Jimoyiannis \& Komis, 2007; Neyland, 2011; Buabeng-Andoh, 2012), educators are not agreed upon what role technology should have as a teaching tool, and how much exposure students should have to devices - screen time - while at school. One of the critiques of new technologies in the classroom has been that their use can be in direct conflict with time spent outdoors, physical activity, learning, and social development (Athman \& Bates, 1998; Mooij, 
2004; Louv, 2005; Kahn \& Kellner, 2007; Jimoyiannis \& Komis, 2007). Despite these concerns, most Ontario schools and classrooms have embraced new technologies with the regular student use of laptops, tablets, e-homework, and assignment distribution through online portals (e.g., Google Classroom) (Chen, Gallagher-McKay \& Kidder, 2014).

The present study was conducted in Toronto, Ontario and involved educators working with the Toronto District School Board (TDSB). As previously mentioned, curriculum is mandated provincially and, therefore, through the provincial policy, Acting Today, Shaping Tomorrow (2009a), TDSB teachers are required to teach environmental education in all subject areas through K-12 (Education Act, R.S.O. 1990, c. E.2, s.8 (1), par. 3.; OMOE, 2009; OMOE, 2019). However, over the last decade, the successful implementation of intra-curricular and inter-annual environmental education has been questioned (Karrow \& Fazio 2013; Pedretti \& Nazir, 2014; Mnyusiwalla et al., 2016), where experts have identified systemic barriers to inclusion. Therefore, the present research aims to investigate the opportunities and challenges of implementing environmental curriculum, while examining how teachers can optimally use technology as a teaching tool. Moreover, this research postulates that various information and communication technologies (ICTs) can be used, or created, to encourage teaching and learning about the environment in local schoolyards.

\subsection{Purpose and Objectives}

The purpose of this research is to identify and describe the barriers and opportunities to the delivery of environmental education using information and communication technologies (ICTs) within Canada's largest schoolboard, the Toronto District School Board (TDSB). Four objectives have been outlined to achieve this purpose: 
1. To identify and recruit a representative sample of TDSB environmental educators for participation in an online survey and semi-structured focus group;

2. To use responses arising from the online survey and semi-structured focus group (Objective One) to identify opportunities and barriers associated with the delivery of formal environmental education, especially to students at urban schools;

3. To use responses arising from the online survey and semi-structured focus group (Objective One) to identify opportunities and barriers to using information and communication technologies (ICTs) in teaching, and especially when teaching about the environment; and,

4. To investigate potential associations between TDSB educator demographics, knowledge, and views, and their propensity to use ICTs as part of their delivery of formal environmental education. 


\subsection{Thesis Outline}

This research is organized into five chapters, and is presented in a formal thesis format as per the requirements of Ryerson University's Master of Environmental Applied Science and Management (EnSciMan) Program. Chapter One provides a synopsis of the thesis focus as well as the study's purpose and objectives. Chapter Two includes a review of the literature as it relates to environmental education, implementation of environmental curriculum in Ontario and elsewhere, the use of information and communication technologies (ICTs) as a teaching tool, and the potential opportunities and barriers to teaching about the environment in general, and specifically, using ICTs. Study materials and methods are described in Chapter Three, and include preparation and delivery of the online survey, organization and delivery of the semi-structured focus group, and approaches used to analyse data arising from each of the information gathering tools. Chapter Four presents the results of the online survey in regards to participant demographics and perception of environmental education, and using technology in the classroom, quantitative analysis using the Mantel-Haenszel test of trend, as well as the semi-structured focus group results using NVivo for qualitative analysis. Chapter Five presents the discussion with the intention of placing findings in the context of previous work, and in light of the delivery of formal environmental education becoming increasingly important in contemporary society. Chapter Six identifies limitations to the work, and proposes some direction for future research. Finally, Chapter Seven provides a summary conclusion of this research. The Appendices include ethics documents, online survey and focus group questions, and the raw data arising from the information collection tools. 


\section{CHAPTER TWO: LITERATURE REVIEW}

This review of the literature details what formal environmental education is, and how it is (or can be) practiced. It then describes the history of environmental education within the context of Ontario, Canada. Finally, the use of information and communication technologies (ICTs), as teaching tools or platforms for information delivery, and as complementary sources of information, is explored. Moreover, focus is given to how ICTs are currently (or can be) applied to the delivery of environmental education.

\subsection{Environmental Education: Literacy and Stewardship}

Environmental education is an interdisciplinary subject area designed to provide students with awareness and knowledge about the environment, including the relationships humans have with, and within, the natural world (Fien, 1993; Canadian Environmental Grantmakers Network, 2006). Over the past twenty-five years, research focussed on environmental education has widened its scope from traditional topics such as outputs (e.g., number of students taught), to a detailed look at the outcomes of approaches and methods used to teach environmental content (e.g., outdoor education, place-based education) (Rickinson, 2001; Ardoin et al., 2013; Ardoin et al., 2018).

Work by Adroin et al. (2018) assessed 119 peer-reviewed articles addressing formal environmental education, published over a nine-year period (1994-2013), and from 36 independent journals. These authors found that formal environmental education yields positive outcomes including greater environmental awareness, topical skill development, and a propensity for stewardship. Moreover, evidence of important non-direct environmental outcomes, such as general academic achievement and developmental progress (i.e., social and emotional learning) was highlighted (Adroin et al., 2018). For example, benefits to students resulting from interacting with, and experiencing, the outdoors in formal educational settings were identified by Blatt (2013) to 
include student 'identity development', 'emotional health', and 'conservation-oriented behavior'. Similarly, research by Mårtensson et al. (2009) concluded that formal environmental education 'improved attentiveness' and enhanced 'cognitive potential'. Despite these findings, it is also regularly reported in the literature that formal environmental education is an area of teaching riddled with complexities that span concerns including limitations in teacher knowledge and confidence, to limited resource availability (Wells, 2000; Faber-Taylor \& Kuo, 2009; Karrow \& Fazio 2013; Pedretti \& Nazir, 2014; Mnyusiwalla et al., 2016).

According to the CEGN (2006), "The ultimate goal or outcome of environmental education is the creation of environmentally literate citizens." (p. 2). This refers to formal education's role in creating citizens who are empathetic toward ethical-environmental issues, demonstrate care and stewardship for the environment (local and global), and are equipped with the necessary skills to conserve, protect, and restore the environment (Fien, 1993; Pedretti \& Nazir, 2014). However, in order to truly have environmentally-literate citizens, their environmental education needs to be well-rounded, as in 'about, through and for the environment' (Fien, 1993; Sobel, 1993, 1996, 1998; Mannion \& Adey, 2011; Pedretti \& Nazir, 2014).

Education about the environment refers to facts and knowledge regarding environmental systems, including their processes and management (Fien, 1993; Mannion \& Adey, 2011; Pedretti \& Nazir, 2014). This is viewed as a naturalist and conservationist approach to environmental education, as it seeks to enlighten students about environmental issues through the scientific processes, how these processes are disrupted by human activity, and the emergent outcomes (positive and negative) (Fien, 1993; Mannion \& Adey, 2011; Pedretti \& Nazir, 2014). Education through the environment refers to using direct interaction with the environment as an integral component of the educational experience (Fien, 1993; Mannion \& Adey, 2011). The theory behind 
learning through the environment stems from the belief that in order to foster stewardship students require real-world, direct, and positive interactions with the outdoor environment (Pedretti \& Nazir, 2014). Learning through the environment is often accomplished through field studies (frequently leaving the indoor classroom) and place-based education (Sobel, 2004; Gruenewald, 2008; Mannion \& Adey, 2011). Lastly, education for the environment focuses on promoting sustainable lifestyles and practices by learning about the politics of environmental issues, and the actions necessary to achieve eco-justice for all living organisms (Lowenstein et al., 2010; Pedretti \& Nazir, 2014).

There are many terms and niche topics under the umbrella of environmental education, which include, but are not exclusive to: climate change and environmental education, conservation education, wilderness education, ecological education, education for sustainable development, outdoor education, place-based education, and sustainability education (Fien, 1993, Sobel, 2004; Canadian Environmental Grantmakers Network, 2006; Gruenewald, 2008; Mannion \& Adey, 2011). In the present research, the umbrella term 'environmental education' will be used to reference all of these varying philosophies and approaches. However, the pedagogical framework for the present study is rooted in place-based education (PBE).

\subsection{Place-Based Education}

Place-based education (PBE) relies on learning through experiencing an issue where it occurs; grounding an educational topic in a discreet or semi-discreet location as a way of influencing problem-solving (Mannion \& Adey, 2011). Gruenewald (2008) states that PBE is needed in order for students to learn about the space they occupy, how they impact it, and what that means to them and to society. Moreover, PBE is a method to anchor student learning in the practical (nonabstract), as it focuses on using the local community and environment as a starting point to 
communicate and reinforce concepts in subjects including the language arts, mathematics, social studies, and science through "hands-on, real-world learning experiences" (Sobel, 2004 p. 7). PBE allows students to become involved with their surroundings, whether it is the schoolyard or the broader community. This can support the development of relationships between students and their communities, and enhances overall understanding and appreciation for nature in the context of the curriculum (Sobel, 2004).

\subsection{History of Environmental Education in Ontario}

In Canada, delivery of education is a constitutional responsibility exercised by the powers of Provincial legislatures, in section 93 of the Constitution Acts, 1867 to 1982 (Government of Canada, 2017, 2018, 2020). This means that each province dictates what curriculum is to be taught, what qualifications educators must obtain to teach, and how funding for school programs is determined and allocated (OMOE, 2019). Within the Province of Ontario, the Education Act outlines the responsibilities of the Ministry, boards, and teachers respectively (Education Act, R.S.O. 1990, c. E.2).

Environmental education in Ontario has a long history, and has received varying degrees of attention depending on the political climate (government in power) and societal interests. During the agrarian revolution in Ontario in the 1800s, Egerton Ryerson, who is credited with created Ontario's modern education system, included agricultural education into the framework for the education system in Ontario (Davey, 2003; Borland, 2011). Agricultural studies provided an opportunity for children and youth to learn about agricultural sciences, gardening and nature studies, which positively impacted families who relied on agriculture for their livelihood (Davey, 2003; Borland, 2011). Agricultural education evolved into agricultural sciences during the turn of the century, which included themes of outdoor education through farm labour and other activities 
(Borland, 2011). During the 1960s, agricultural sciences shifted focus to environmental sciences and studies, and the provincial government approved the creation of environmental field centres for school boards with more than 10,000 students (Passmore, 1972; Pyle, 2001; Andrews, 2003; Borland, 2011). During the 1970s, environmental education became synonymous with outdoor education, and natural science and environmental lab-based studies became more prominent (Pyle, 2001; Andrews, 2003). However, in the 1990s, the Ontario political landscape changed, and the province divested its support in the broader education system (Henderson \& Potter, 2001). An early outcome of spending cuts to education was the closure of outdoor education centres that were considered, by the government in power, as non-essential (Borland, 2009; 2011). By the end of the 1990s, secondary school environmental science courses had also been removed from the Ontario curriculum (Borland, 2011; Pedretti \& Nazir, 2014; Fazio \& Karrow, 2015; Mnyusiwalla \& Bardecki, 2017).

The removal of environmental sciences and studies from secondary school curriculum, and closures of outdoor education centres, did not go unnoticed by the education community (Government of Canada, 2002; Environmental Education Ontario, 2003, 2018; OMOE, 2007; York University, 2016). As a result, Environmental Education Ontario (EEON) was established by educators in 2000 with the goal of improving environmental education across Ontario (EEON, 2018). In 2003, EEON produced a strategic public education plan, Greening the Way Ontario Learns. The result of over two years work, and input from more than 500 Ontarian's, the goal of this plan was to create a more 'ecologically literate province' (EEON, 2018).

Around the same time, the EcoSchools model was gaining traction in Ontario. EcoSchools was launched in four European countries in 1994, as a response to the United Nations Conference on Environment and Development (EcoSchools, 2019). Inspired by the UN indorsed EcoSchools 
program, the Toronto District School Board (TDSB) created the their own EcoSchools Program in 2002 (TDSB, 2014a). Specifically, the TDSB EcoSchools Program promotes 'greening' of school grounds, understanding of how a school is run (through the lens of environmental sustainability) and how it can be improved, as well as curriculum and extra-curricular activities undertaken by both teachers and students (TDSB, 2014a). The TDSB EcoSchools Program indicates that "Its central focus is supporting students and staff in learning about, caring for, and protecting the environment starting right in their own school" (TDSB, 2014a, para 1). By 2005, the EcoSchools model had been adopted by seven other Ontario school boards, and associated with York University and the Toronto and Region Conservation Authority (Ontario EcoSchools, 2018).

In tandem, the predecessor to the Ontario EcoSchools project was created out of the work conducted by York University's Faculty of Environmental Studies (FES). The FES associate dean (1998-2001) Lewis Molot acted as the primary investigator, where the FES formed associations with Ontario school boards to research and develop resources for lesson plans that would help teachers incorporate environmental themes from K-12 (York University, 2016). This consortium evolved into the Ontario EcoSchools, which was modelled after the UN-inspired TDSB EcoSchools, and as of February 2019 it is now known as EcoSchools Canada (York University, 2016; Ontario EcoSchools, 2018; EcoSchools Canada, 2019).

EcoSchools Canada is overseen by the Foundation for Environmental Education (FEE), and is the Canadian National Operator of the international EcoSchools Program (EcoSchools Canada, 2019). Similar to the TDSB EcoSchools, EcoSchools Canada is a voluntary program that encourages, supports and celebrates environmental achievements (both through environmental education and through greening the teaching facility), while providing a number of opportunities every year for the school community more broadly to participate in green activities (Ontario 
EcoSchools, 2018a; EcoSchools Canada, 2019). It should be noted that the EcoSchools programming (whether Canada or TDSB) does not directly influence provincially mandated curriculum, it does, however, create an atmosphere within the school community that is focused on supporting green initiatives, and learning about the environment and sustainability that complements the mandated curriculum.

While not specific to Ontario, the National Consultation on Environmental Education and Sustainability was conducted by Environment Canada from 1999-2002 (Government of Canada, 2002). This consultation process was in response to the more than 100 Canadians who wrote to the Minister of Environment expressing their desire for Environment Canada to "renew its commitment to support environmental learning and sustainability" (Government of Canada, 2002, p. 2). More than 5,500 Canadians across the country participated in this consultation by completing online or hard copy questionnaires, and by attending meetings that were held across the country (Government of Canada, 2002). The results highlighted that Canadians believed it was important for citizens to be aware of, and understand, environmental and sustainability issues. Moreover, this multi-year consultation demonstrated that there was a collective belief among Canadians that the environment was a shared responsibility, and that one way to achieve knowledge sharing, and commensurate skills development, was through a focus on the environment in the formal education system (Government of Canada, 2002).

In 2007, the Government of Ontario created the Working Group on Environmental Education. This working group was tasked with creating a report that analyzed environmental education in Ontario (OMOE, 2007). EEON supported the efforts of the Working Group on Environmental Education, and provided input during the creation of their report, Shaping Schools, Shaping Our Future (EEON, 2018). This report, also known as the Bondar Report (2007) was 
produced to analyze the "needs and research successful approaches to teaching and learning about the environment in elementary and secondary schools" (OMOE, 2007, p. 3). The Bondar Report (2007) made recommendations to the Ontario Ministry of Education (OMOE) with respect to reinstating environmental education in the curriculum. The most significant recommendation was that the OMOE should embed environmental education throughout all subject areas, and across all grades from K-12 (OMOE, 2007).

The OMOE responded to the Bondar Report (2007) by creating the policy framework entitled Acting Today, Shaping Tomorrow (2009a), which continues to the present as the Province of Ontario's approach to environmental education. In this policy framework, the OMOE recognizes the important role schools play "in preparing our youth to take their place as informed, engaged, and empowered citizens who will be pivotal in shaping the future of our communities, our province, our country, and our global environment" (OMOE, 2007, p. 1). Furthermore, the OMOE created environmental education documents (2007 and revised in 2017), which provide teachers with prompts and examples concerning how they can include environmental themes in their lesson plans, organized by grade and by subject area (OMOE, 2017). Irrespective of this decision to embed environmental education in all K-12 subject areas, questions and concerns have emerged about implementation.

\subsection{The Framework of Environmental Education in Ontario}

Several studies have been conducted that focus on understanding formal K-12 environmental education in Ontario. One such study by Pedretti and Nazir (2014) created a baseline of knowledge detailing teacher views of environmental education within Ontario. They surveyed 377 Ontario teachers using an online survey, with the option for survey respondents to further their participation in a semi-structured interview. Pedretti and Nazir's (2014) results revealed that $47 \%$ of survey 
respondents included weekly environmental education in their teaching, $14 \%$ included it every two weeks, $17 \%$ included it once a month, $6 \%$ every two months, $10 \%$ once a semester, and $6 \%$ never included it. Overall, these results demonstrate that while environmental education is occurring, the frequency of it is dependent on the teacher, and that it does not appear to be delivered with the regularity required in the policy framework document, Acting Today, Shaping Tomorrow (2009a).

Barriers experienced by teachers concerning the inclusion of environmental education in their classrooms were identified by Fazio and Karrow (2013) and by Predretti and Nazir (2014). These barriers included limited planning time, lack of funding for material and resources, class schedule, overcrowded curriculum, alignment of environmental education with other teaching expectations and requirements. Fazio and Karrow (2013) highlight that that environmental education is often considered a demanding subject to teach, especially when there is a lack of support from a school board or from government. When support is limited, environmental education can often be considered by educators as "in conflict with the dominant purposes, structures, and practices of schooling” (Fazio \& Karrow, 2013 p. 641; Stevenson, 2007).

In 2015, a round table discussion was held at Ryerson University that included educators drawn from the Ontario Ministry of Education, colleges and university, and K-12 teachers. Its focus was to assess the implementation of the 2007 Bondar Report (Mnyusiwalla et al., 2016). The round table discussions highlighted the findings of Fazio and Karrow (2013) and Predretti and Nazir (2014), especially with regard to implementation barriers. The theme of 'disconnection', described as a lack of translation from the OMOE to Ontario K-12 teachers concerning expectations, and how to achieve requirements stipulated in the Acting Today, Shaping Tomorrow (2009a) policy framework. And, while many supporting documents had been prepared, it was noted by Mnyusiwalla et al. (2016) that teachers were either were unaware of their existence or 
did not have a solid understanding of their content. Moreover, teachers and principals (groundlevel educators), believed there was a divide between the expectations outlined by the Ministry of Education, and what was practical for a classroom setting.

Another concern when considering the delivery of environmental education noted by Pedretti and Nazir (2014) was the source of their participants (Ontario teachers) environmental education. It should be noted that Pedretti and Nazir (2014) survey question, they asked participants to select all environmental education sources that applied to their circumstances. Their results showed that more than $75 \%$ of the participants in their study cited 'personal studies' rather than 'professional training' (preservice training 10.4\%, additional qualifications courses $11.7 \%$ ) as a source of their environment and environmental education knowledge (Pedretti \& Nazir, 2014, p. 275-276). Surprisingly, $11.7 \%$ of study participants reported that they had no environmental education (Pedretti \& Nazir, 2014, p. 275-276). To further this notion, at the 2013 Education Experts' Workshop: Implementation of the Bondar Report (2007) roundtable, the idea of 'not feeling like an environmental educator' was expressed by some teachers, and that there is a perceived disconnect between how teachers are trained, and in the in-classroom expectations (Mnyusiwalla et al., 2016). This is not to say that every teacher needs to feel deeply connected to environmental education content to be effective, but highlights that teachers would benefit from having formal understanding and knowledge, which would contribute to a level of confidence that allows for the meaningful inclusion of environmental education in the classroom (Fazio \& Karrow, 2013; Pedretti \& Nazir, 2014; Fazio \& Karrow, 2015; Mnyusiwalla et al., 2016).

When environmental educators were asked what they believed should be the focus of teaching support to deliver environmental curriculum, they cited content knowledge, pedagogical strategies, assessment techniques, curriculum development, and the use of outdoor education 
assessment techniques (Fazio \& Karrow, 2013; Pedretti \& Nazir, 2014; Mnyusiwalla et al., 2016). These preferences for learning, coupled with the information gleaned about where study respondents acquired their environmental education, underscores the value of teachers receiving their own version of formal education about the environment, how to effectively implement environmental education in the classroom, and the benefit if having support in the form of resources for environmental education implementation. Pedretti and Nazir's (2014) study participants who self-identified as being enthusiastic about environmental education, felt that their passion [for environmental education] was not shared by the majority of their colleagues.

Fazio and Karrow (2013) summarize suggestions made by teachers to improve delivery of environmental education. Some of the responses included: lessons and activities that can be combined with mandated curriculum, release time to help develop environmental education lessons and resources, in-school time for cross-grade/subject teacher collaboration, and financial assistance for environmental initiatives. Overall, the findings from each of these studies, Fazio and Karrow (2013) and Pedretti and Nazir's (2014), illustrate that even with a policy framework in place, and strong educator belief in the value of environmental education, without resources and support, including financial and training to effectively implement policy, there can be little meaningful change.

\subsection{Information and Communication Technologies (ICTs)}

Access to information - anywhere and anytime-is an expectation in most contemporary societies. Information and Communication Technologies (ICTs) are technological tools and resources that are "used to communicate, produce, distribute, store, and manage information" (Majoka et al., 2013, p. 38). Examples of commonly used ICTs are: computers and mobile devices, the Internet, radio, television, and telephones (Blurton, 2002; Majoka et al. 2013). In recent decades, there has 
been rapid growth of ICTs, ultimately changing how society learns, and consequently how humans live (Buabeng-Andoh, 2012). As a result, pedagogy as it relates to K-12 teaching and learning has changed and responded to the ubiquity of digital devices, and to new tools concerning educational instruction (and perhaps student distraction) (Selwyn, 2009; Nasah et al., 2010; Vongkulluksn et al., 2018).

\subsection{Digital Education: Literacy and Fluency}

The digital revolution, or the 'fourth industrial revolution', gained momentum when personal computers began to appear in the late 1970s (Selwyn, 2009). However, the major shift to the digital era began in earnest during the late 20th and early 21 st century. This is because technology, in particular information and communication technologies (ICTs), were no longer only found in specialized workplaces, but rather had started to become an integral part of the economy and of society, especially in the global north (Educational Testing Service, 2002; Selwyn, 2009; Chen, 2015).

ICTs, and the development of related applications, expanded rapidly outward to social and community settings, and were quickly adopted in homes and at schools (Educational Testing Service, 2002). Since the early 2000 s, the capacity to share and receive information through technological means has skyrocketed, and with it an increase in access to the internet through public and private WiFi connections, and via mobile data plans. In short, Canadian society has become 'plugged in', relying heavily on the internet and wireless technology for information and to communicate; teaching and learning in Ontario schools has mirrored this societal trend (Nasah et al., 2010; Chen, 2015; Sinay, et al., 2016; Laronde et al., 2017).

The term 'digital literacy' was first used by Gilster (1997) to emphasize critical thinking, as compared to technical or IT skills (Calvani et al., 2008). Over the last two decades, however, 
digital literacy has emerged to refer to the ability to "read, select, interpret and evaluate digital data and information taking into account their pertinence and reliability" (Calvani et al., 2008 p.187). Whereas 'digital fluency' means having the necessary skills and knowledge to understand digital tools, and to apply them in practical and meaningful ways to create, design, communicate, and express oneself in order to synthesize information (Hsi et al., 2005; Wang, et al., 2012; Sinay, et al., 2016).

The role of the formal education system with respect to digital literacy and fluency is to adequately prepare students with the knowledge and skills to succeed in real-world scenarios, and especially within a rapidly changing technological world (Sinay, et al., 2016). This being said, current K-12 students were born in the 21 st century and, therefore, have only ever known this era of digital information ubiquity. The idea that people who were born in the late 20 th century and early $21_{\text {st }}$ century are drastically different than past generations of learners as their entire lives have been immersed in digital technology (Prenksy, 2001; Selwyn, 2009; Nasah et al., 2010). Moving into the 21 st century, new digital technologies for personal, educational, and economic uses, further emphasizes the era of digital information ubiquity. It should be noted that today's educators range in age from ‘baby boomers' (1946-1964) to 'millennials' (1981-1996), with 'generation z' (19962014) as their students (Towner and Lego Munoz, 2016; University of Waterloo, n.d.); and just as their age ranges, so too does their use, confidence in, and knowledge of, technology as a teaching and learning tool (Prensky, 2001; Nasah, 2010; Vongkulluksn et al., 2018).

\subsubsection{ICTs in the Classroom}

Due to the rapid growth and pervasiveness of ICTs in society, the formal education system has had to respond by adopting ICTs to help prepare students with skills necessary to succeed in a knowledge-based society (Jimoyiannis \& Komis, 2007; Buabeng-Andoh, 2012). Education 
systems around the world have made investments modifying schools and classrooms to become 'wired' places of learning (Buabeng-Andoh, 2012). While varying opinions exist among educators, most agree that as ICTs, and technology in general, evolve, they should be used in the education system as learning and teaching tools (Higgins et al., 2012; Petko, 2012). Research shows that students are overwhelmingly interested in, and eager to use, ICTs within the classroom (John \& Sutherland, 2004). These same authors found that teaching with ICTs in formal education can increase student interest and engagement. Furthermore, a study conducted by McKnight et al. (2016) highlights benefits for both teachers and students when technology is incorporated into the classroom. This includes improved access to up-to-date learning resources and information, improved time management for students and teachers (e.g., increased access to lessons and assignments for absent students, tracking and recording marks, and feedback dissemination, etc.). As well as the transformation of teaching in the classroom, shifting teachers' primary role from 'content specialists' to 'learning specialists' (Glassett \& Schrum, 2009; Levin \& Schrum, 2013; McKnight et al., 2016).

Despite many of the inherent positives of incorporating ICT into formal K-12 curricula (Higgins et al., 2012; Petko, 2012), effective use of technology in classroom settings remains complex for many educators (Mooij, 2004; Wee \& Bakar, 2006; Jimoyiannis \& Komis, 2007). Vongkulluksn et al. (2018) argues that, although equitable access is vital to technology implementation in the classroom, it "does not automatically equate to greater or higher quality of technology integration" (p. 70); rather, teacher beliefs and attitudes toward technology were important factors when looking at technology integration into the classroom (Wozney et al., 2006; Ottenbreit-Leftwich et al., 2010; Buabeng-Andoh, 2012). For example, if a teacher perceives ICTs as not benefitting their students or their teaching style, they are less likely to incorporate them into 
their lesson plans (Buabeng-Andoh, 2012). Not surprisingly, if a teacher's perception of ICTs is positive, this strongly influences their willingness to include technology for teaching and learning in their classroom (Hew \& Brush, 2007; Keengwe \& Onchwari, 2008; Ottenbreit-Leftwich et al., 2010; Buabeng-Andoh, 2012; Vongkulluksn et al., 2018).

Heavy workloads along with an already crowded curriculum are other important barriers that have been identified as preventing educators' inclusion of ICTs in their teaching methods (Neyland, 2011; Buabeng-Andoh, 2012). It follows that when a teacher feels that they do not have the time or capacity to learn a new technological tool or approach, then the likelihood of them doing so to incorporate it into their classroom instruction is diminished (Neyland, 2011; BuabengAndoh, 2012). Therefore, where technology could benefit educators in their delivery of teaching materials, and support students in their learning, in must be intuitive and have a minimal learning curve.

A further complexity many educators wrestle with, and one regularly cited in the literature, concerns optimal levels of student exposure to technology (a.k.a. screen time) (Jimoyiannis \& Komis, 2007; Mooij, 2004). As Eickelmann (2011) points out, there is a tension that exists among some educators about the compatibility of technology with other more 'traditional' forms of education. One such tension exists with the perception of conflict between the use of technology in the classroom and student appreciation of nature. As was previously discussed, ensuring students have adequate access to, and time within, natural environments, is also regularly discussed in the literature (Faber-Taylor \& Kuo, 2009; Wells, 2000). It is precisely this perceived tensiontechnology versus appreciation for nature-that the present research explores. In fact, it is postulated that with careful planning and design, ICTs can enhance students' experience within, and about, the natural world. 


\subsection{Environmental Education and ICTs}

Although the incorporation of ICTs into the classroom has not been seamless or without issue, there is no surprise that researchers and educators alike are looking for engaging and meaningful ways to leverage technology as educational tools (Giezma et al., 2013; Lai \& Hwang, 2014; Kalagiannakis \& Papadakis, 2017); and, utilizing ICTs for the delivery of environmental education is no exception. As previously discussed, environmental education is a multidisciplinary and interdisciplinary subject that allows for inclusion opportunities across the formal education system (Kalagiannakis \& Papadakis, 2017). With the increase of access to technology, in both the school systems and personally (McKnight et al., 2016), creates an opportunity for educators to include ICTs as a method of delivery for environmental education. As previously discussed, there are tensions in regards to using technology in the classroom, especially for environmental education, as they seem to be at odds with each other, the issue of too much screen time and a lack of appreciation for nature (Wells, 2000; Mooij, 2004; Jimoyiannis \& Komis, 2007; Faber-Taylor \& Kuo, 2009). However, educators are using technology to delivery environmental education whether they actively realize it or not. Leveraging technology to delivery environmental education can be as simple as accessing online news sources (written or video), watching films (documentaries, non-fiction, fiction), and software such as GIS to spatially analyze data. It can also become more complex and technologically advanced through the use of virtual reality, digital gamification, and web-based or mobile applications (Cheng et al., 2013; Buchanan et al., 2018).

ICTs represent a broad category of tools and, therefore, this research has focused mostly on those ICTs that have the potential to be mobile, whether directly (physical presence in an outdoor learning space with a mobile device and application that complements learning), or indirectly (by pairing outdoor experiences with a device and application used indoors to record 
and document the outdoor learning experience; examples include data entry, mapping and analysis). Leveraging the mobility of ICTs, such as mobile devices, allows students to interact with the real world while being able to connect, research, analyze, and/or complete assignments through various means of technology (Johnson et al., 2013; Kalagiannakis \& Papadakis, 2017). Moreover, using technology to complete assignments and educational tasks, while interacting with the surrounding environment (e.g., schoolyard, community, outdoor education centre, other field trip sites, etc.) allows place-based education and field studies methods to be utilized, which overall aim to enhance the students experience and connection to nature (Rickinson, 2001; Sobel, 2004; Gruenewald, 2008; Mannion \& Adey, 2011; Ardoin et al., 2018; Buchanan et al., 2018). Combining mobile ICTs with environmental education not only provides a supplementary knowledge base for the teacher, it also has the potential to boost student engagement, while fostering positive experiences in nature (John \& Sutherland, 2004; Gruenewald, 2008; Kalagiannakis \& Papadakis, 2017).

\subsubsection{Environmental Education and ICTs Case Study: Citytrees}

One example of an ICT that attempts to bridge technology to learning about, and appreciation for, nature is the Citytrees Project (www.citytrees.ca) being developed at Ryerson University. Citytrees was conceived of as an interactive citizen science tool that allows users to map and interact with individual urban trees, and to explore their ecosystem services (Bowie et al., 2014). More recently, Citytrees has undertaken the development of a suite of tools, one of which is designed to be used directly by K-12 educators and will be deployed through Google Classroom. In fact, this tool will be piloted by select TDSB teachers in Spring 2020. The goal of Citytrees Schoolyard is to provide short educational modules that complement mandated Ontario K-12 curriculum. For example, Citytrees Schoolyard contains a Grade 6 - Understanding Life Systems 
- Biodiversity module. This unit has students examine biodiversity in a local environment, trees in their schoolyard, and place this information in the context of ecological resilience and the structure of the city-wide urban forest. Guided by Citytrees Schoolyard, teachers and students use the Citytrees Engage app to interact with the urban forest in their schoolyard, compare and contrast its characteristics to those of the broader school board, or a geographic area of interest. 


\section{CHAPTER THREE: METHODOLOGY}

This chapter describes the study context, the ethics approval process required to collect teacher responses, the participant recruitment process, the data collection methods (online survey and the semi-structured focus group), and the analytical approaches used to summarize and present results.

\subsection{Study Context}

This research was conducted within the Toronto District School Board (TDSB). Teachers within the TDSB were chosen as the study group because this is the largest school board in Canada (as of 2014: 582 schools; 246,000 students; 17,000 permanent teachers; 5,800 occasional teachers; 15,500 permanent support staff; 4,000 supply/casual employees) (TDSB, 2014b). As a highly urban learning environment, the TDSB is faced with many challenges, and potential barriers, concerning the implementation of environmental education. For example, many TDSB schools have large portions of their schoolyards covered with impermeable materials, as well as an uneven distribution of vegetation and natural spaces. With this said, a highly urbanized environment contains other opportunities for teachers and students such as creating awareness of the nuances and complexities of nature within a socio-ecological system. An investigation of educators' use of ICTs as teaching and learning tools was possible due to the 'wired' nature of the city.

\subsection{Ethics}

Research involving human participants, whether directly or indirectly, requires the investigator(s) to consider the ethical implications of their research. Such approval must be in place before study participants are approached, and in advance of data collection. This is the case at Ryerson University, and at the TDSB, where investigators apply to an independent research ethics committee, before they can begin their research. The present study required ethics approval from both of the Ryerson Research Ethics Board (REB) and subsequently from the Toronto District 
School Board's External Research Review Committee (ERRC). As part of this process, the primary researcher (Courtney Carrier) submitted a Tri-Council Policy Statement: Ethical Conduct for Research Involving Humans (TCPS 2 - https://tcps2core.ca/). Ethics approval was obtained from the Ryerson REB (REB-2019-003) on 8 March 2019. Similarly, ethics approval was obtained from the ERRC (2018-2019-46), and granted 13 June 2019. For all supporting ethics and research permissions documents, please see Appendix A.

\subsection{Study Design}

\subsubsection{Data Collection}

Two primary data collection tools were used in this research: (1) an online survey, and (2) a semi-structured focus group. The purpose of the online survey sought to generate a better understanding of the frequency and level of importance teachers placed on environmental education and using technology (ICTs) within the classroom. The semi-structured focus group mirrored the themes of the online survey, and was employed to stimulate organic conversation from the participants about the general themes of teaching environmental education and the use of ICTs with students. Specifically, the semi-structured focus group was viewed as a data collection tool that would assist in unearthing a deeper understanding and appreciation of the online survey responses, and as a way of identifying common and divergent perspectives and narratives. The online survey was made available to prospective participants for five months, from July to November 2019; the majority of responses occurred from September to November, 2019, when

teachers had returned to the classroom following their summer break. The semi-structured focus group occurred at Ryerson University on 12 September 2019. 


\subsubsection{Participant Recruitment}

In the ethics applications submitted to Ryerson's REB and to the TDSB's ERRC, a key contact at the TDSB was identified. This individual (two separate persons during the span of the project) was a full-time employee of the TDSB, and worked within the Sustainability Office and the EcoSchools Program. Specific contact details for TDSB teachers are not made public for privacy reasons; therefore, the project's TDSB contact served the role of 'gatekeeper' concerning access to teacher and principal email addresses. In other words, it was through this individual that study participant recruitment occurred.

A combination of purposive sampling and opportunistic sampling was done for both the online survey and semi-structured focus group recruitment. Purposive sampling refers to the process in which participants are selected based on their potential contribution as an 'informationrich' participant for the purpose of the study (Patton, 1990; van Rijnsoever, 2017). Opportunistic sampling refers to utilizing participants from a target population who are available at the time of the research, and who are willing to take part (i.e., based on convenience) (Patton, 1990; van Rijnsoever, 2017).

Email invitations to participate in the research project included information describing both the online survey and semi-structured focus group. Emails were sent by the TDSB gatekeeper to principals, vice principals, and curriculum teachers who worked at schools that belonged to the TDSB EcoSchool Program, and had an environmental and/or information and communications technology (ICT) Specialist High Skills Major (SHSM) Program. Reasoning behind these criteria stemmed from previous studies highlighting opportunities and barriers to teaching environmental education, and teaching with ICTs, in Ontario classrooms (Keengwe \& Onchwari, 2008; Fazio \& 
Karrow, 2013; Schaal \& Lude, 2015; Sinay et al., 2016). Moreover, to interest potential research participants, pre-knowledge of, and interest in, a subject area was deemed necessary.

As the TDSB has an anti-spam policy, invitations to participate were emailed in small batches. Recipients of the invitations were also asked to forward the research study information to other potential participants within their school communities who taught courses related to the above mentioned-themes. Participation in the research study was strictly voluntary. Participants for the semi-structured focus group were identified collectively, by the TDSB contact person and the Ryerson researchers; these teachers had expressed interest participating in the focus group upon completion of the online survey. Participant selection, as described here, can be considered stratified, meaning that the potential study contributors belonged to a subset of TDSB teachers, and are so distinguished by their affiliation with the EcoSchools Program, and their teaching subjects. This selection bias was introduced to target teachers with the necessary interest, knowledge and experiences, to understand the state of formal environmental education delivery in the classroom, and the use of ICTs as part of a pedagogical teaching strategy.

\subsubsection{Online Survey}

The online survey was deployed through a Google Form, that was created using a secure faculty account in Ryerson University's Google Suite. This survey format was chosen as all potential participants, TDSB teachers, use a Google affiliated e-mail address with convenient and secure integration with the TDSB's Google Suite. The researchers also believed that prospective participants would have pre-existing familiarity with a Google Form and, therefore, would not require additional learning to use one.

The full online survey, as received by participants, is found in Appendix B. Necessary information about the study, and associated consent forms (Appendix A), is found in Sections One to Three of the survey. To capture basic demographic characteristics of the participants, survey 
questions in Section Four included: gender identity, age range, level of employment, years of teaching experience, and whether the participant undertook additional qualification courses in the realm of environmental education. Section Five focuses on learning about the participants' inclusion of environmental education within their classrooms, as a way to document a baseline for this research project, and to compare teacher responses to previous studies (Fazio \& Karrow, 2013; Pedretti \& Nazir, 2014; Fazio \& Karrow, 2015; Mnyusiwalla et. al., 2016; Mnyusiwalla et. al., 2017). Questions ranged from the participants' knowledge and understanding of environmental education, to their level of enjoyment and confidence including environmental themes in the classroom.

This survey also sought to uncover opportunities and barriers to the use of ICTs as teaching tools. Questions in Section Six were designed to first establish a baseline of understanding concerning how participants currently use technology in their teaching, student responses to its use, and then to investigate respondents' views and perceptions of technology use in their schools more broadly. Finally, to examine the potential for associations between participant beliefs, and their likelihood to use ICTs for formal environmental education, Section Seven includes questions that probed views on the potential for a synergistic association between ICT use and formal environmental education.

\subsubsection{Semi-Structured Focus Group}

A focus group can be defined as a group of people who are interviewed together, and frequently enter into a researcher-facilitated discussion; they typically include six to 12 participants (Kitzinger, 1995). A semi-structured focus group is a variant of this, and refers to an interview process that encourages participants to respond organically, sometimes allowing the discussion to move into directions the researcher might not have anticipated, yet still maintains a 
level of structure necessary for participants to stay on track with answers conforming to the overall study objectives (Kitzinger, 1995).

For this research, a semi-structured focus group was held on Thursday, September 12, 2019 at Ryerson University for approximately 1.5 hours. At the beginning of the meeting, written consent from each participant was obtained, and included permission to take notes on the ensuing conversation, as well as to audio record it for subsequent transcription (see Appendix A). The TDSB EcoSchools program provided a half-day release for all focus group participants, meaning they received supply coverage for their classrooms.

The organization of the semi-structured focus group developed for this research study included a series of seven questions (Appendix C). These questions were intended to guide the discussion between the researcher and participants, and sometimes among participants. Questions mirrored those posed in the online survey (i.e., themes of environmental education and technology in the classroom), and were posed in an open-ended way with the intention of inviting in-depth answers and experiences from participants. Participants sat in a circular arrangement around a table. This was done to minimize the possibility of perceptions of hierarchy between the researchers and the participants.

While semi-structured focus groups recommend between six and eight people to ensure each participant is able to adequately contribute, due to timing constraints for the TDSB participants (a threat of union labour action affecting release availability), the number of participants was not capped and only one semi-structured focus group was held. While a greater number of participants in one focus group may have limited participant interaction, the researchers believed it was still of value to hold this data collection forum as a way of placing in to context 
online survey results, and potentially understanding more of the nuance associated with participant views and opinions.

During any focus group, let alone one with a large participant count, a potential limitation is that participants may modify their opinions, or how they portray their opinions (if given), about the question or topic at hand (Krueger, 1997; Kidd \& Parshall, 2000). To minimize this potential, as well as to potentially mitigate not being able to hear from all participants on a given topic, the researchers covered the meeting table in large sheets of paper, and participants were all given access to pens and markers. Participants were asked to first listen to each question presented by the researcher, and then to take the first one to two minutes to quietly write down their thoughts on the paper sheets. Following this, the researcher asked participants to voice their ideas and responses aloud to the group. All participants were encouraged to write down any additional ideas that came to mind while others were speaking. When conversation abated (rarely), the researcher had a list of prompts to re-invigorate participants and re-focus attention. All focus group participants were encouraged to contribute aloud, whether it was echoing another participant's experience or sharing a unique experience that had not yet been discussed.

\subsubsection{Data Processing}

Online survey responses were downloaded from the Google Form in a Microsoft Excel file format. Data was then scrubbed of participant identity to ensure respondent anonymity. Response frequency for select survey questions was visualized using pie charts. A master list of questions was curated for statistical analysis, and focused on investigating the potential for bivariate associations. 


\subsubsection{Statistical Test For Association}

A Mantel-Haenszel test of trend was used to determine whether there is a linear trend (i.e., a linear relationship/association) between two ordinal variables that are represented in a contingency table (Agresti, 2007; Kateri, 2014; Mantel, 1963). This statistical test has two assumptions: (1) you have two ordinal variables, and (2) you expect that there may be a linear relationship between the two variables. In general, the Mantel-Haenszel test of trend mirrors a Pearson correlation; and, where the variables are ordered (numbered) you can test for linear association. It makes no distinction between independent and dependent variables (Agresti, 2013). The Mantel-Haenszel test of trend determines whether the population correlation coefficient ( $\rho)$ is equal to zero (as is done for the Pearson correlation coefficient), as follows:

$\begin{array}{ll}\text { Null Hypothesis: Ho: } \rho=0 & \text { Equation } 1\end{array}$

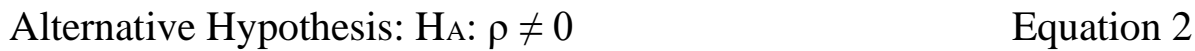

In this research, the Mantel-Haenszel test of trend was run in SPSS (v25) software. It involved two steps: (1) crosstabulation with Chi-square test, and (2) a bivariate test with Pearson correlation coefficient. Tests were valuated for significance using alpha $(\alpha)$ threshold of 0.05 .

\subsubsection{Qualitative Data Analysis}

The semi-structured focus group was audio recorded using Otter.ai software (v2.2.5) (automated audio-to-text), which had the ability to auto-transcribe the recording. The transcribed audio recording was then manually edited for accuracy, and formatted by the researchers, while simultaneously listening to the audio file for clarification. Participant notes made on the papers that lined the table (i.e., ideas and responses written down following each focus group question) were collected and transcribed. 
The text resulting from each transcription was then imported into NVivo software (v12), and nodes were created and used to code the overarching research themes, including: (1) environmental education about, for, and through the environment, and (2) opinions about ICTs and environmental education, including opportunities and barriers. NVivo uses a coding system based on nodes to assist researchers with the organization of information. Specifically, "Nodes are what researchers use to place meaning on different parts of the text" (Leech \& Onwuegbuzie, 2011, p. 74). Typically, nodes can take the form of a 'tree' node or a 'free' node. Tree nodes are a grouping of similarly themed nodes, and free nodes are ones that have not been added to a tree (e.g., may be categorically unique) (Leech \& Onwuegbuzie, 2011).

The purpose of coding is to ensure consistency in interpretation, which allows for constant comparison analyses. Developed in 1967 by Glaser and Strauss, constant comparison analysis is a commonly used approach in qualitative research (Leech, 2004; Leech \& Onwuegbuzie, 2011). As an example, once text is coded and nodes have been assigned, a constant comparison analysis can allow for the cross-interrogation of different sources of data such as: oral communication, participant observation, visuals (e.g., drawings, photographs, video, etc.), and written documents (i.e., past or present). In the present research, only text documents were analyzed arising from the transcriptions of the focus group conversation and participant notes. While only two sources of input data, coding allowed for constant comparison using an inter-source content analysis (i.e., assessment of the presence of words or concepts within or across documents) (Merriam \& Tisdell, 2015).

Word Frequency Tables were generated in NVivo as a basic approach to identifying the content frequency (i.e., occurrence of words used by participants in the focus group and in their associated note taking). Although word counts are not always regarded as useful, Leech and 
Onwuegbuzie (2011) give three reasons for their value in qualitative data analysis: (1) to assist with pattern identification, (2) for hypothesis verification, and (3) to maintain analytical integrity). In the present research, word counts were used to identify and characterize participant perceptions and opinions as they related to questions posed during the focus group. In order to create the word clouds, the word Frequency Tables underwent a process known as 'data reduction' (Appleton, 1995). This refers to the researcher "selecting, focusing, simplifying, abstracting and transforming" (Appleton, 1995, p. 995) the data for relevant words and phrases (Miles \& Huberman, 1994). The relevancy of words and phrases was determined by the researcher by listening to the audio recording of the semi-structured focus group, while reading the written transcript, in order to familiarize the context of the codes, within the broader conversation (Marshall \& Rossman, 1989). This refers to removing words with no significance to the overall code focusing on nouns, verbs, and by combining words to create short phrases, within the context of the code. An example of this would be joining "community" and "garden" to create the phrase "community garden", as these words have more of a contextual impact together, rather than separate. Word clouds were then generated using Word Art software to visualize word count frequency data (i.e., higher frequency word use is proportionate to the size the word/phrase is rendered in the graphic). 


\section{CHAPTER FOUR: RESULTS}

The online survey received a total of 54 complete responses, which refers to the number of participants who gave full consent (sections One through Three), and subsequently completed all required questions in the survey. Working with the TDSB contact gatekeeper, it was determined that 415 unique email addresses received invitations to participate in the survey. From this, a 13\% survey response rate (54/415) was calculated.

\subsection{Online Survey}

\subsubsection{Survey Participant Demographics}

Section Four of the online survey captured basic participant demographics. Age of participants ranged from 30 to less than 60 years old, with almost half (42\%) identifying as ' 40 to less than 50 years old' (Figure 1a). The great majority of participants, $83 \%$, identified as female with only $17 \%$ identifying as male (Figure $1 \mathrm{~b}$ ). In addition to personal demographic data, the survey inquired about professional experience (i.e., years teaching, (Figure 1c)). A large majority of respondents $(76 \%)$ indicated they had ten years or more of teaching experience; only $3 \%$ of respondents identified as new teachers ( $<2$ years of experience). Secondary school teachers made up $60 \%$ of the participants; the remaining respondents were elementary teachers.

\subsubsection{Knowledge and Perceptions of Environmental Education}

The Fifth Section of the online survey focused on teachers' understanding of Ontario policy concerning formal environmental education, their knowledge of environmental education goals, and their perceptions about teaching of environmental education. Respondents were asked if they knew about the Acting Today, Shaping Tomorrow (2009a) policy framework, which mandates delivery of environmental education across all subjects, and inter-annually across K-12. The majority of respondents (73\%) indicated they knew that the Ontario Ministry of Education 
(a)

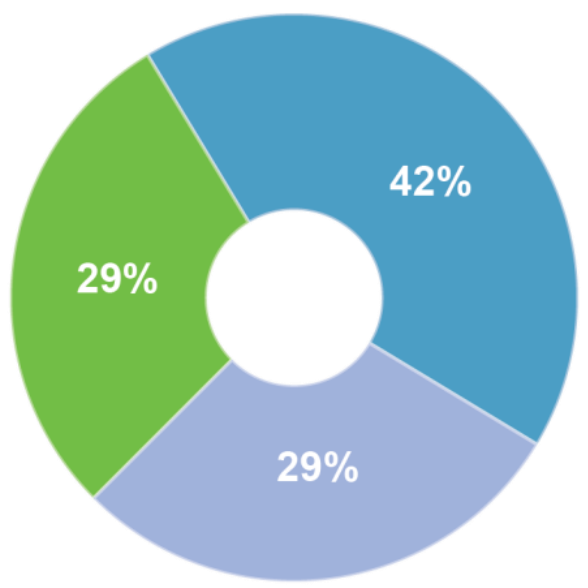

Age (years)

30 to $<40$ - 40 to $<50$ to $<60$

(c)

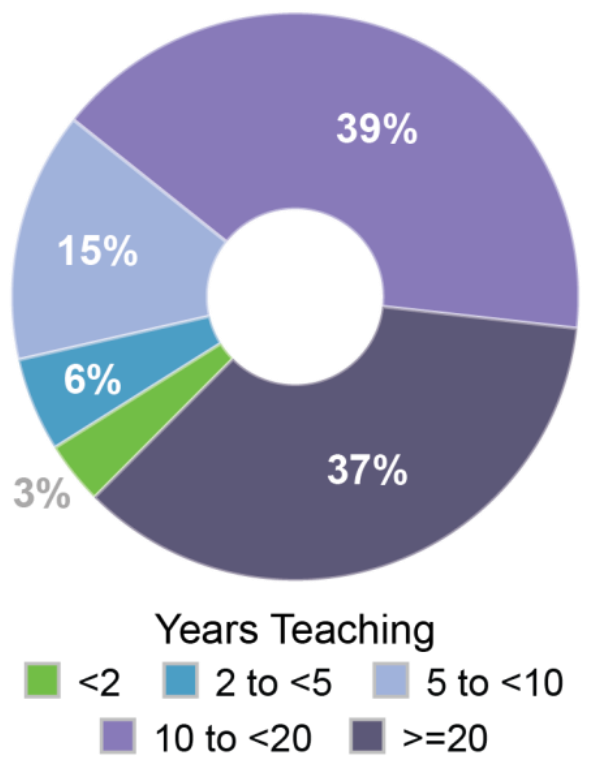

(b)

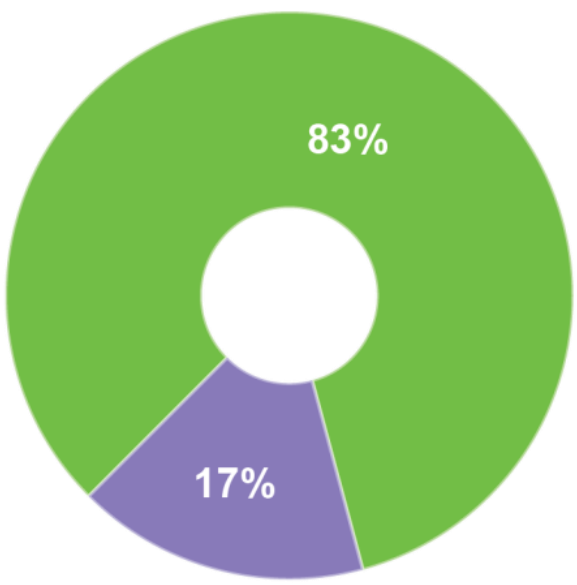

Gender Identity

Female Male

Figure 1: Demographic characteristics of online survey participants

Demographic characteristics of study participants: (a) Age, (b) Gender Identity, and (c) Years Teaching. Data obtained from online survey. 
(a)

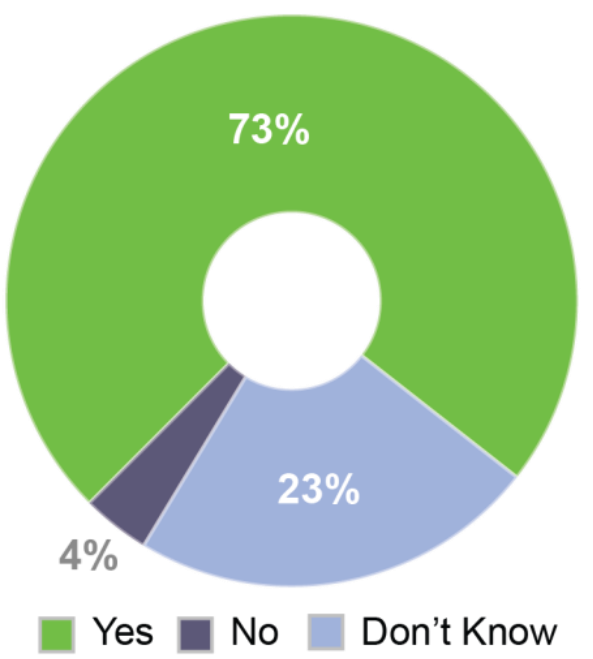

(b)

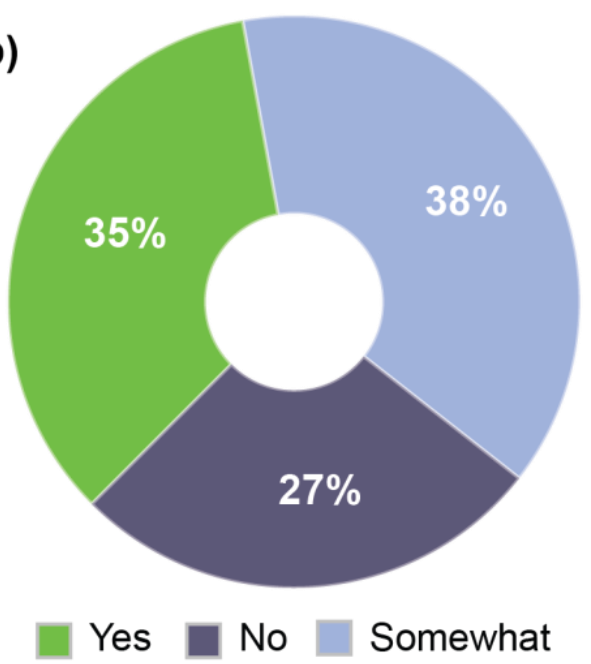

(c)

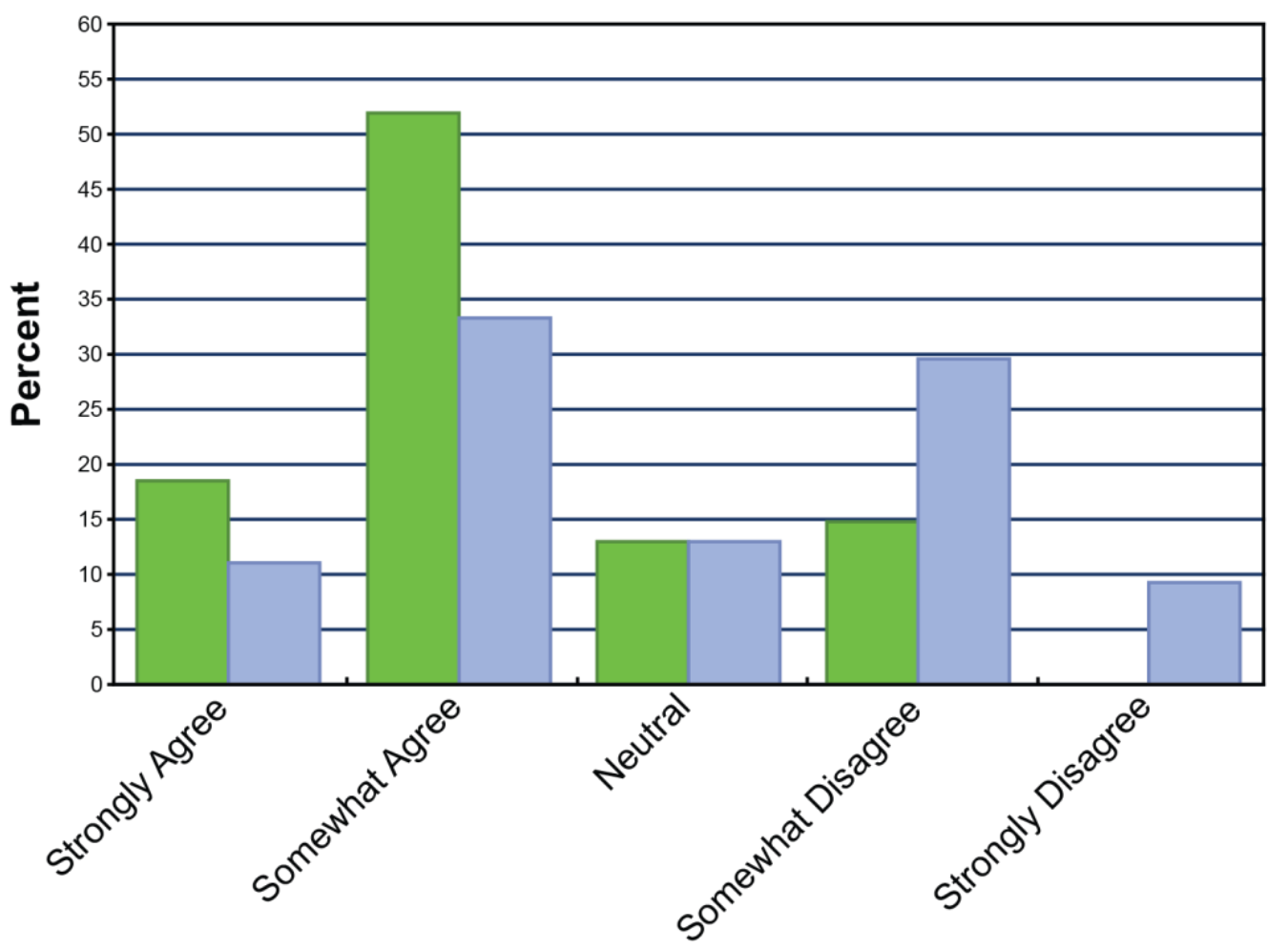

The quality of environmental education you are teaching is adequate

The quality of environmental education your school is implementing is adequate

Figure 2: Online survey participants' knowledge of environmental education policy and implementation

Study participant: (a) knowledge of Ontario Ministry of Education environmental education mandate, (b) familiarity with Ontario Ministry of Education's environmental education goals, (c) perception of the quality of environmental education they deliver, and the adequacy of environmental education delivered across their school. Data obtained from online survey. 
mandates environmental education (Figure 2a). Subsequently, survey participants were questioned whether or not they were familiar with the Ontario Ministry of Education's environmental education goals. Responses were less definitive, with just over one-third of participants (35\%) affirming 'yes' they were familiar, and greater than one-quarter (27\%) reporting 'no' familiarity (Figure 2b). Overall, survey respondents strongly believed that they are delivering adequate environmental education (Figure 2c), while they are somewhat less confident in the adequacy of the environmental education delivered across their school.

Respondent perceptions of environmental education were explored in greater detail. When asked about the importance of formal environmental education, an overwhelming majority (98\%) indicated that they believed environmental education is important throughout K-12 (Figure 3a), three-quarters (74\%) stated that environmental education is a priority in their classrooms (Figure 3b). Survey participants strongly agreed (76\%) that teaching about the environment with handson assignments (e.g., data collection, field observations, experiments) helped students with understanding and comprehension about the environment; only 4\% disagreed (Figure 3c). In terms of respondent impressions of the practicality of delivering formal education throughout $\mathrm{K}-12$, half (51\%) 'strongly agreed' that it was realistic, while only $13 \%$ disagreed (Figure $3 \mathrm{~d})$. Student engagement with topics concerning the environment was 'always' and 'very often' believed, by survey respondents, to be positive (Figure 3e). Environmental education was overwhelmingly seen as a positive influence on student behavior ( $84 \%$ of respondents agreed); no one disagreed (Figure 3f).

Potential barriers to implementation of environmental education were explored, first by simply asking online survey respondents if they perceived there are barriers to the inclusion of 
(a)

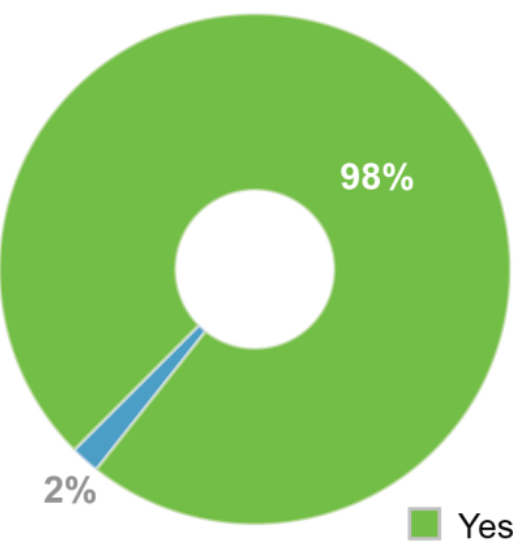

(c)

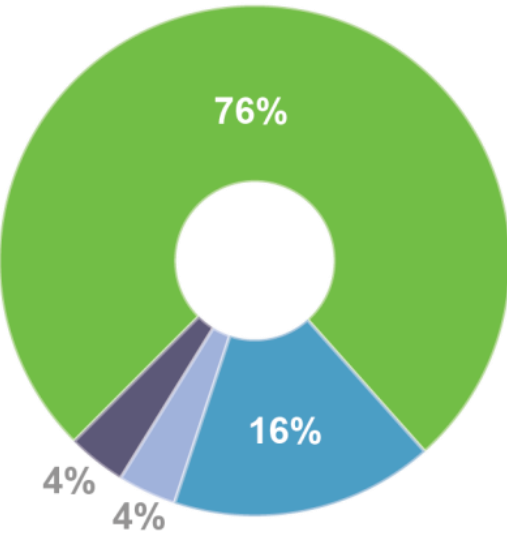

Strongly Agree Somewhat Disagree

(e)

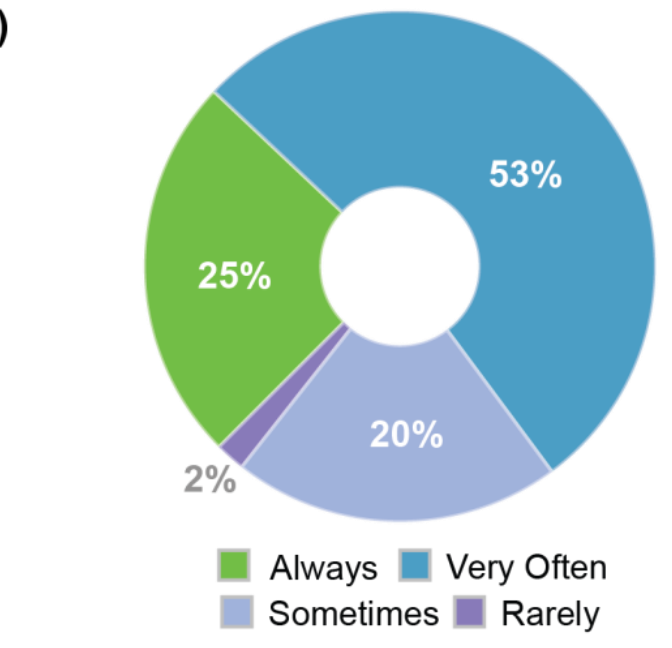

(b)

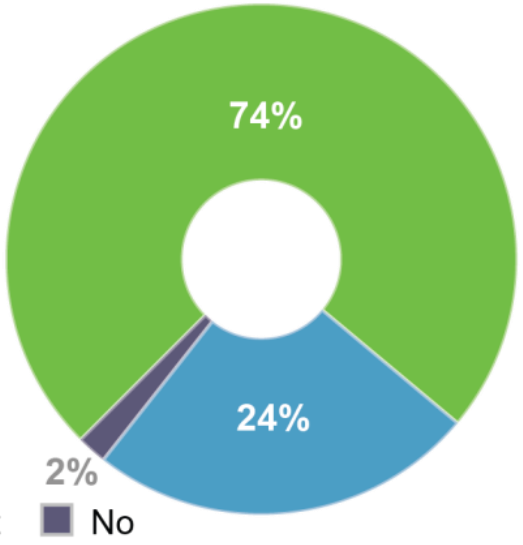

(d)

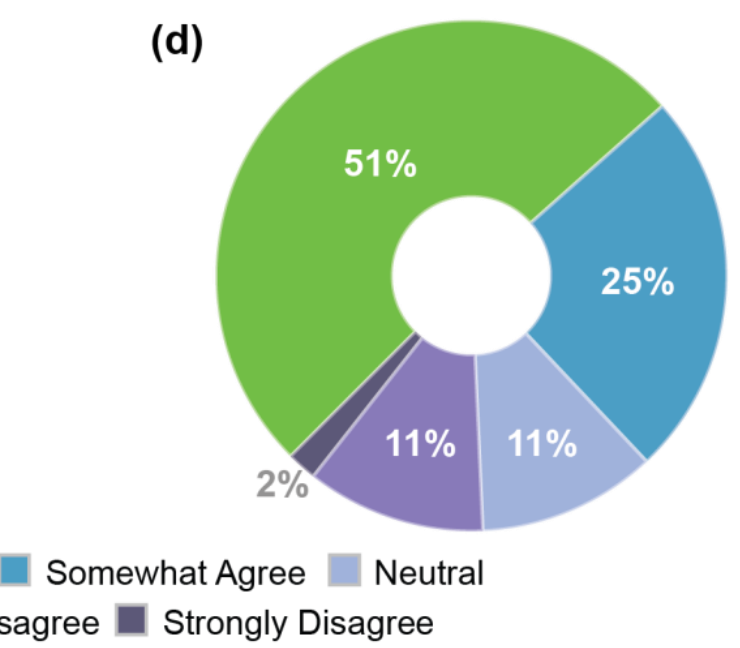

(f)

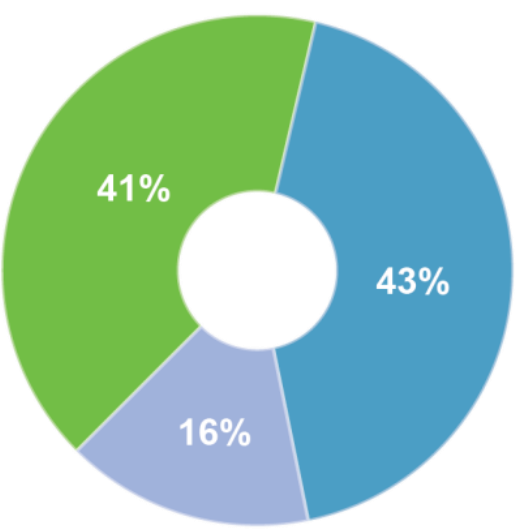

Strongly Agree $\square$ Somewhat Agree Neutral

\section{Figure 3: Online survey participants' perception of environmental education}

Survey respondent: (a) view that environmental education is important in K-12, (b) environmental education is a priority in their classroom, (c) view that teaching about the environment with hands-on assignments helps students to understand complicated subject matter, (d) opinion that environmental education in all subject areas is realistic for $\mathrm{K}-12$, (e) belief that students are engaged when they teach about the environment, (f) belief that positive changes in student behaviour can be attributable to environmental education. Data obtained from online survey. 
formal environmental education in their teaching. Just over half (53\%), of the participants responded affirmatively; just over one-third (38\%) said no (Figure 4a). Almost three-quarters of respondents (74\%) were agreeable to the statement that environmental education was an afterthought in the curriculum; only 11\% disagreed (Figure 4b). When online survey participants were asked about planning and delivering field trips off of school property, 39\% of respondents disagreed that it was straightforward, while only $15 \%$ strongly agreed (Figure $4 \mathrm{c}$ ). Half of the study participants (50\%) disagreed that it was possible to conduct environmental education without leaving the classroom; only $6 \%$ strongly agreed that this was possible (Figure $4 \mathrm{~d}$ ).

The actual barriers to implementation of formal environmental education identified by the online survey participants are shown in the word cloud (Figure 4e). Specifically, this graphic shows words and phrases, scaled in magnitude, according to identification frequency, by online survey participants. Crowded curriculum, resources/financial, and difficulty running field trips were reported with the greatest regularity. Teacher knowledge, time, and staff support, also factored as important.

The online survey participants were then asked if they believed that teachers received adequate training to deliver formal environmental education (Figure 5a). Only $2 \%$ of respondents strongly agreed, while greater than three-quarters (77.5\%) registered disagreement. This question was followed by asking survey respondents where they obtained their environmental knowledge (Figure 5b). For this question, participants were asked to select what sources (if any) had provided them with environmental understanding. Respondents could select all sources that applied to them, as well as add to the pre-determined list from personal studies (i.e., in non-formal ways), whereas only 7 respondents indicated that teachers' college had prepared them with some of their knowledge. 
(a)

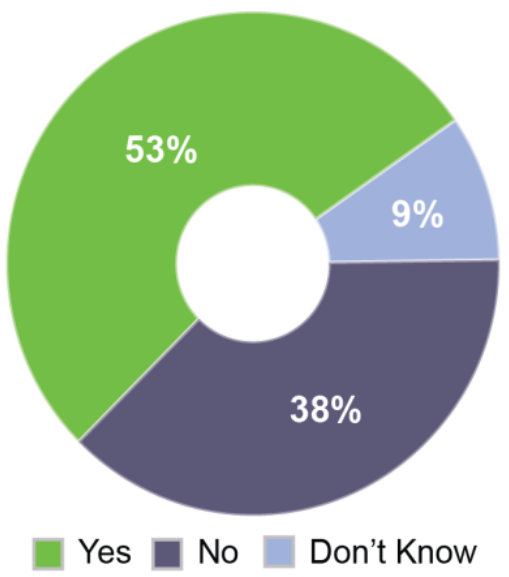

(c)

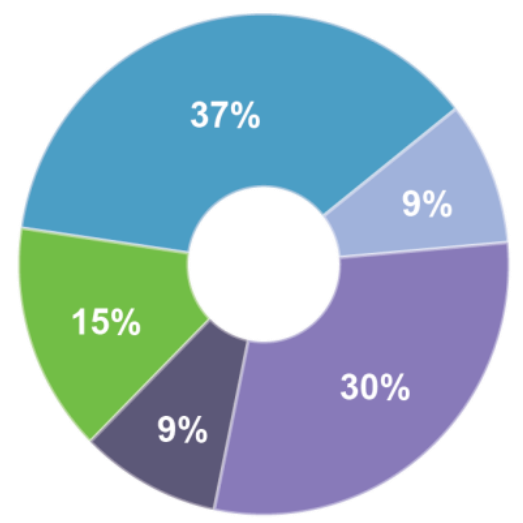

Strongly Agree

Somewhat Disagree $\square$ Strongly Disagree

(e)

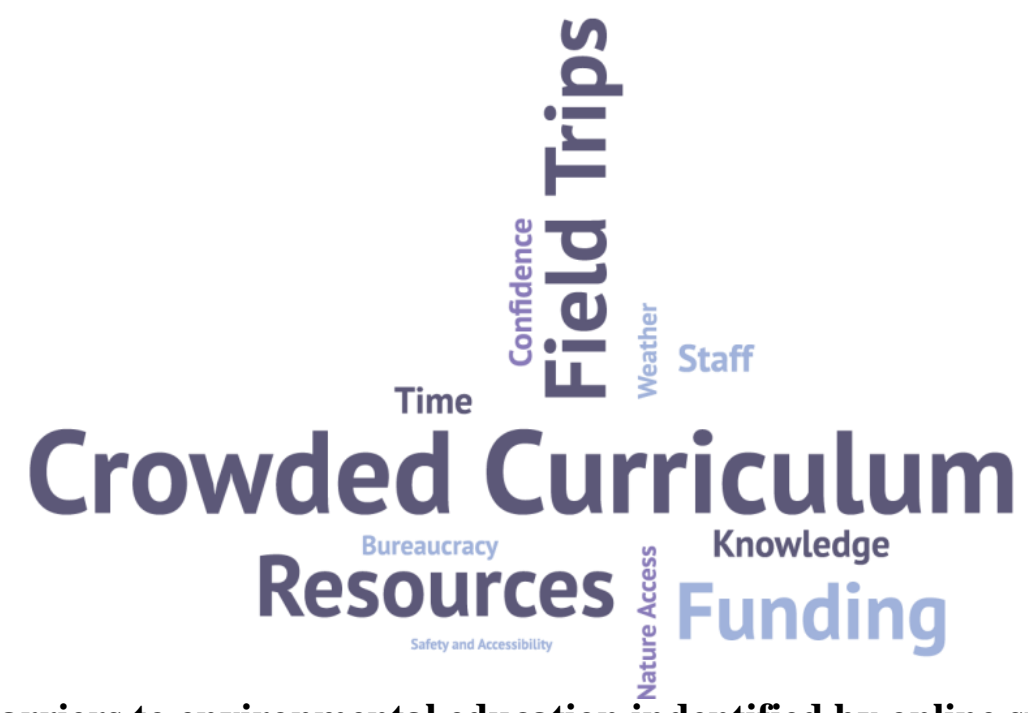

Figure 4: Barriers to environmental education indentified by online survey participants Study respondent views as to whether: (a) there are barriers to including environmental education in their classroom/lesson plans, (b) environmental education is an afterthought in curriculum requirements, (c) organizing field trips to take students off school property is straightforward, (d) it is possible to include environmental education curriculum adequately without leaving the classroom; and, a (e) a word cloud illustrating barriers perceived by teachers to the inclusion of environmental education in their teaching. Data obtained from online survey. 
(a)

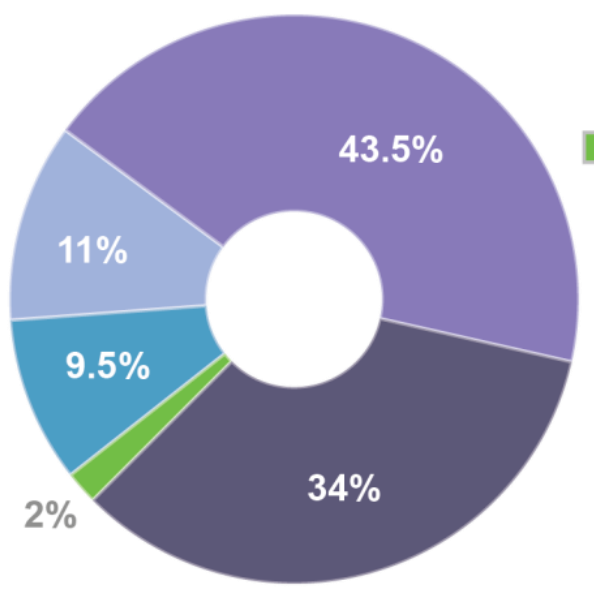

(b)

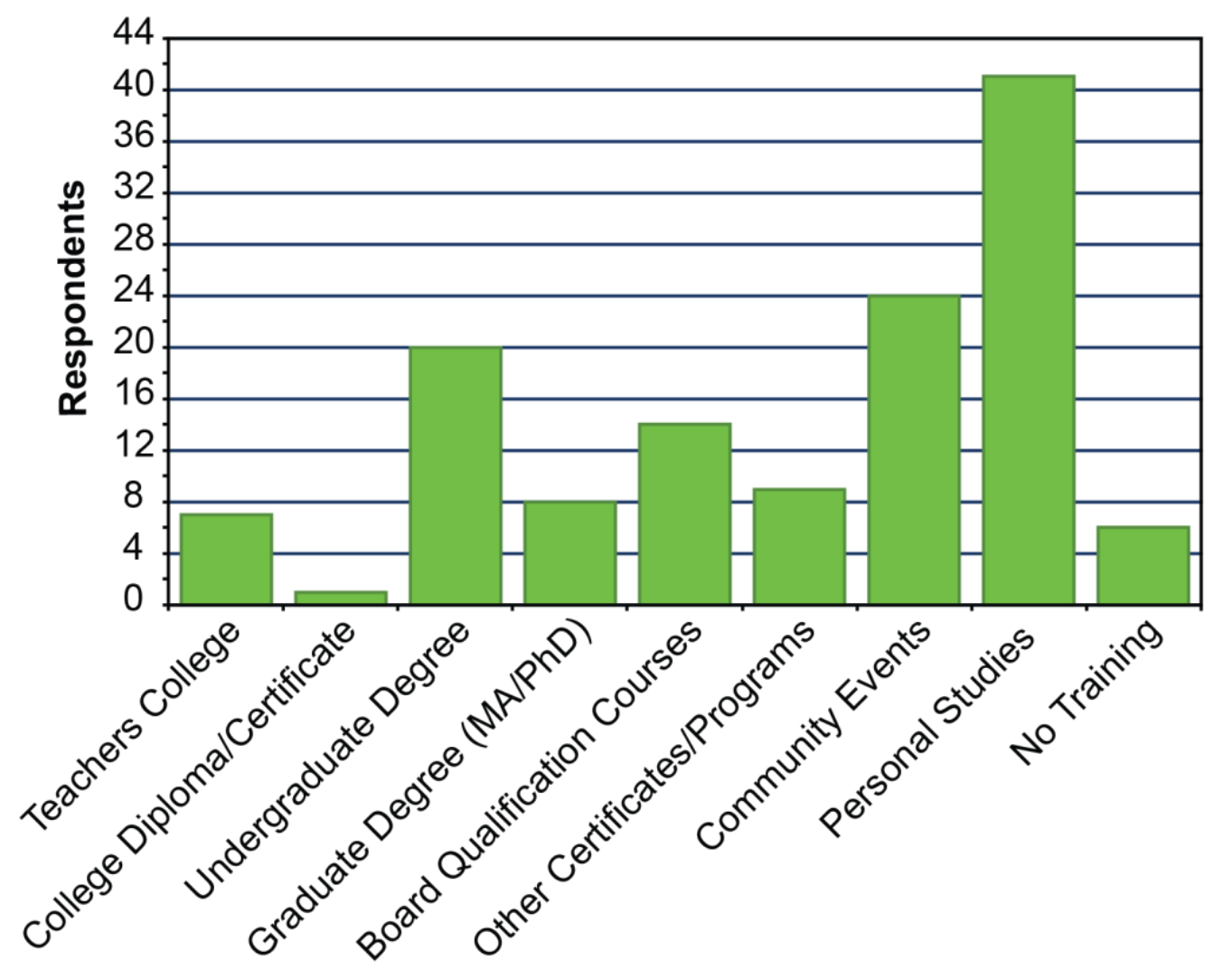

Figure 5: Online survey participants' perception of environmental education training

Study participant: (a) perceptions of whether they received adequate training to teach about the environmental, and (b) sources of environmental knowledge. Data obtained from online survey. The majority (41 respondents) indicated that they obtained some of their environmental knowledge 


\subsubsection{Information and Communication Technology}

In Section Six, online survey respondents were asked to reflect on Information and Communication Technology (ICT) use in the classroom. Specifically, questions sought to discover how technology is used, what kind of technologies are used, and what teachers' perceptions are of the use of ITC as a classroom teaching tool. Two questions were posed to the online survey participants, which included the frequency (a) they employ ICTs as teaching tools in their teaching, and (b) their broader school uses ICTs as teaching tools (Figure 6a).

Respondents seem to agree that ICT use was prominent as a teaching tool, and that they may actually use it more regularly as a teaching instrument when compared to their boarder school's use. The broader (school-wide) receptiveness to using ICTs in the classroom was probed in a further question (Figure 6b). No one indicated that their schools were unreceptive to ICTs; in fact, all of the respondents conveyed receptiveness as 'always' or 'very often'.

Participants responded positively (76\%) when asked if they perceived ICTs were useful as educational teaching tools throughout K-12 subjects; no on responded negatively (Figure 6c). Teachers' perception of student responsiveness to the use of ICTs as teaching tools was assessed by asking study participants if they believe students were more engaged when taught with ICTs (Figure 6d). Three-quarters (74\%) of respondents answered affirmatively, while only 9\% reported moderate disagreement. Just over half of study participants $(56 \%)$ indicated that they believed students retain more information when taught using ICTs; one-quarter indicated neutrality, while one-fifth (19\%) moderately disagreed with the statement (Figure 6e). 
(a)

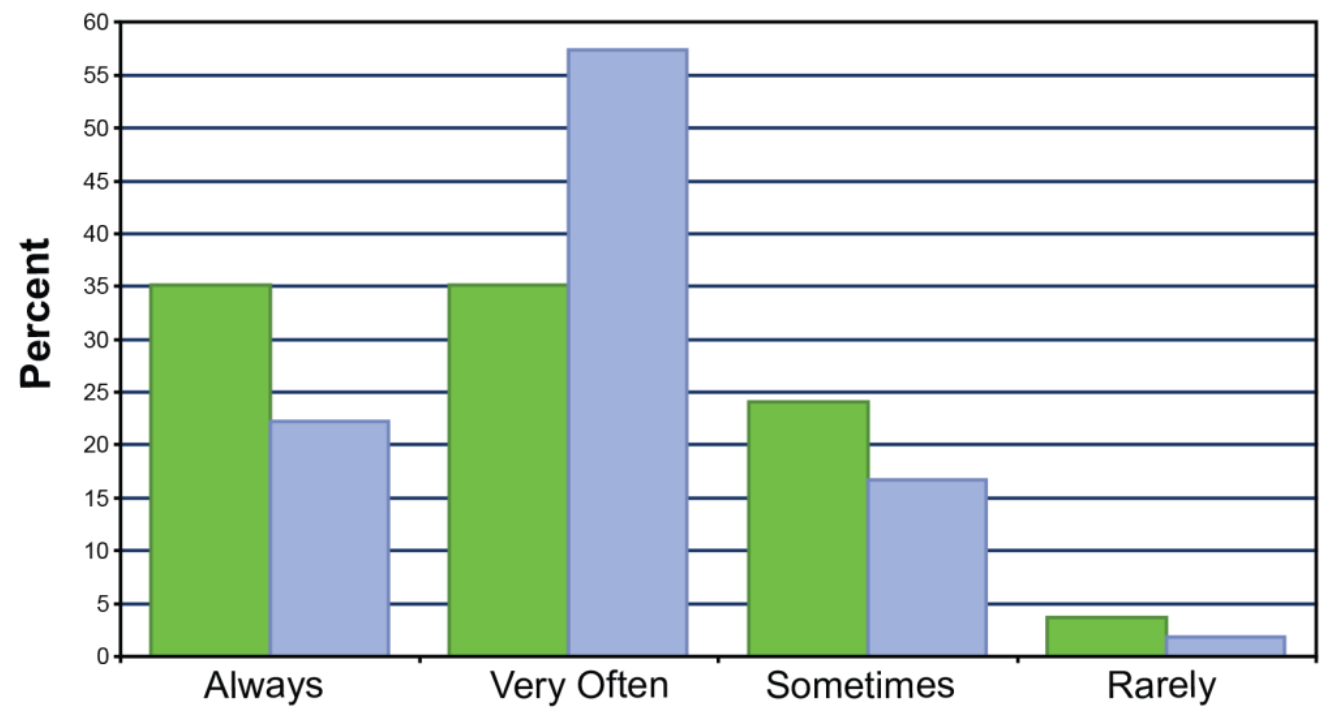

You use technology in your classroom

Your school uses technology in its classrooms

(b)

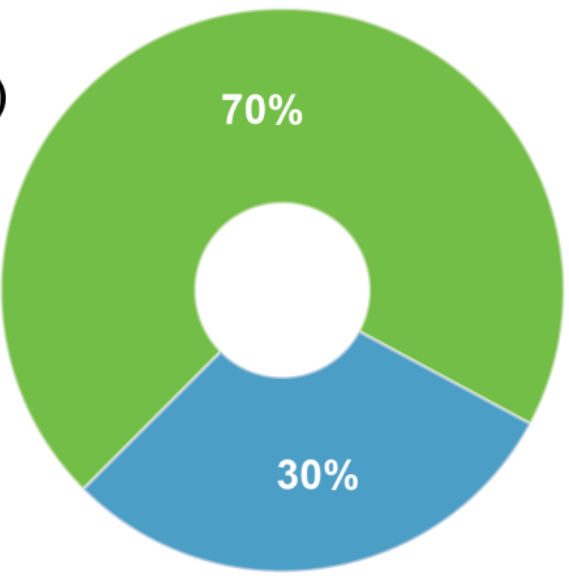

Always $\square$ Very Often (c)

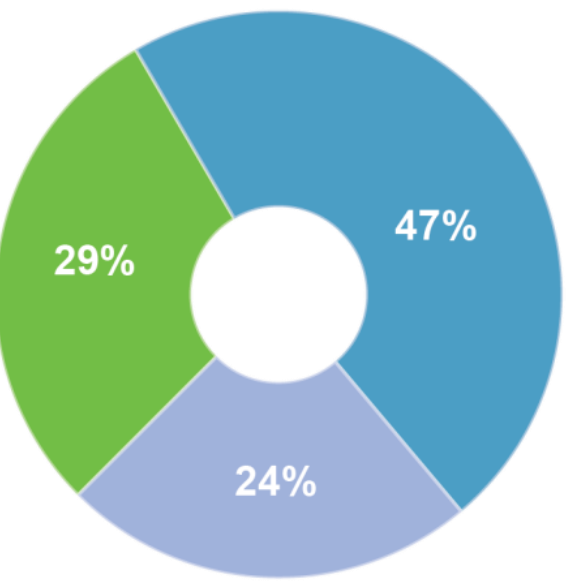

Sometimes

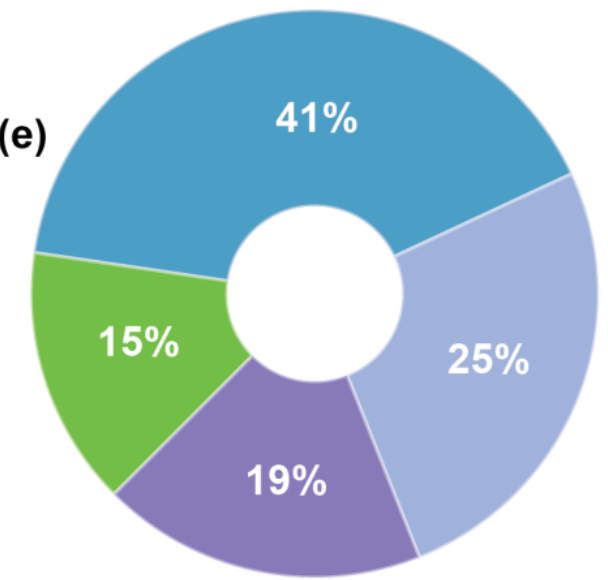

Neutral Somewhat Disagree

Strongly Agree $\quad$ Somewhat Agree

Figure 6: Online survey participants' perception of technology use in the classroom Respondent views on: (a) their use, and their school's use, of ICTs for teaching, (b) the receptiveness of their school to using ICTs in the classroom for education, (c) whether technology is helpful for delivery of K-12 education, (d) whether students are more engaged when taught using ICTs, and (e) whether students retain more information when taught with ICTs. Data obtained from online survey. 
To understand more about technology use in the classroom, study participants were asked to identify perceived barriers to using ICTs as a teaching tool (Figure 7a). The word cloud prioritizes words and phrases, scaled in magnitude, according to identification frequency, by the study participants. Similar to the question about barriers to teaching environmental education, this question had respondents select from a list of barriers, as well as provide them with the option to add their own. Availability of resources, as well as teacher knowledge and confidence, was the most frequently identified barrier. ICTs were identified by four-fifths (81\%) of study respondents as causing them some personal frustration when they use it in their teaching, with $15 \%$ indicating that it was often frustrating form them (Figure 7b). As a follow-up question concerning student focus, $33 \%$ of survey participants moderately agreed that ICTs can be a distraction for students; one-quarter (26\%) responded neutrally, and 37\% registered disagreement with this concern (Figure $7 \mathrm{c})$.

Study participants were then asked about their perception of ICTs as tools to deliver formal environmental education. Specifically, they were asked if they believe environmental education and technology are at odds with each other (Figure 8a). Four-fifths of respondents (82\%) disagreed with this statement, while only one-tenth (9\%) somewhat agreed; no one indicated affirmatively with 'yes'. Almost three-quarters (74\%) of survey respondents indicated that ICTs can facilitate environmental education in K-12; no one responded negatively (Figure 8b). Use of the internet and software applications was common among survey respondents as part of their teaching about the environment (Figure 8c). Greater than nine-tenths (92\%) of study participants affirmed use, whereas only $8 \%$ reported their use was 'rare' or 'never'. The suitability of participant schoolyards to teaching about environmental education was affirmed by three- quarters (76\%) of survey 
(a)

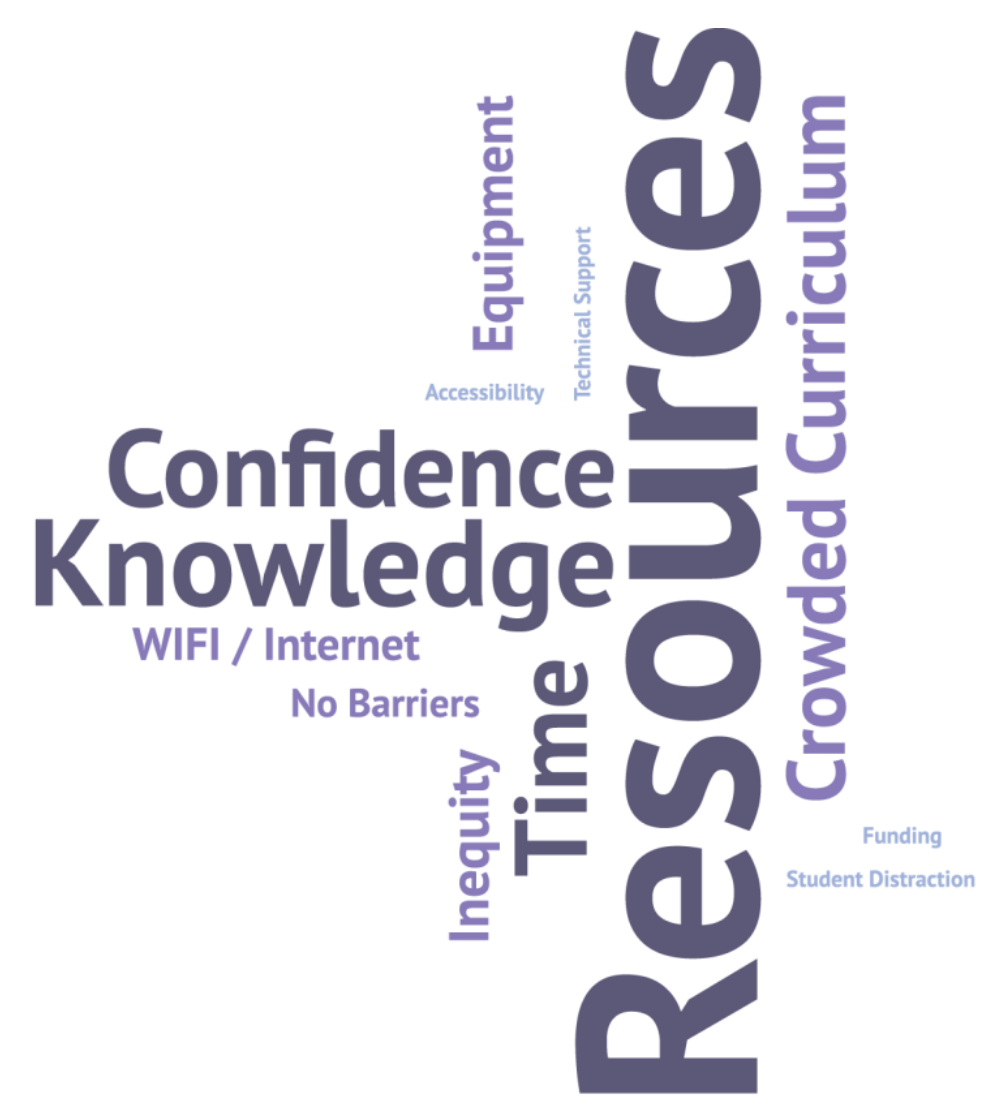

(b)

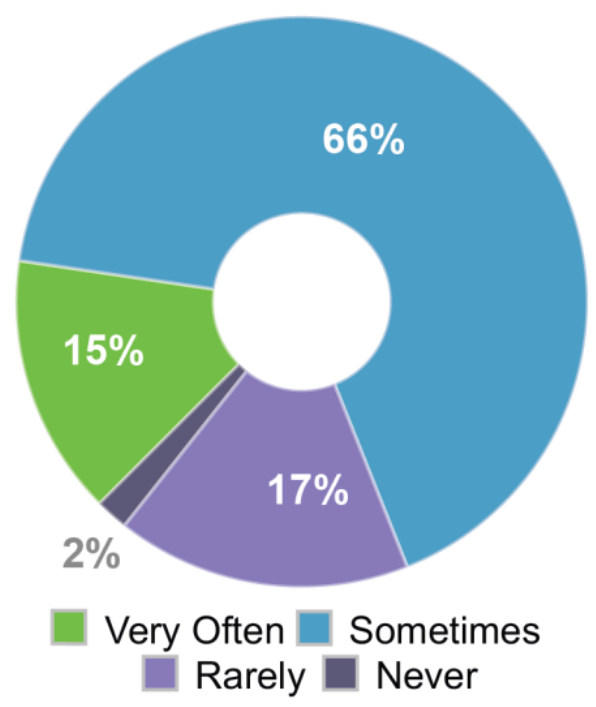

(C)

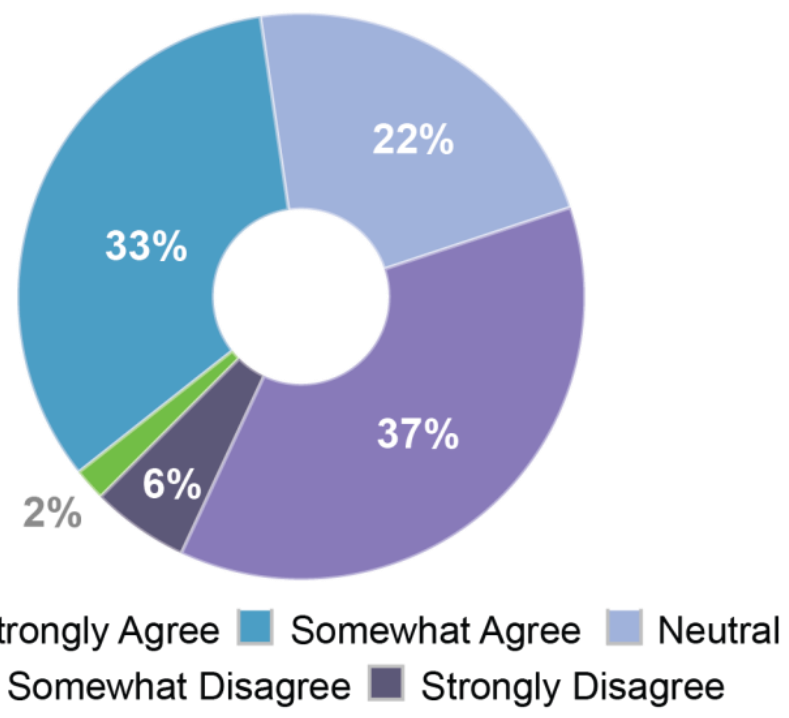

Figure 7: Barriers to using technology in the classroom identified by online survey participants

Study respondent: (a) identification of barriers to the use of ICTs as educational teaching tools, (b) experience of personal frustration when using ICTs for teaching, (c) perception of student distraction when learning-focused ICTs are used in the classroom. Data obtained from online survey. 
(a)

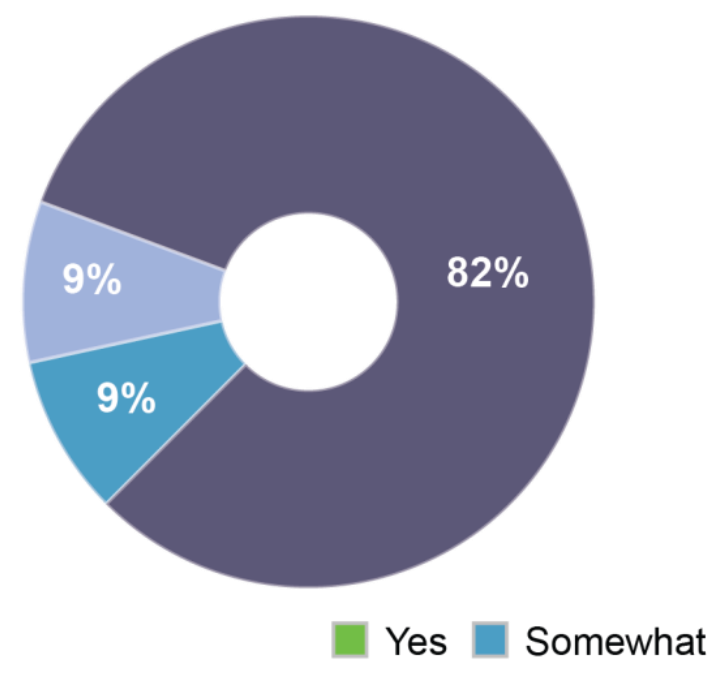

(c)

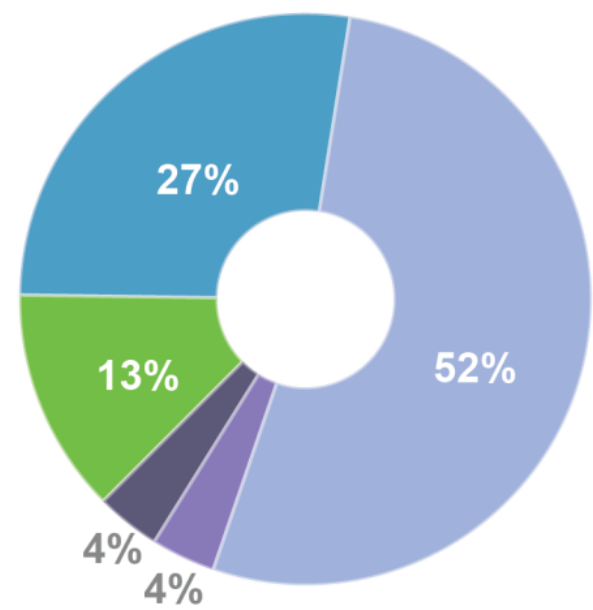

Always $\square$ Very Often $\square$ Sometimes Rarely $\square$ Never (b)

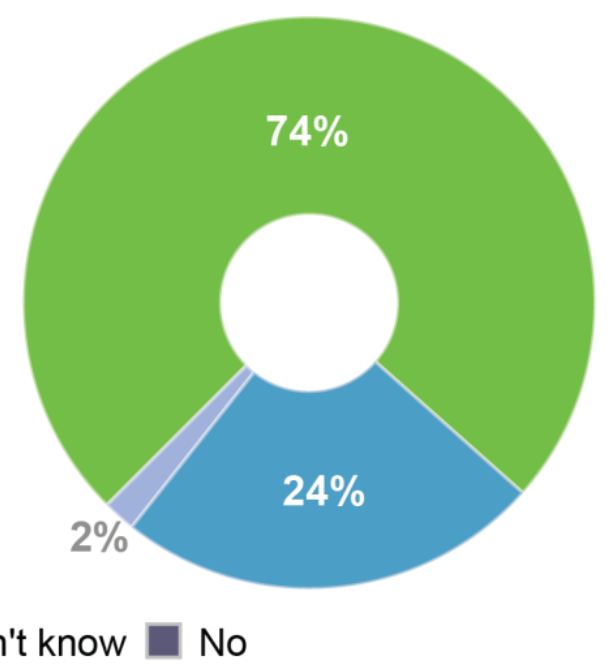

(d)

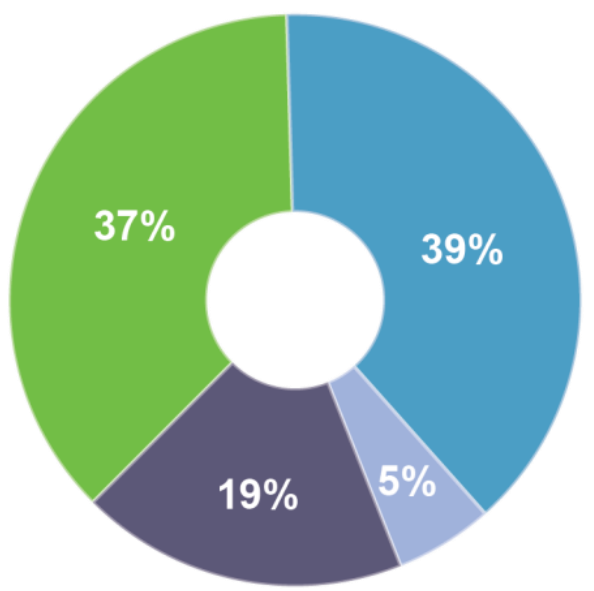

Strongly Agree $\square$ Somewhat Agree $\square$ Neutral

Somewhat Disagree $\square$ Strongly Disagree

Figure 8: Online survey participants' pereption of leveraing technology to deliver environmental education

Study participant perceptions that: (a) environmental education and ICTs are at odds with each other, (b) ICTs can facilitate teaching environmental education in K-12; and, whether (c) your classes use the internet or apps to learn about the environment, and (d) your outdoor schoolyard/grounds is adequate to use for environmental education. 
respondents selecting 'yes' or 'somewhat' to the question of aptness; however, one-fifth (19\%) strongly disagreed (Figure 8d).

\subsection{Quantitative Analysis: Tests of Association}

The Mantel-Haenszel test of trend was used to investigate whether study participant demographics were associated with the frequency teachers included environmentally themed education into their lessons. The was no statistically significant association found between the age of a teacher, or their gender identity, and regularity with which the taught environmentally themed content (Table 1). Years of experience teaching, however, was found to be statistically significantly positively associated with the frequency of which environmental content was taught. Specifically, with more years of teaching experience, teachers included greater amounts of environmental content in their lessons.

The frequency with which teachers taught environmental content was also statistically significantly positively associated with the regularity that they took their classes outside as part of educational lessons. Moreover, study participant perceptions of both student enjoyment in, and engagement with, subject matter were both highly statistically significantly positively associated with the frequency of environmental content included in their lessons. Finally, and not

surprisingly, as study participants placed greater personal priority on environmental content there was a statistically significantly positive association with regularity in which they included environmental content in their lessons. 
Table 1: Frequency of environmental themed education and demographics

Association between the frequency a respondent teaches environmentally-themed education and their age $(n=54)$, gender identity $(n=54)$, years teaching $(n=54)$, holding lessons outside of the school building $(n=54)$, enjoyment of the subject(s) $(n=53)$, their perception of student engagement when they teach about the environment $(n=52)$, the priority they give to environmental education in their classroom $(n=52)$, and whether they believe they have received adequate training to deliver environmental education to their students $(n=54)$. Numbers in parenthesis indicate percent of respondents identifying the presence of barriers, according to characteristic grouping.

\begin{tabular}{|c|c|c|c|c|c|c|c|}
\hline Characteristics & Frequency 1 & hing Enviro & tally-The & Content & $\chi^{2}$ & $p$ & $\mathbf{r}$ \\
\hline & Rarely & Regularly & & & & & \\
\hline Age (years) & & & & & 3.136 & 0.077 & 0.248 \\
\hline $\begin{array}{l}30 \text { to }<40 \\
40 \text { to }<50 \\
50 \text { to }<60\end{array}$ & $\begin{array}{l}6(40) \\
3(14) \\
2(13)\end{array}$ & $\begin{array}{r}9(60) \\
19(86) \\
13(87)\end{array}$ & & & & & \\
\hline & Once/Twice & Monthly & Weekly & Daily & & & \\
\hline Age (years) & & & & & 1.873 & 0.171 & 0.192 \\
\hline $\begin{array}{l}\mathbf{3 0} \text { to }<\mathbf{4 0} \\
\mathbf{4 0} \text { to }<\mathbf{5 0} \\
\mathbf{5 0} \text { to }<\mathbf{6 0}\end{array}$ & $\begin{array}{c}4(27) \\
1(4.5) \\
2(13)\end{array}$ & $\begin{array}{r}2(13) \\
2(9) \\
0(0)\end{array}$ & $\begin{array}{r}3(20) \\
5(23) \\
5(33.5)\end{array}$ & $\begin{array}{r}6(40) \\
14(63.5) \\
8(53.5)\end{array}$ & & & \\
\hline & Once/Twice & Monthly & Weekly & Daily & & & \\
\hline $\begin{array}{l}\text { Gender Identity } \\
\text { Female } \\
\text { Male }\end{array}$ & $\begin{array}{r}6(13.5) \\
1(11)\end{array}$ & $\begin{array}{l}2(4.5) \\
2(22)\end{array}$ & $\begin{array}{r}13(29) \\
1(11)\end{array}$ & $\begin{array}{r}24(53) \\
5(56)\end{array}$ & 0.084 & 0.773 & -0.040 \\
\hline $\begin{array}{l}\text { Years Teaching } \\
<2 \\
2 \text { to }<5 \\
5 \text { to }<10 \\
10 \text { to }<20 \\
>=20\end{array}$ & $\begin{array}{l}1(50) \\
1(33) \\
2(25) \\
1(5) \\
2(10)\end{array}$ & $\begin{array}{r}1(50) \\
0(0) \\
1(12.5) \\
1(5) \\
1(5)\end{array}$ & $\begin{array}{r}0(0) \\
0(0) \\
3(37.5) \\
7(33) \\
4(20)\end{array}$ & $\begin{array}{r}0(0) \\
2(67) \\
2(25) \\
12(57) \\
13(65)\end{array}$ & $6.221 *$ & 0.013 & 0.343 \\
\hline $\begin{array}{l}\text { Lessons Outdoors } \\
\text { Never } \\
\text { Rarely } \\
\text { Sometimes } \\
\text { Often } \\
\text { Always }\end{array}$ & $\begin{array}{r}3(75) \\
0(0) \\
4(18) \\
0(0) \\
0(0)\end{array}$ & $\begin{array}{r}1(25) \\
2(100) \\
1(5) \\
0(0) \\
0(0)\end{array}$ & $\begin{array}{r}0(0) \\
0(0) \\
9(41) \\
4(27) \\
1(9)\end{array}$ & $\begin{array}{r}0(0) \\
0(0) \\
8(36) \\
11(73) \\
10(91)\end{array}$ & $24.468 *$ & 0.000 & 0.679 \\
\hline $\begin{array}{l}\text { Subject Enjoyment } \\
\text { Sometimes } \\
\text { Often } \\
\text { Always }\end{array}$ & $\begin{array}{r}4(67) \\
1(9) \\
1(2.5)\end{array}$ & $\begin{array}{r}1(16.5) \\
3(27) \\
0(0)\end{array}$ & $\begin{array}{r}1(16.5) \\
2(18) \\
11(31)\end{array}$ & $\begin{array}{r}0(0) \\
5(46) \\
24(66.5)\end{array}$ & $21.588^{*}$ & 0.000 & 0.644 \\
\hline $\begin{array}{l}\text { Student Engagement } \\
\text { Rarely } \\
\text { Sometimes } \\
\text { Often } \\
\text { Always }\end{array}$ & $\begin{array}{r}1(100) \\
2(20) \\
2(7) \\
0\end{array}$ & $\begin{array}{r}0 \\
2(20) \\
2(7) \\
0\end{array}$ & $\begin{array}{l}2(20) \\
9(32) \\
3(23)\end{array}$ & $\begin{array}{r}0 \\
4(40) \\
15(54) \\
10(77)\end{array}$ & $9.587 *$ & 0.002 & 0.434 \\
\hline
\end{tabular}




\begin{tabular}{|c|c|c|c|c|c|c|c|}
\hline \multirow[t]{2}{*}{ Characteristics } & \multicolumn{4}{|c|}{ Frequency Teaching Environmentally-Themed Content } & \multirow{3}{*}{$\begin{array}{c}\chi^{2} \\
14.564^{*}\end{array}$} & \multirow{3}{*}{$\begin{array}{c}p \\
0.000\end{array}$} & \multirow{3}{*}{$\begin{array}{c}\mathbf{r} \\
0.534\end{array}$} \\
\hline & Once/Twice & Monthly & Weekly & Daily & & & \\
\hline $\begin{array}{l}\text { Teaching Priority: } \\
\text { Environment } \\
\text { Content }\end{array}$ & & & & & & & \\
\hline $\begin{array}{l}\text { Yes } \\
\text { Somewhat } \\
\text { No }\end{array}$ & $\begin{array}{r}1(2.5) \\
4(33) \\
0(0)\end{array}$ & $\begin{array}{l}1(2.5) \\
2(17) \\
1(100)\end{array}$ & $\begin{array}{r}11(28) \\
3(25) \\
0(0)\end{array}$ & $\begin{array}{r}26(67) \\
3(25) \\
0(0)\end{array}$ & & & \\
\hline Adequately Trained & & & & & 1.713 & 0.191 & -0.180 \\
\hline $\begin{array}{l}\text { Strongly Agree } \\
\text { Somewhat Agree } \\
\text { Neutral } \\
\text { Somewhat Disagree } \\
\text { Strongly Disagree }\end{array}$ & $\begin{array}{l}0(0) \\
1(17) \\
0(0) \\
3(13) \\
3(17)\end{array}$ & $\begin{array}{r}0(0) \\
0(0) \\
1(17) \\
0(0) \\
3(17)\end{array}$ & $\begin{array}{l}1(100) \\
1(17) \\
0(0) \\
6(26) \\
6(33)\end{array}$ & $\begin{array}{r}0(0) \\
4(67) \\
5(83) \\
14(61) \\
6(33)\end{array}$ & & & \\
\hline
\end{tabular}

${ }^{*} \mathrm{p}<=0.05$

Association between whether survey respondents perceived difficulty in teaching environmental education, and characteristics including demographic features, teaching experience, sources of environmental knowledge, thematic passion, and adequacy of training, were assessed (Table 2). While the number of study participants identifying as male was small, there was still a statistically significant association between gender identity and difficulty teaching about the environment; males found it more challenging. Predictably, there was a statistically significant negative association between survey respondents who had a greater passion for the environment and the degree to which they registered difficulty teaching about it. No other statistically significant associations with teaching about the environment were found. 
Table 2: Perception of barriers to environmental educaton and demographics

Respondent perception of personal challenge teaching environmental education in the classroom according to educator age $(n=51)$, gender identity $(n=53)$, years teaching $(n=53)$, whether summer training for skills development was sought $(n=50)$, respondent holds an environmentrelated university degree $(n=47)$, the priority they give to environmental education in their classroom $(\mathrm{n}=52)$, and whether they believe they have received adequate training to deliver environmental education to their students $(\mathrm{n}=53)$. Numbers in parenthesis indicate percent of respondents identifying the presence of barriers, according to characteristic grouping.

\begin{tabular}{|c|c|c|c|c|c|}
\hline \multirow[t]{2}{*}{ Characteristics } & \multicolumn{2}{|c|}{ Difficulty Teaching About Environment } & \multirow[t]{2}{*}{$\chi^{2}$} & \multirow[t]{2}{*}{$p$} & \multirow[t]{2}{*}{$\mathbf{r}$} \\
\hline & Somewhat & No & & & \\
\hline Age (years) & & & 0.147 & 0.701 & -0.054 \\
\hline $\begin{array}{l}30 \text { to }<40 \\
40 \text { to }<50 \\
50 \text { to }<60\end{array}$ & $\begin{array}{l}5(33) \\
6(29( \\
6(40)\end{array}$ & $\begin{array}{r}10(67) \\
15(71) \\
9(60)\end{array}$ & & & \\
\hline Gender Identity & & & $5.842 *$ & 0.016 & -0.335 \\
\hline $\begin{array}{l}\text { Female } \\
\text { Male }\end{array}$ & $\begin{array}{r}11(25) \\
6(67)\end{array}$ & $\begin{array}{r}33(75) \\
3(33)\end{array}$ & & & \\
\hline Years Teaching & & & 1.730 & 0.188 & 0.182 \\
\hline $\begin{array}{l}<2 \\
2 \text { to }<5 \\
5 \text { to }<10 \\
10 \text { to }<20 \\
>=20\end{array}$ & $\begin{array}{l}1(50) \\
2(67) \\
3(38) \\
6(29) \\
5(26)\end{array}$ & $\begin{array}{r}1(50) \\
1(33) \\
5(62) \\
15(71) \\
14(74)\end{array}$ & 1527 & 0215 & 172 \\
\hline $\begin{array}{l}<10 \\
>=10\end{array}$ & $\begin{array}{r}6(46) \\
11(28)\end{array}$ & $\begin{array}{r}7(54) \\
29(72)\end{array}$ & 1.531 & 0.215 & $0.1 / 2$ \\
\hline Summer Training & & & 0.079 & 0.779 & -0.040 \\
\hline $\begin{array}{l}\text { Yearly } \\
\text { Every Few Years } \\
\text { Rarely }\end{array}$ & $\begin{array}{l}2(33) \\
9(32) \\
6(38)\end{array}$ & $\begin{array}{r}4(67) \\
19(68) \\
10(62)\end{array}$ & & & \\
\hline Environment Degree & & & 0.299 & 0.585 & -0.081 \\
\hline $\begin{array}{l}\text { Yes } \\
\text { No }\end{array}$ & $\begin{array}{l}9(31) \\
7(39)\end{array}$ & $\begin{array}{l}20(69) \\
11(61)\end{array}$ & & & \\
\hline $\begin{array}{l}\text { Teaching Priority: } \\
\text { Environment } \\
\text { Content }\end{array}$ & & & $10.718 *$ & 0.001 & -0.458 \\
\hline $\begin{array}{l}\text { Yes } \\
\text { Somewhat } \\
\text { No }\end{array}$ & $\begin{array}{r}8(21) \\
8(67) \\
1(100)\end{array}$ & $\begin{array}{r}31(79) \\
4(33) \\
0(0)\end{array}$ & & & \\
\hline Adequately Trained & & & 2.257 & 0.133 & 0.208 \\
\hline $\begin{array}{l}\text { Strongly Agree } \\
\text { Somewhat Agree } \\
\text { Neutral } \\
\text { Somewhat Disagree } \\
\text { Strongly Disagree }\end{array}$ & $\begin{array}{r}1(100) \\
1(17) \\
1(17) \\
4(17) \\
10(59)\end{array}$ & $\begin{array}{r}0(0) \\
5(83) \\
5(83) \\
19(83) \\
7(41)\end{array}$ & & & \\
\hline
\end{tabular}

$* \mathrm{p}<=0.05$ 
The perception of the presence of barriers to including environmental education in the classroom was investigated in relation to participant demographic characteristics, years of teaching experience, and sources of environmental knowledge (Table 3). A teacher's age was determined to be statistically significantly associated with the perception that barriers to the teaching environmental education exist. Perception of barriers to teaching about the environment was not found to be statistically significantly associated with any of the other characteristics evaluated.

The frequency with which survey respondents reported using ICTs in their teaching was investigated in relation to teacher demographic characteristics, classroom and school-wide teacher receptiveness to technology, perception of usefulness as a teaching tool, and its compatibility when teaching environmental content (Table 4). Teacher demographic characteristics were not statistically significantly associated with the regularity they reported using ICTs as teaching tools. However, statistically significant strong positive associations were found between frequency of classroom ICT use and both of (i) the perception that technology is useful for teaching K-12 subject matter, (ii) a respondent's receptiveness to teaching with technology, and (iii) the perception of a study participant that technology in their school was reliable. Unsurprisingly, a statistically significant negative association was found between the regularity of technology use and a teacher's propensity to view technology as being frustrating when used in teaching. No other statistically significant associations were determined with ICT use frequency in the classroom. 
Table 3: Perception of barriers to environmental education and teaching careers Respondent perception of barriers to including environmental education in the classroom according to educator age $(n=51)$, gender identity $(n=54)$, years teaching $(n=53)$, whether summer training for skills development was sought $(\mathrm{n}=51)$, respondent holds an environmentrelated university degree $(n=46)$, environmental knowledge has been developed through personal interests $(\mathrm{n}=46)$, and respondents attend community events as a way of learning more about the environment $(n=46)$. Numbers in parenthesis indicate percent of respondents identifying the presence of barriers, according to characteristic grouping.

\begin{tabular}{|c|c|c|c|c|c|c|}
\hline \multirow[t]{2}{*}{ Characteristics } & \multicolumn{3}{|c|}{ Barriers Exist } & \multirow{3}{*}{$\begin{array}{c}\chi^{2} \\
5.628^{*}\end{array}$} & \multirow{3}{*}{$\begin{array}{c}p \\
0.018\end{array}$} & \multirow{3}{*}{$\begin{array}{c}\mathbf{r} \\
0.335\end{array}$} \\
\hline & Yes & No & $\begin{array}{l}\text { Don't } \\
\text { Know }\end{array}$ & & & \\
\hline Age (years) & & & & & & \\
\hline $\begin{array}{l}30 \text { to }<40 \\
40 \text { to }<50 \\
50 \text { to }<60\end{array}$ & $\begin{array}{r}10(67) \\
13(59) \\
4(29)\end{array}$ & $\begin{array}{l}5(33) \\
7(32) \\
7(50)\end{array}$ & $\begin{array}{r}0(0) \\
2(9) \\
3(21)\end{array}$ & & & \\
\hline Gender Identity & & & & 0.502 & 0.479 & -0.097 \\
\hline $\begin{array}{l}\text { Female } \\
\text { Male }\end{array}$ & $\begin{array}{r}16(36) \\
4(44)\end{array}$ & $\begin{array}{r}23(51) \\
5(56)\end{array}$ & $\begin{array}{r}6(13) \\
0(0)\end{array}$ & & & \\
\hline Years Teaching & & & & 1.709 & 0.191 & 0.181 \\
\hline $\begin{array}{l}<2 \\
2 \text { to }<5 \\
5 \text { to }<10 \\
10 \text { to }<20 \\
>=20\end{array}$ & $\begin{array}{r}1(50) \\
3(100) \\
2(25) \\
15(71) \\
7(44)\end{array}$ & $\begin{array}{l}1(50) \\
0(0) \\
6(75) \\
4(19) \\
9(56)\end{array}$ & $\begin{array}{r}0(0) \\
0(0) \\
0(0) \\
2(10) \\
3(70)\end{array}$ & & 000 & $0 \cap 0$ \\
\hline $\begin{array}{l}<10 \\
>=10\end{array}$ & $\begin{array}{r}6(46) \\
22(55)\end{array}$ & $\begin{array}{r}7(54) \\
13(33)\end{array}$ & $\begin{array}{r}0(0) \\
5(12)\end{array}$ & 0.030 & 0.005 & $0.2+0$ \\
\hline Summer Training & & & & 0.007 & 0.933 & 0.083 \\
\hline $\begin{array}{l}\text { Yearly } \\
\text { Every Few Years } \\
\text { Rarely }\end{array}$ & $\begin{aligned} & 2(33) \\
& 18(64) \\
& 7(41)\end{aligned}$ & $\begin{array}{l}3(50) \\
7(25) \\
9(53)\end{array}$ & $\begin{array}{l}1(17) \\
3(11) \\
1(6)\end{array}$ & & & \\
\hline Environment Degree & & & & 1.244 & 0.265 & 0.166 \\
\hline $\begin{array}{l}\text { Yes } \\
\text { No }\end{array}$ & $\begin{aligned} 12 & (41) \\
6 & (35)\end{aligned}$ & $\begin{array}{r}16(55) \\
8(47)\end{array}$ & $\begin{array}{l}1(4) \\
3(18)\end{array}$ & & & \\
\hline Personal Interests & & & & 2.281 & 0.131 & 0.225 \\
\hline $\begin{array}{l}\text { Yes } \\
\text { No }\end{array}$ & $\begin{array}{r}11(34.5) \\
\quad 7(50)\end{array}$ & $\begin{array}{r}19(59.5) \\
5(36)\end{array}$ & $\begin{array}{r}2(6) \\
2(14)\end{array}$ & & & \\
\hline Community Events & & & & 0.114 & 0.735 & 0.050 \\
\hline $\begin{array}{l}\text { Yes } \\
\text { No }\end{array}$ & $\begin{array}{r}8(42) \\
10(37)\end{array}$ & $\begin{array}{l}10(53) \\
14(52)\end{array}$ & $\begin{array}{r}1(5) \\
3(11)\end{array}$ & & & \\
\hline
\end{tabular}

$* \mathrm{p}<=0.05$ 
Table 4: Frequency of technology use in the classroom and demographics

Respondent use of technology in the classroom as a teaching tool according to their age $(n=52)$, gender identity $(n=54)$, years teaching $(n=54)$, whether technology is useful when teaching $k-12$ students $(n=54)$, receptiveness to teaching with technology $(n=54)$, whether environmental education is at odds with teaching with technology $(n=54)$, perceived frustration when teaching with technology $(\mathrm{n}=54)$, whether they believe their school has reliable and current technology for teaching $(n=54)$, and whether they believe students retain more information when taught with learning-focused technology $(n=53)$. Numbers in parenthesis indicate percent of respondents identifying the presence of barriers, according to characteristic grouping.

\begin{tabular}{|c|c|c|c|c|c|c|c|}
\hline \multirow[t]{2}{*}{ Characteristics } & \multicolumn{4}{|c|}{ Use of Technology when Teaching } & \multirow[t]{2}{*}{$\chi^{2}$} & \multirow[t]{2}{*}{$p$} & \multirow[t]{2}{*}{$\mathbf{r}$} \\
\hline & Rarely & Sometimes & Often & Always & & & \\
\hline Age (years) & & & & & 0.394 & 0.530 & -0.088 \\
\hline $\begin{array}{l}30 \text { to }<40 \\
40 \text { to }<50 \\
50 \text { to }<60\end{array}$ & $\begin{array}{r}0(0) \\
1(4) \\
1(6.5)\end{array}$ & $\begin{array}{l}4(27) \\
7(32) \\
1(6.5)\end{array}$ & $\begin{array}{l}6(40) \\
7(32) \\
6(40)\end{array}$ & $\begin{array}{l}5(33) \\
7(32) \\
7(47)\end{array}$ & & & \\
\hline Gender Identity & & & & & 0.079 & 0.779 & -0.039 \\
\hline $\begin{array}{l}\text { Female } \\
\text { Male }\end{array}$ & $\begin{array}{r}2(4.5) \\
0(0)\end{array}$ & $\begin{array}{r}11(24.5) \\
2(22)\end{array}$ & $\begin{array}{r}16(35.5) \\
4(44.5)\end{array}$ & $\begin{array}{r}16(35.5) \\
3(33.5)\end{array}$ & & & \\
\hline Years Teaching & & & & & 0.366 & 0.545 & -0.083 \\
\hline $\begin{array}{l}<2 \\
2 \text { to }<5 \\
5 \text { to }<10 \\
10 \text { to }<20 \\
>=20\end{array}$ & $\begin{array}{l}0(0) \\
0(0) \\
0(0) \\
1(5) \\
1(5)\end{array}$ & $\begin{array}{l}1(50) \\
0(0) \\
4(50) \\
4(19) \\
4(20)\end{array}$ & $\begin{array}{r}1(50) \\
3(100) \\
0(0) \\
8(38) \\
8(40)\end{array}$ & $\begin{array}{l}0(0) \\
0(0) \\
4(50) \\
8(38) \\
7(35)\end{array}$ & & & \\
\hline $\begin{array}{l}\text { Tech Useful for } \\
\text { Teaching k-12 }\end{array}$ & & & & & $17.029 *$ & 0.000 & 0.567 \\
\hline $\begin{array}{l}\text { Rarely } \\
\text { Often } \\
\text { Always }\end{array}$ & $\begin{array}{r}2(17) \\
0(0) \\
0(0)\end{array}$ & $\begin{array}{r}7(58) \\
4(15) \\
2(12.5)\end{array}$ & $\begin{array}{r}3(25) \\
13(50) \\
4(25)\end{array}$ & $\begin{array}{r}0(0) \\
9(35) \\
10(62.5)\end{array}$ & & & \\
\hline $\begin{array}{l}\text { Receptive to } \\
\text { Teaching with Tech }\end{array}$ & & & & & $14.775^{*}$ & 0.000 & 0.528 \\
\hline $\begin{array}{l}\text { Somewhat Agree } \\
\text { Strongly Agree }\end{array}$ & $\begin{array}{r}2(15.5) \\
0(0)\end{array}$ & $\begin{array}{l}6(46) \\
7(17)\end{array}$ & $\begin{array}{r}5(38.5) \\
15(36.5)\end{array}$ & $\begin{array}{r}0(0) \\
19(46.5)\end{array}$ & & & \\
\hline $\begin{array}{l}\text { Environmental } \\
\text { Education and Tech are } \\
\text { at Odds }\end{array}$ & & & & & 0.531 & 0.466 & -0.100 \\
\hline $\begin{array}{l}\text { Somewhat } \\
\text { No } \\
\text { Don't Know }\end{array}$ & $\begin{array}{l}0(100) \\
2(4.5) \\
0(100)\end{array}$ & $\begin{array}{r}2(40) \\
11(25) \\
0(100)\end{array}$ & $\begin{array}{r}2(40) \\
14(32) \\
4(80)\end{array}$ & $\begin{array}{r}1(20) \\
17(38.5) \\
1(20)\end{array}$ & & & \\
\hline $\begin{array}{l}\text { Frustration Teaching } \\
\text { with Tech }\end{array}$ & & & & & $6.231^{*}$ & 0.013 & -0.343 \\
\hline $\begin{array}{l}\text { Never } \\
\text { Rarely } \\
\text { Sometimes } \\
\text { Often }\end{array}$ & $\begin{array}{r}0(0) \\
0(0) \\
0(0) \\
2(25)\end{array}$ & $\begin{array}{r}0(0) \\
1(11) \\
10(28) \\
2(25)\end{array}$ & $\begin{array}{r}0(0) \\
3(33.5) \\
15(41.5) \\
2(25)\end{array}$ & $\begin{array}{r}1(100) \\
5(55.5) \\
11(30.5) \\
2(25)\end{array}$ & & & \\
\hline
\end{tabular}




\begin{tabular}{|c|c|c|c|c|c|c|c|}
\hline \multirow[t]{2}{*}{ Characteristics } & \multicolumn{4}{|c|}{ Use of Technology when Teaching } & \multirow[t]{2}{*}{$\chi^{2}$} & \multirow[t]{2}{*}{$p$} & \multirow[t]{2}{*}{$\mathbf{r}$} \\
\hline & Rarely & Sometimes & Often & Always & & & \\
\hline $\begin{array}{l}\text { Reliable/Current Tech } \\
\text { for Teaching Use }\end{array}$ & & & & & $13.574 *$ & 0.000 & 0.506 \\
\hline $\begin{array}{l}\text { Rarely } \\
\text { Sometimes } \\
\text { Often } \\
\text { Always }\end{array}$ & $\begin{array}{l}1(25) \\
1(4.5) \\
0(0) \\
0(0)\end{array}$ & $\begin{array}{r}2(50) \\
9(41) \\
2(9) \\
0(0)\end{array}$ & $\begin{array}{r}0(0) \\
8(36.5) \\
11(48) \\
1(20)\end{array}$ & $\begin{array}{r}1(25) \\
4(18) \\
10(43) \\
4(80)\end{array}$ & & & \\
\hline $\begin{array}{l}\text { Student Info Retention } \\
\text { when Taught with Tech }\end{array}$ & & & & & $8.287^{*}$ & 0.004 & 0.399 \\
\hline $\begin{array}{l}\text { Somewhat Disagree } \\
\text { Neutral } \\
\text { Somewhat Agree } \\
\text { Strongly Agree }\end{array}$ & $\begin{array}{r}0(0) \\
2(14.5) \\
0(0) \\
0(0)\end{array}$ & $\begin{array}{l}5(50) \\
3(21.5) \\
3(14.5) \\
2(25)\end{array}$ & $\begin{array}{r}4(40) \\
8(57) \\
7(33.5) \\
1(12.5)\end{array}$ & $\begin{array}{r}1(10) \\
1(7) \\
11(52) \\
5(62.5)\end{array}$ & & & \\
\hline
\end{tabular}

$* \mathrm{p}<=0.05$

Teacher perception of barriers to the use of ICTs in teaching was explored in relation to respondent demographic characteristics, years teaching, and participants' pursuit of additional skills and qualifications (Table 5). Gender identity was the only characteristic where a statistically significant association was found with the perception of barriers to using technology. Specifically, those participants reporting their identity as female were more likely to perceive the presence of barriers. Similarly, when investigating teacher agreement with the notion that technology and environmental education are compatible, a statistically significant positive association was only found with the teacher characteristic of prioritizing ICTs for use in their teaching (Table 6). No other statistically significant associations were found with teacher views on the compatibility of ICTs with environmental education. 
Table 5: Perception of barriers to using technology in the classroom and demographics

Respondent perception of barriers to teaching with technology according to educator age $(n=52)$, gender identity $(\mathrm{n}=54)$, years teaching $(\mathrm{n}=54)$, and whether summer training for skills development was sought $(n=51)$. Numbers in parenthesis indicate percent of respondents identifying the presence of barriers, according to characteristic grouping.

\begin{tabular}{|c|c|c|c|c|c|c|c|}
\hline \multirow[t]{2}{*}{ Characteristics } & \multicolumn{4}{|c|}{ Barriers Exist } & \multirow{3}{*}{$\begin{array}{c}\chi^{2} \\
0.327\end{array}$} & \multirow{3}{*}{$\begin{array}{c}\boldsymbol{p} \\
0.568\end{array}$} & \multirow{3}{*}{$\begin{array}{c}\mathbf{r} \\
-0.08\end{array}$} \\
\hline & Never & Rarely & Sometimes & Often & & & \\
\hline Age (years) & & & & & & & \\
\hline \multirow[t]{2}{*}{$\begin{array}{l}30 \text { to }<40 \\
40 \text { to }<50 \\
50 \text { to }<60\end{array}$} & $\begin{array}{l}0(0) \\
0(0) \\
1(7)\end{array}$ & $\begin{array}{l}3(20) \\
4(18) \\
2(14)\end{array}$ & $\begin{array}{r}9(60) \\
15(68) \\
10(67)\end{array}$ & $\begin{array}{l}3(20) \\
3(14) \\
2(14)\end{array}$ & & & \\
\hline & No & Yes & & & \multirow[b]{2}{*}{0.000} & \multirow[b]{2}{*}{1.00} & \multirow[b]{2}{*}{0.000} \\
\hline $\begin{array}{l}30 \text { to }<40 \\
40 \text { to }<50 \\
50 \text { to }<60\end{array}$ & $\begin{array}{l}3(20) \\
4(18) \\
3(20)\end{array}$ & $\begin{array}{l}12(80) \\
18(82) \\
12(80)\end{array}$ & & & & & \\
\hline \multirow[b]{2}{*}{$\begin{array}{l}\text { Gender Identity } \\
\text { Female } \\
\text { Male }\end{array}$} & Never & Rarely & Sometimes & Often & \multirow[b]{2}{*}{$4.155^{*}$} & \multirow[b]{2}{*}{0.042} & \multirow[b]{2}{*}{0.280} \\
\hline & $\begin{array}{l}1(2) \\
0(0)\end{array}$ & $\begin{array}{l}5(11) \\
4(44)\end{array}$ & $\begin{array}{r}31(69) \\
5(56)\end{array}$ & $\begin{array}{r}8(18) \\
0(0)\end{array}$ & & & \\
\hline & Never & Rarely & Sometimes & Often & 2.149 & 0.143 & -.201 \\
\hline $\begin{array}{l}\text { Years Teaching } \\
<2 \\
2 \text { to }<5 \\
5 \text { to }<10 \\
10 \text { to }<20 \\
>=20\end{array}$ & $\begin{array}{l}0(0) \\
0(0) \\
0(0) \\
1(5) \\
0(0)\end{array}$ & $\begin{array}{l}0(0) \\
0(0) \\
1(12) \\
3(14) \\
5(20)\end{array}$ & $\begin{array}{r}2(100) \\
2(67) \\
5(63) \\
13(62) \\
14(70)\end{array}$ & $\begin{array}{l}0(0) \\
1(33) \\
2(25) \\
4(19) \\
1(10)\end{array}$ & \multirow[b]{2}{*}{1.910} & \multirow{2}{*}{0.167} & \multirow{2}{*}{-0.190} \\
\hline $\begin{array}{l}<10 \\
>=10\end{array}$ & $\begin{array}{l}0(0) \\
1(2)\end{array}$ & $\begin{array}{r}1(8) \\
8(20)\end{array}$ & $\begin{array}{r}9(69) \\
27(66)\end{array}$ & $\begin{array}{l}3(23) \\
5(12)\end{array}$ & & & \\
\hline \multirow[b]{2}{*}{$\begin{array}{l}<2 \\
2 \text { to }<5 \\
5 \text { to }<10 \\
10 \text { to }<20 \\
>=20\end{array}$} & No & Yes & & & \multirow[b]{2}{*}{1.794} & \multirow[b]{2}{*}{0.180} & \multirow[b]{2}{*}{-.184} \\
\hline & $\begin{array}{l}0(0) \\
0(0) \\
1(13) \\
4(19) \\
5(25)\end{array}$ & $\begin{array}{l}2(100) \\
3(100) \\
7(87) \\
17(81) \\
15(75)\end{array}$ & & & & & \\
\hline $\begin{array}{l}<10 \\
>=10\end{array}$ & $\begin{array}{r}1(7) \\
9(22)\end{array}$ & $\begin{array}{l}12(93) \\
32(78)\end{array}$ & & & 1.305 & 0.253 & 0.024 \\
\hline \multirow[b]{2}{*}{ Summer Training } & Never & Rarely & Sometimes & Often & \multirow{3}{*}{1.594} & \multirow{3}{*}{0.207} & \multirow{3}{*}{-0.179} \\
\hline & & & & & & & \\
\hline \multirow[t]{2}{*}{$\begin{array}{l}\text { Yes } \\
\text { No }\end{array}$} & $\begin{array}{l}1(3) \\
0(0)\end{array}$ & $\begin{array}{l}4(12) \\
5(29)\end{array}$ & $\begin{array}{r}23(67.5) \\
11(65)\end{array}$ & $\begin{array}{r}6(17.5) \\
1(6)\end{array}$ & & & \\
\hline & No & Yes & & & \multirow[b]{2}{*}{1.524} & \multirow[b]{2}{*}{0.217} & \multirow[b]{2}{*}{-0.175} \\
\hline $\begin{array}{l}\text { Yes } \\
\text { No }\end{array}$ & $\begin{array}{l}5(15) \\
5(29)\end{array}$ & $\begin{array}{l}29(85) \\
12(71)\end{array}$ & & & & & \\
\hline
\end{tabular}

$* \mathrm{p}<=0.05$ 
Table 6: Participant perception of using technology to facilitate environmental education Respondent perception that technology can facilitate teaching environmental education according to educator age $(n=52)$, gender identity $(n=54)$, years teaching $(n=54)$, whether students are capable of effectively using technology as a learning tool $(n=54)$, whether teaching with current technology is a priority for them $(n=54)$, whether the school they teach at is receptive to using technology in the classroom for educational purposes $(n=54)$, whether they perceive their students to be distracted when learning-focused technology is used in the classroom $(n=54)$, whether they perceive students to be more engaged when taught with technology $(\mathrm{n}=54)$, and whether they perceive students enjoy being taught using technology $(\mathrm{n}=54)$. Numbers in parenthesis indicate percent of respondents with a specific view of technology's role in teaching environmental education, according to characteristic grouping or agreement with statement.

\begin{tabular}{|c|c|c|c|c|c|c|}
\hline \multirow[t]{2}{*}{$\begin{array}{l}\text { Characteristic / } \\
\text { Statement }\end{array}$} & \multicolumn{3}{|c|}{$\begin{array}{c}\text { Tech Facilitates Environmental } \\
\text { Teaching }\end{array}$} & \multirow[t]{2}{*}{$\chi^{2}$} & \multirow[t]{2}{*}{$p$} & \multirow[t]{2}{*}{$\mathbf{r}$} \\
\hline & Yes & Somewhat & Don't Know & & & \\
\hline Age (years) & & & & 1.302 & 0.254 & 0.160 \\
\hline $\begin{array}{l}30 \text { to }<40 \\
40 \text { to }<50 \\
50 \text { to }<60\end{array}$ & $\begin{array}{l}14(93) \\
15(68) \\
11(73)\end{array}$ & $\begin{array}{l}1(7) \\
6(27) \\
4(27)\end{array}$ & $\begin{array}{l}0(0) \\
1(5) \\
0(0)\end{array}$ & & & \\
\hline Gender Identity & & & & 0.138 & 0.711 & -0.051 \\
\hline $\begin{array}{l}\text { Female } \\
\text { Male }\end{array}$ & $\begin{array}{r}33(73.5) \\
\quad 7(78)\end{array}$ & $\begin{array}{l}11(24.5) \\
2(22)\end{array}$ & $\begin{array}{l}1(2) \\
0(0)\end{array}$ & & & \\
\hline Years Teaching & & & & 0.641 & 0.423 & 0.110 \\
\hline $\begin{array}{l}<2 \\
2 \text { to }<5 \\
5 \text { to }<10 \\
10 \text { to }<20 \\
>=20\end{array}$ & $\begin{array}{l}2(100) \\
2(67) \\
8(100) \\
12(57) \\
16(80)\end{array}$ & $\begin{array}{r}0(0) \\
1(33) \\
0(0) \\
9(43) \\
3(15)\end{array}$ & $\begin{array}{l}0(0) \\
0(0) \\
0(0) \\
0(0) \\
1(5)\end{array}$ & & & \\
\hline \multicolumn{7}{|l|}{$\begin{array}{l}\text { Students Capable of } \\
\text { Learning with Tech }\end{array}$} \\
\hline $\begin{array}{l}\text { Strongly Agree } \\
\text { Somewhat Agree } \\
\text { Neutral } \\
\text { Somewhat Disagree } \\
\text { Strongly Disagree }\end{array}$ & $\begin{array}{l}21(91) \\
15(65) \\
0(0) \\
3(100) \\
1(100)\end{array}$ & $\begin{array}{r}2(9) \\
7(30.5) \\
4(100) \\
0(0) \\
0(0)\end{array}$ & $\begin{array}{r}0(0) \\
1(4.5) \\
0(0) \\
0(0) \\
0(0)\end{array}$ & 2.043 & 0.153 & 0.196 \\
\hline $\begin{array}{l}\text { Teaching with } \\
\text { Current Tech is a } \\
\text { Priority }\end{array}$ & & & & $4.399 *$ & 0.036 & 0.288 \\
\hline $\begin{array}{l}\text { Strongly Agree } \\
\text { Somewhat Agree } \\
\text { Neutral } \\
\text { Somewhat Disagree } \\
\text { Strongly Disagree }\end{array}$ & $\begin{array}{r}16(84) \\
16(80) \\
6(54.5) \\
2(50)\end{array}$ & $\begin{array}{r}3(16) \\
4(20) \\
4(36.5) \\
2(50)\end{array}$ & $\begin{array}{l}0(0) \\
0(0) \\
1(9) \\
0(0)\end{array}$ & & & \\
\hline $\begin{array}{l}\text { School is Receptive to } \\
\text { Teaching with Tech }\end{array}$ & & & & 0.888 & 0.346 & 0.129 \\
\hline $\begin{array}{l}\text { Strongly Agree } \\
\text { Somewhat Agree }\end{array}$ & $\begin{array}{r}30(79) \\
10(62.5)\end{array}$ & $\begin{array}{l}7(18.5) \\
6(37.5)\end{array}$ & $\begin{array}{r}1(2.5) \\
0(0)\end{array}$ & & & \\
\hline
\end{tabular}




\begin{tabular}{|c|c|c|c|c|c|c|}
\hline \multirow[t]{2}{*}{$\begin{array}{l}\text { Characteristic / } \\
\text { Statement }\end{array}$} & \multicolumn{3}{|c|}{$\begin{array}{l}\text { Tech Facilitates Environmental } \\
\text { Teaching }\end{array}$} & \multirow[t]{2}{*}{$\chi^{2}$} & \multirow[t]{2}{*}{$p$} & \multirow[t]{2}{*}{$\mathbf{r}$} \\
\hline & Yes & Somewhat & Don't Know & & & \\
\hline $\begin{array}{l}\text { Students Distracted } \\
\text { by Tech in Classroom }\end{array}$ & & & & 0.215 & 0.643 & -0.064 \\
\hline $\begin{array}{l}\text { Strongly Agree } \\
\text { Somewhat Agree } \\
\text { Neutral } \\
\text { Somewhat Disagree } \\
\text { Strongly Disagree }\end{array}$ & $\begin{array}{l}1(100) \\
13(72) \\
7(58.5) \\
16(80) \\
3(100)\end{array}$ & $\begin{array}{r}0(0) \\
5(28) \\
5(41.5) \\
3(15) \\
0(0)\end{array}$ & $\begin{array}{l}0(0) \\
0(0) \\
0(0) \\
1(5) \\
0(0)\end{array}$ & & & \\
\hline $\begin{array}{l}\text { Students More } \\
\text { Engaged Using Tech }\end{array}$ & & & & 3.331 & 0.068 & 0.251 \\
\hline $\begin{array}{l}\text { Strongly Agree } \\
\text { Somewhat Agree } \\
\text { Neutral } \\
\text { Somewhat Disagree }\end{array}$ & $\begin{array}{r}9(90) \\
23(76.5) \\
5(56) \\
3(60)\end{array}$ & $\begin{array}{r}1(10) \\
7(23.5) \\
3(33) \\
2(40)\end{array}$ & $\begin{array}{r}0(0) \\
0(0) \\
1(11) \\
0(0)\end{array}$ & & & \\
\hline $\begin{array}{l}\text { Students Enjoy Being } \\
\text { Taught with Tech }\end{array}$ & & & & 2.023 & 0.155 & 0.195 \\
\hline $\begin{array}{l}\text { Strongly Agree } \\
\text { Somewhat Agree } \\
\text { Neutral }\end{array}$ & $\begin{array}{r}28(82) \\
11(61) \\
1(50)\end{array}$ & $\begin{array}{l}5(15) \\
7(39) \\
1(50)\end{array}$ & $\begin{array}{l}1(3) \\
0(0) \\
0(0)\end{array}$ & & & \\
\hline
\end{tabular}

$* \mathrm{p}<=0.05$

\subsection{Focus Group}

The focus group was held at Ryerson University on Thursday September 12, 2019 with a total of 18 participants. This number does not include the primary and secondary researchers, or the TDSB gatekeeper, who were also present during the focus group. The focus group demographics consisted of predominantly white passing women in the age range of 30 to 50, with approximately $20 \%$ of the focus group represented by visible racial minorities, and approximately $10 \%$ of the participants identified as male. Additionally, of the 18 participants, 14 had completed the online survey before focus group meeting, one participant completed it after the focus group, and three participants did not complete the online survey.

It should be noted that, as briefly mentioned in the methods section 3.3 .4 , the semistructured focus group did not have a participant limit as a result of the socio-political climate of impending labour-action at the time the focus group was held. It should be noted that the size of 
the focus group was larger than is customary for this format of data gathering. However, to help mitigate any negative impacts arising from group size, the researchers provided participants with paper and writing utensils to record their contributions in a written format in addition to, or instead of, verbally. As per the instructions of the focus group, outlined in the methodology section, participants were asked to write down answers to the questions prior to anyone starting a discussion. This was to help ensure the researchers recorded the answers of participants, whether they were able to verbally answer or add to the discussion of the question being asked. This method of having both written and verbal answers were helpful to capture the groups responses, as there were approximately 6 to 8 participants who consistently contributed throughout the focus group. With that being said, every participant did verbalize their thoughts, ideas, and experiences at some point during the discussion.

The focus group discussion was recorded and auto-transcribed using the software Otter.ai (v2.2.5). The resulting text was reviewed, manually edited for accuracy, and saved in a standard word processing format. Additionally, the papers in which the participants wrote on were manually transcribed into and saved as a standard word processing format. Both documents were then imported into NVivo (v12) software and coded to distinguish patterns and themes within the participant responses. The code/node breakdown is described in Table 7, and was applied to both of the focus group documents: (i) the audio-transcription of the discussion, and (ii) the written responses provided by focus group participants. With the coded documents, word and phrase frequency table for each code was created and analyzed. The frequency tables were created by taking all of the coded information for a specific node, and breaking them up into individual words to count the frequency of use. 


\section{Table 7: NVivo code frequency}

Nodes created in NVivo (v12), and the frequency that they were referenced by focus group participants in the audio transcript, and in the words and phrases written down during the group discussion.

\begin{tabular}{|c|c|c|c|}
\hline \multirow[b]{2}{*}{ NVivo Node's } & \multicolumn{2}{|c|}{ NVivo Files } & \multirow[b]{2}{*}{ Tota } \\
\hline & $\begin{array}{c}\text { Focus Group Audio } \\
\text { Transcript }\end{array}$ & $\begin{array}{c}\text { Focus Group } \\
\text { Written Responses }\end{array}$ & \\
\hline $\begin{array}{l}\text { Barriers to } \\
\text { Environmental } \\
\text { Education }\end{array}$ & 20 & 29 & 49 \\
\hline $\begin{array}{l}\text { Barriers to Using } \\
\text { Technology in the } \\
\text { Classroom }\end{array}$ & 13 & 4 & 17 \\
\hline $\begin{array}{l}\text { Environmentally } \\
\text { Friendly Classroom or } \\
\text { School }\end{array}$ & 9 & 4 & 13 \\
\hline $\begin{array}{l}\text { Environmental } \\
\text { Education }\end{array}$ & 16 & 38 & 54 \\
\hline $\begin{array}{l}\text { Environmental } \\
\text { Education } A B O U T \text { the } \\
\text { Environment }\end{array}$ & 15 & 58 & 73 \\
\hline $\begin{array}{l}\text { Environmental } \\
\text { Education } F O R \text { the } \\
\text { Environment }\end{array}$ & 10 & 19 & 29 \\
\hline $\begin{array}{l}\text { Environmental } \\
\text { Education THROUGH } \\
\text { the Environment }\end{array}$ & 20 & 46 & 66 \\
\hline $\begin{array}{l}\text { Mental Health and } \\
\text { Wellbeing }\end{array}$ & 6 & 2 & 8 \\
\hline Sustainability & 14 & 10 & 24 \\
\hline $\begin{array}{l}\text { Technology (for } \\
\text { Environmental } \\
\text { Education) }\end{array}$ & 12 & 37 & 49 \\
\hline
\end{tabular}

\subsubsection{NVivo Coding}

Codes were created to reflect the classification of environmental education into the pillars of about, for, and through the environment. Nodes were then built to reflect each aspect of the three pillars. This process was undertaken to identify common views that participants had about 
each pillar, and to highlight what areas of environmental education received the greatest emphasis in the focus group discussion. Any instances of participants referring to environmental education in a manner that did not exclusively fit into one of these categories was coded generally as environmental education. Similarly, if focus group participants discussed the use of technology to deliver environmental education, or the creation of environmentally-friendly classrooms/ schools, these were coded accordingly. The theme of sustainability was also coded, as it was raised specifically in the focus group. Mental health and wellbeing of students, in relation to climate and broader environmental crisis, was coded to reflect this participant concern. Lastly, coding focused on participant perceived barriers to delivering environmental education, and to the use of ICTs as teaching tools.

\subsubsection{Environmental Education}

Although the first two questions posed by researchers to the focus group included: (i) "What comes to mind when you hear environmental education?" and, (ii) How do you include environmental education into your classroom?", participants discussed their answers to these questions throughout the duration of the focus group. Responses to these questions were coded in almost all of the nodes, including: Environmental Education, Environmental Education About the Environment, Environmental Education For the Environment, Environmental Education Through the Environment, Sustainability, Environmentally-Friendly Classrooms/Schools, Mental Health, and Barriers to Environmental Education.

Environmental Education About the Environment was the node that received the highest frequency of references (73); indicating that the participants described environmental education in terms that were associated with science, physical processes and systems, geography, etc. Specifically, the words with the highest use frequency in relation to this code are illustrated in a 
word cloud (Figure 9a). Topping the list of occurrences was science, and associations with science (e.g., biology, ecology). The concepts and examples of "climate change, physical processes, environmental sustainability, stewardship, global [and carbon] footprint, resource manag ement" (Focus Group Participant), population dynamics, food webs and predator prey relationships were all present when participants discussed how they implement environmental education in their classrooms. Perhaps unsurprisingly, focus group participants commonly associated environmental education with the physical sciences and geography, as the Ontario K-12 curriculum connections with environmental education in these subjects are more direct.

Out of the three pillars of environmental education nodes, the least coded ( 29 focus group references) was Environmental Education For the Environment, which is associated with teaching and learning focused on environmental and social inequities. Coding frequency, as shown in the word cloud (Figure 9b), was greatest for Indigenous studies, livable communities and environmental waste. Specifically related to this node, focus group participants discussed how they used current and historical events to demonstrate examples of environmental racism, and the need for eco-politics, eco-justice, and activism, to raise awareness among students. One focus group participant highlighted that when they teach engineering or technological courses in particular, they like to show their students documentaries highlighting digital waste. This is "because a lot of our waste stems from overconsumption", and the waste tends to end up in Global South countries, which results in people living in these countries experiencing negative, inequitable consequences, especially in regards to physical health, from the over consumption of Global North countries. This participant also stated that "when the students find out [about the environmental and social injustices] they get a lot more interested in being aware, and how much they don't really need the latest [technology]". 
Word and phrase frequency associated with the node Environmental Education Through the Environment, which references using direct, positive, experiences with the environment as educational opportunities, was further incorporated in to a word cloud (Figure 9c). This node was the second most coded with a total of 66 references, with 'outside' and 'field trips' the most heavily cited. More specifically, participants discussed how they integrated activities such as photo walking tours, utilizing the outdoors as a classroom, organized field trips to the zoo and various parks within the City of Toronto, as well as projects such as vermicomposting and gardening (e.g., butterfly gardens, fruit and vegetables) into their lesson plans.

Participant responses were coded to Environmental Education if the reference was to delivery methods, or to aspects of environmental education that did not fall into the through, for, or about categories (Figure 10a). It was coded 54 times, and included responses such as: interdisciplinary and extra-curricular environmental clubs, which both relate to the objectives of environmental education, across subjects and inter-annually through the grades, identified by the policy framework, Acting Today, Shaping Tomorrow (2009a). Focus group participants also discussed environmental education delivery methods that incorporated guest speakers, workshops, webinars, green design, and role modeling of sustainability practices. The importance of role modeling sustainable practices and behaviours was first brought up by a participant who described it as "accidental education that [teachers] give students when they witness adult behavior, or habits, resourcefulness - or lack thereof".

To further capture the nuances of the delivery methods of environmental education, accidental or intentional, discussed by participants, the node 'Environmentally-Friendly Classroom or School' was created. This included references to how focus group participants, or their schools, create environmentally-friendly learning spaces. Responses were separated into 
(a)

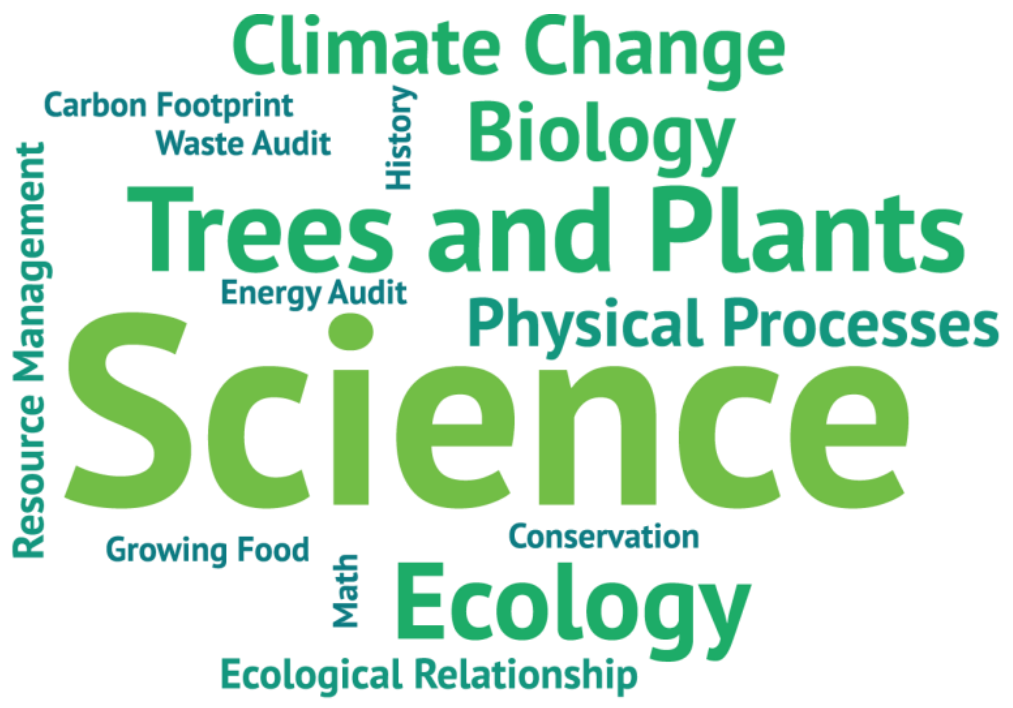

(b)

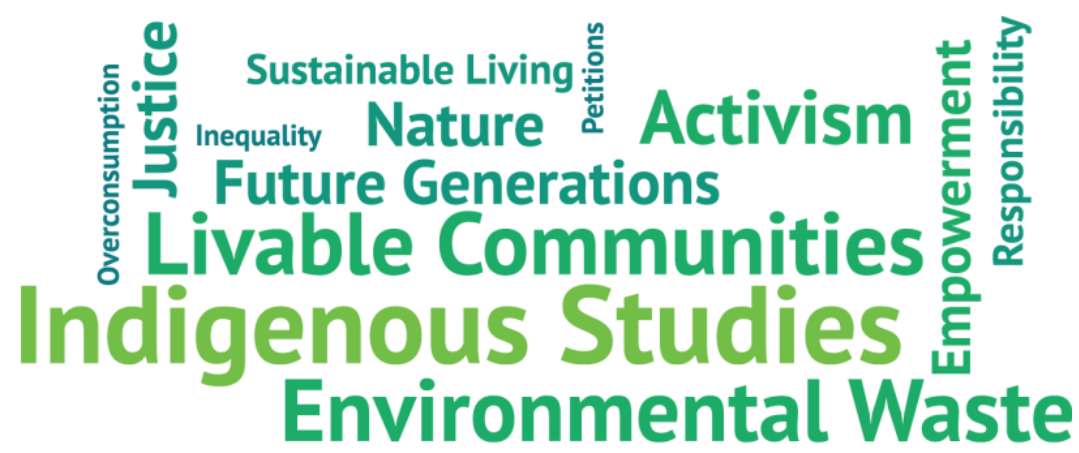

(c)

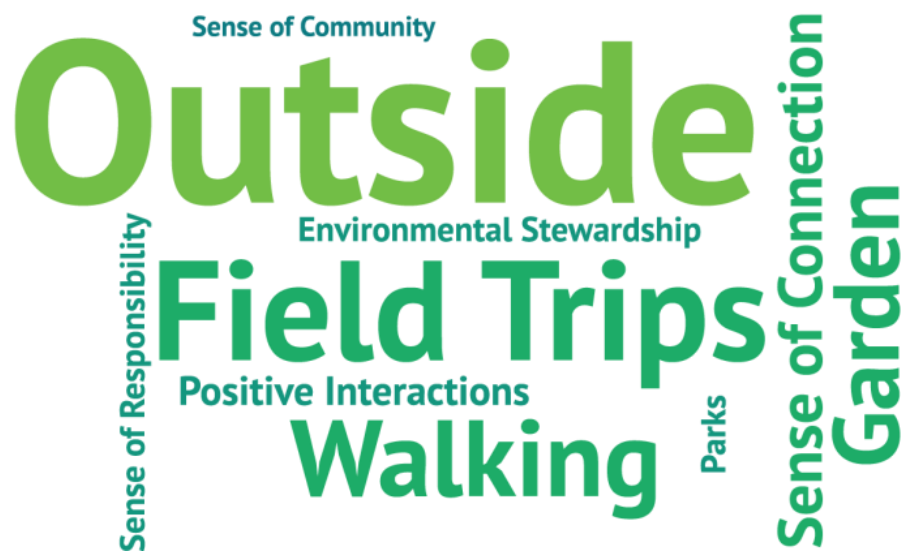

Figure 9: Focus group participants' perception of environmental education about, through $\&$ for the environment

Word clouds illustrating frequency of responses given by focus group participants regarding environmental education: (a) about the environment, which refers to facts and knowledge regarding environmental systems; (b) for the environment, which refers to the learning of, and action for, sustainable lifestyles and environmental justice; (c) through the environment, which refers to using direct (positive) experiences with the environment as education experiences. Words and phrases are scaled in magnitude according to frequency of use by focus group participants. 
(a)

(b)

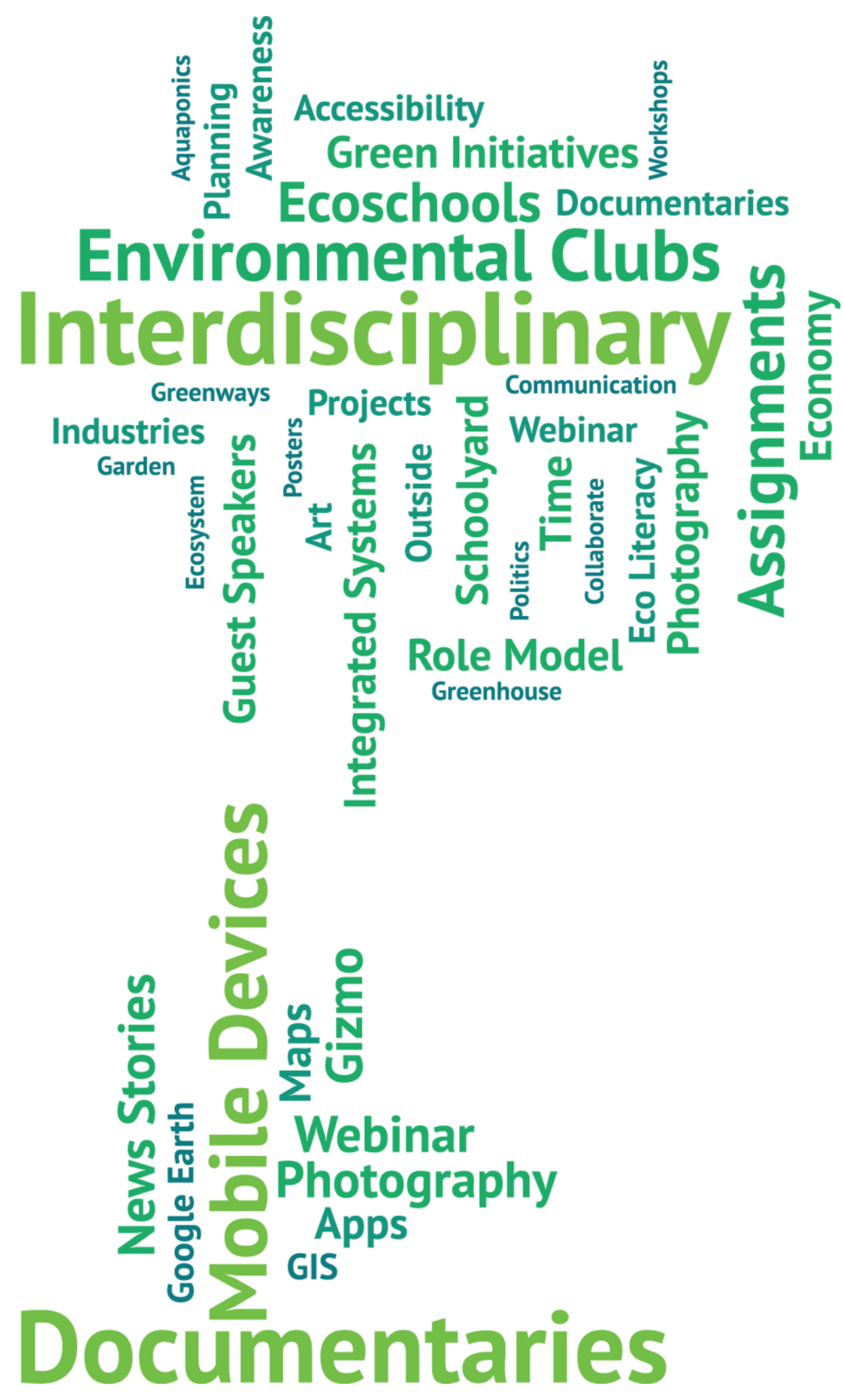

Figure 10: Focus group participants' perception of environmental education and technology

Word clouds illustrating frequency of responses given by workshop participants regarding: (a) environmental education delivery that doesn't exclusively fall into the categories about, for and through; and, (b) the use of technology within the context of environmental education delivery. 
Words and phrases are scaled in magnitude according to frequency of use by focus group participants.

three categories that include how environmentally-conscious behaviour is: (i) promoted in their classroom, (ii) promoted within broader school programming, and (iii) incorporated into their course content. Examples given by the focus group participants included encouraging proper waste diversion (e.g., respect for separation into garbage, recycling, and green bin), going paperless (or limiting paper), as well as trying to exhibit green behaviours in the form of 'accidental education' - role modelling. Role modelling examples included actions such as carrying a reusable mug, using a refillable water bottle, limiting single use plastics, and reusing and re-purposing materials within the classroom. To paraphrase one of the focus group participants, the 'accidental education' of easy, accessible, everyday environmentally-friendly actions is just as important for student learning as is the formal side of environmental education.

\subsubsection{Information and Communication Technology}

Technology has become pervasive in classrooms and schools with focus group participants indicating that they use it on a daily basis for the purpose of teaching their lessons or administering projects, assignments, and readings. All of the participants were familiar with using tools such as Google Classroom to deploy classroom content and assignments. In addition, responses from the participants included watching documentaries and news clips, using web-based applications, and resources such as 'Gizmo's' and 'What in The World' to help supplement learning in their classrooms. Participants felt that their students not only enjoy using technology, but that there is a growing level of expectation concerning its use.

The role of ICTs in the delivery of environmental education was explored through the coding of the node 'Technology (for Environmental Education)'. Focus group participant reference to types of technology used in the delivery of environmental education is shown in the 
word cloud, Figure 10b. Documentaries emerged as the most frequently referenced form of ICT use, followed by working with mobile devices (typically learning tablets). A diversity of tools, that included photography, computer-based mapping (e.g., Google Earth, GIS), and webinars, were also cited as approaches to teaching and learning about the environment with ICTs.

\subsubsection{Barriers to Delivering Environmental Education}

The focus group participant responses concerning 'barriers to environmental education' were grouped into five themes: (i) time, (ii) buy-in, (iii) accessibility, (iv) teacher knowledge/ confidence, and (v) funding. Interestingly, in response to the first focus group question, "What comes to mind when you hear 'Environmental Education'?”, participants quickly raised concerns that related to barriers. The word cloud in Figure 11a represents the words, or short phrases, used with the greatest frequency by focus group participants. Having inadequate time was referred to most often as a barrier in the focus group responses (both verbally and written). This barrier was further described by participants as the time to: get through the curriculum, prepare environmentally-themed lessons, and to plan field trips and excursions. The sentiment that Ontario curriculum is dense, and often over-crowded, was expressed by many of the participants. Moreover, one participant stated that they were "new to teaching, so I'm finding it hard to stay on track with other teachers [...] I'm just trying to keep up and get it all done”. This statement was not only echoed by teachers who were newer to the profession, but also by the more seasoned teachers, recalling how it takes time to make a course your own, with respect to how long you spend on each unit, which examples are used and the types of assignments and projects, and how, when, and where you can include environmental education outside of a scientific or geographical lens. 
Lack of buy-in originates from both students and other staff members. Focus group participants expressed that it was sometimes difficult to engage students in environmental themed education, specifically when it required them to go outdoors. One participant expressed that they felt there is a "big disengagement right now" in regards to their students and the outdoors, and that “they don't want to go out [of the classroom] because it's 'icky' outside”. Additionally, participants discussed how the narrative of environmental topics is often portrayed by the media and other sources with such a negative tone, and finding ways to talk to students about the environment in positive and empowering ways can be challenging. To paraphrase one focus group participant, the 'doom and gloom' narrative regarding the environment, specifically the negative effects of climate change experienced by people and organisms, and whole ecosystems around the world, is a huge stressor for the students. Generally, it was agreed to by focus group participants that framing environmental education in a positive light, while not downplaying the seriousness of many of the current crisis facing the Earth, is not an easy task for educators.

Focus group participants discussed how they can feel like a minority at their schools, as other teachers and staff members do not share their passion and sense of urgency with regard to environmental education. Several examples from participants included: debates about whether or not climate change is real, other teachers regard for environmental studies as less important than other subjects, and refusal to participate properly in classroom and school-based blue box recycling and green bin composting.

Teachers' lack of knowledge/confidence concerning inclusion of environmental education was also explored by participants in the focus group. Of note, it was revealed that, even though the participants were inclined to include environmental education into their classrooms, the curriculum connections were not always clear. It was even brought up by a participant that "even though my 
background is in environmental education, I found it really, really hard to incorporate what I would have wanted to". Overall, participants expressed the belief that environmental education is not

(a) Administration staff

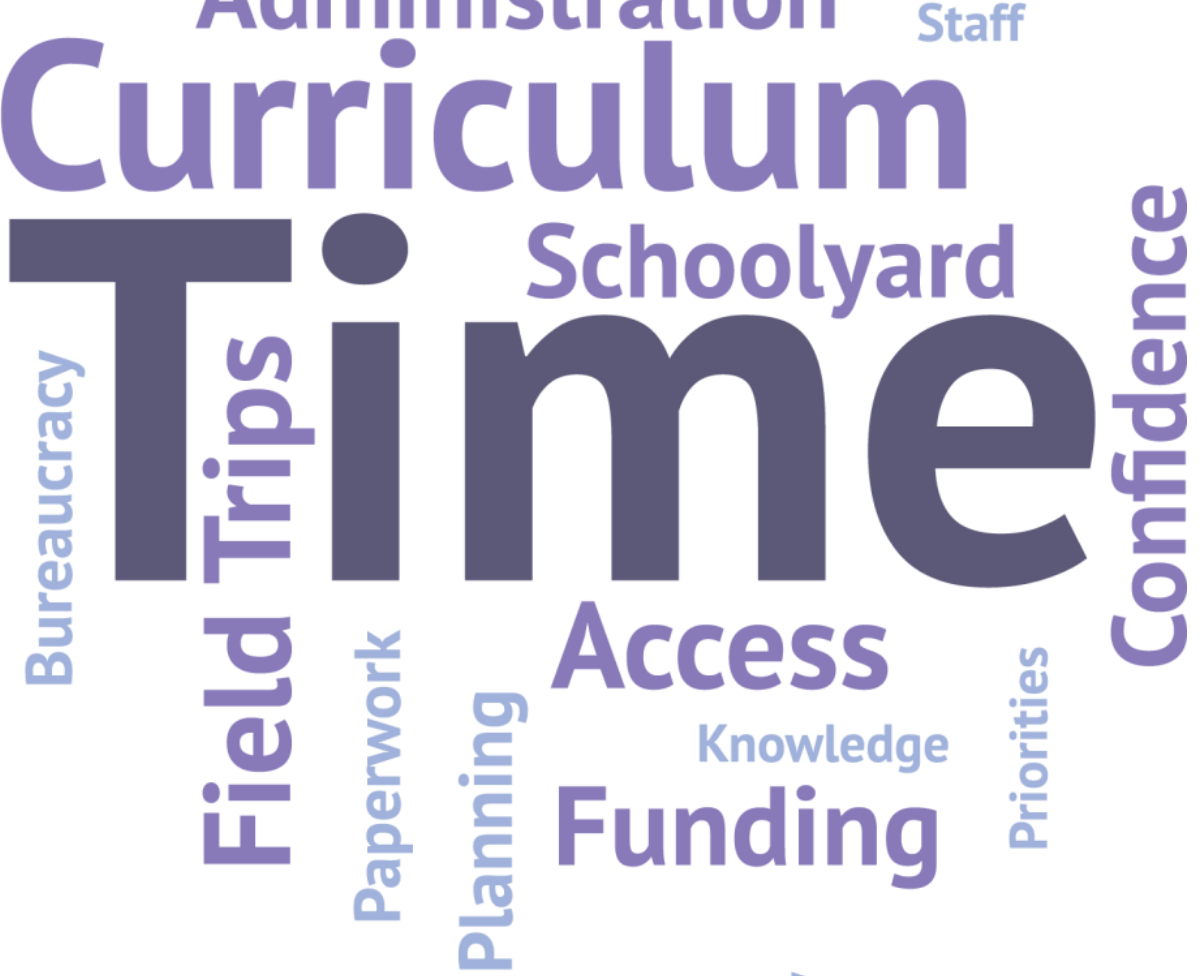

(b)

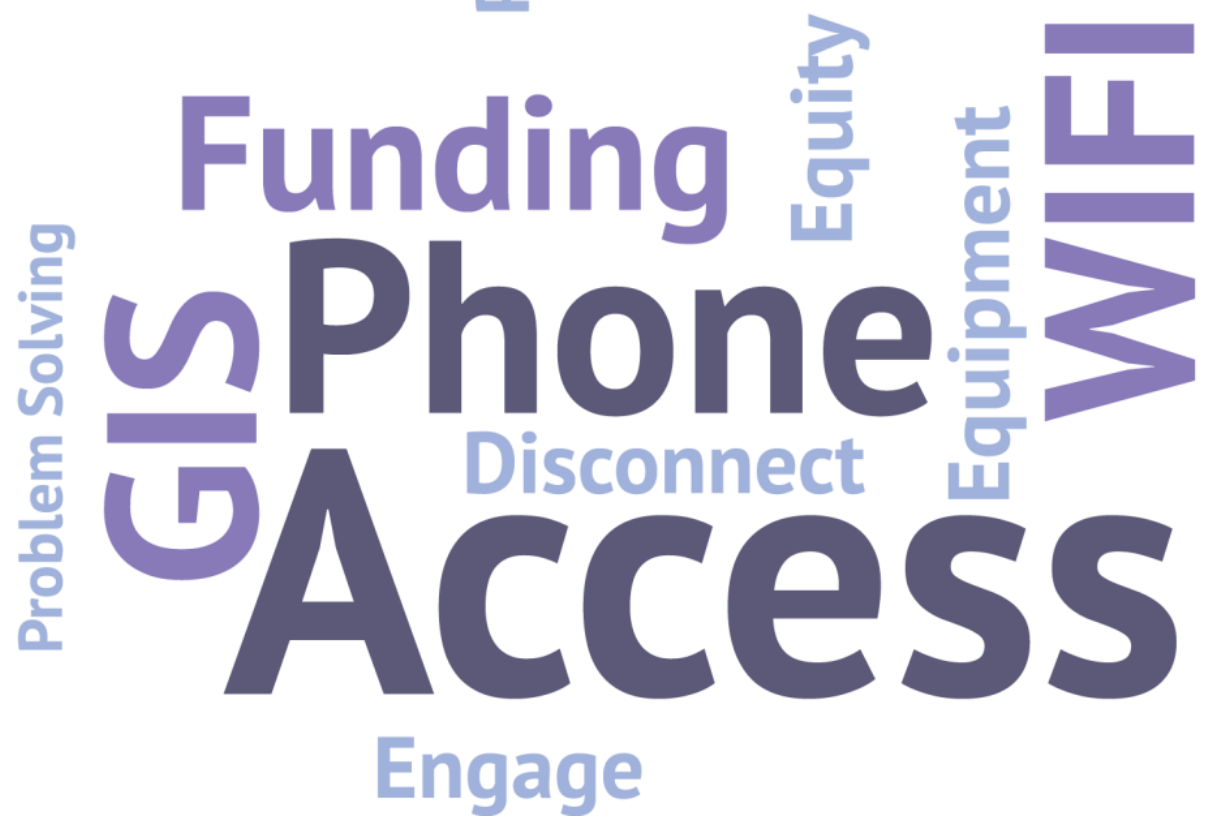

Figure 11: Barriers to environmental education and technology identified by focus group participants 
Word clouds illustrating frequency of barriers perceived by focus group participants for: (a) the inclusion of environmental education in their classroom; and, (b) the use of technology as a teaching tool in their classroom. Words and phrases have been scaled in magnitude according to frequency of use by focus group participants.

properly inserted into the Ontario curriculum, despite the existence of the 2009 policy framework,

Acting Today, Shaping Tomorrow. Moreover, accountability on the part of the Ontario Ministry of Education to ensure that environmental education is actually being implemented, and to ensure that teachers are properly equipped to include it in all subject areas, was viewed by focus group participants as deficient.

Lack of funding and resources necessary to implement environmental education in meaningful and effective ways was also a prominent focus of discussion with the participants. Specifically, the planning of field trips and projects was described by some focus group participants as logistically daunting, and that necessary funding and resources are not always available. Moreover, inadequate funding for equipment necessary to teach about the environment, on a classroom and school-wide basis, was also flagged as an issue.

\subsubsection{Barriers to using ICTs in the Classroom}

While focus group participants agreed that ICTs can be very useful when teaching about the environment, they also expressed concern that they can be distracting to students. Barriers to the use of ICTs as tools to teach about the environment, expressed by focus group participants, were coded and responses grouped into three categories: (i) access/equity, (ii) level of student engagement, and (iii) problem solving. Common terms and phrases that were associated with this node are plotted as a word cloud in Figure 11b. The term 'devices' was the most regularly referenced barrier, and can be explained as 'lack of access', as opposed to 'lack of reliability'. Focus group participants described that inequality existed among schools concerning access to devices, and to the Internet (mostly via Wi-Fi). Similarly, inequality among students who have, 
and do not have, ICTs at home, was raised as potentially influencing ability to research and complete homework.

Although focus group participants generally believed that students enjoyed using ICTs in the classroom, further discussion highlighted that students "love what they love" and, when some educational tools are introduced, such as computer-based mapping (GIS), some students shy away from it. Participants agreed strongly that teachers must actively engage students with an ICT for it to be successfully adopted as an educational tool. Interestingly, focus group participants identified that some students were not easily able to problem solve when ICTs were used as learning tools in the classroom. Specifically, they noted that when ICTs are used a shorter duration of time was spent problem solving at one's desk, or in a group, before coming to the teacher with questions. On the flipside, focus group participants discussed learning about ICTs from their students as an opportunity, and how teachers need to be comfortable with this as it is more likely that the teacher will not have all the answers, but perhaps the students' knowledge can bridge the gap.

\subsubsection{Leveraging ICTs to Teach Environmental Education}

The last topic that was explored with the focus group was the idea of leveraging technology to support the delivery of environmental education in the classroom. Enthusiasm varied, with negative responses focusing on the issue of 'screen time' and perception that students need to disconnect from technology. Another point made by a participant was regarding school contributions to digital/technological waste and the current inevitability of planned obsolescence associated with much of ICTs. Despite this opposition, most focus group participants were already embracing ways in which they could use technology to help deliver environmental education in their classrooms. Additionally, participants discussed how technology can increase access to resources and other sources of knowledge about the environment, from the local to the global, 
while easily offering students connections to opportunities (many extracurricular), that can increase their knowledge and understanding, and perhaps even empower positive actions to address environmental concerns. 


\section{CHAPTER FIVE: DISCUSSION}

Findings arising from this research provide insight in to Ontario teachers' knowledge and perceptions of environmental education, and the use ICTs as teaching tools. While survey respondents and focus group participants were drawn from TDSB schools, which is the largest school board in Canada (TDSB, 2014b), curriculum requirements are set at the provincial level (Government of Canada, 2017), and therefore, many collective views expressed by teachers are transferable outside of Toronto to Ontario schools broadly. Responses are likely to vary, however, to themed questions that generally pertain to resource availability and suitability of schoolyards as outdoor spaces for environmental education. In such cases, a difference between urban and rural, and among urban schools, is expected and may not be represented in the findings of the present research.

The data collected as part of this research study were obtained during summer and fall of 2019, a decade following the Ontario Ministry of Education's formalization of Acting Today, Shaping Tomorrow (2009a) policy. This policy framework remains the province's stance on K-12 environmental education; it mandates embedding it throughout all grades and across subject areas. Subsequent to the issuing of this 2009 policy, several studies were undertaken that sought to assess its effectiveness, especially related to Ontario teachers' ability to interpret and implement directives (see Fazio \& Karrow, 2013, 2015; Pedretti \& Nazir, 2014; Mnyusiwalla et al., 2016, 2017). When comparing the results of the present study to those presented by these authors, it is important to note that survey and focus group methods differed, as did response rates. Where possible, the present research sought to mirror some of the questions used in previous research for the purpose of contrast and comparison. Moreover, the objectives of the present research were 
more expansive in that they also sought information about ITCs and whether formal environmental education could benefit from ICTs as a teaching tool.

\subsection{Ontario's Environmental Education Policy}

The majority of participants $(76 \%)$ in this research study identified in the online survey that they have been teaching for 10 years or more, with $37 \%$ having taught for 20 years or greater. This highlights that the majority of study participants are well-established teachers, and have been involved in formal education since the enactment of the 2009 policy Acting Today, Shaping Tomorrow. Comparatively, the average age of an active member of the Ontario Teachers' Pension Plan, as of 2018, was 43 years old (Ontario Teachers' Pension Plan, 2018), and with the previous educational requirements (undergraduate degree and 1-year teacher's college prior to 2015), it can be speculated that the average length of teaching experience in Ontario is 10 years or more (Ontario Teachers' Pension Plan, 2018; Ontario College of Teachers, 2020a). This indicates that the study participants have equivalent or more teaching experience than the average Ontario teacher. Of the $72 \%$ of study participants that indicated they knew that the Ontario Ministry of Education mandates that environmental education be included in all subject areas, only $33 \%$ identified that they were familiar with the goals outlined in the policy document, Acting Today, Shaping Tomorrow. Moreover, 37\% stated they were only 'somewhat familiar', 26\% said they were 'not familiar', and 4\% said they were 'unsure'. Therefore, despite the policy document being in place since 2009, it is clear that most teachers, even many whose subjects focus on the environment, are

not well informed about its contents and especially requirements for inclusion of environmental education across subjects, and inter-annually from K-12.

Findings emerging from the focus group parallel these survey results, where focus group participants expressed frustration with the Ontario Ministry of Education's lack of accountability 
and support to effectively and meaningfully implement, and measure related impacts, of the policy. One focus group participant talked about their level of frustration with regard to environmental education, and wondered "Is there is a point to having documents [explaining] how we're supposed to all be implementing environmental education [in]to all our subjects? And, no one is really pushing that forward. Or [does] anyone even know that that document exists?".

\subsection{Environmental Education: Barriers, Threats and Shifting Approaches}

Previous studies have identified barriers to the inclusion of environmental education in Ontario classrooms (Fazio \& Karrow, 2013; Predretti \& Nazir, 2014; Mnyusiwalla et al., 2016). These barriers included, but were not exclusive to: limited planning time, lack of funding for material and resources, scheduling conflicts, crowded curriculum, and difficulty aligning environmental education with existing expectations and requirements. Additionally, Mnyusiwalla et al. (2016) cited in their study participants identified a disconnect between the actual delivery of environmental education and Ontario School Board policy (OMOE, 2007), especially in terms of teaching expectations, and feasible strategies for implementation of mandated curriculum. Close to half a decade later, the barriers to implementing formal environmental education in Ontario curriculum do not appear to have changed, and are echoed loudly in the results of the online survey and focus group conducted as part of the present study. In particular, the most cited barriers for environmental education in both methods of data collection were: overcrowded curriculum, difficulty running and organizing field trips, unsupportive administration, lack of resources and lack of teacher knowledge.

While perception of barriers to teaching formal environmental education, in accordance

with mandated policy, have changed little among Ontario teachers, Fazio and Karrow (2013) state in their research that teachers who are personally committed to environmental education will 
navigate these barriers in order to include environmentally themed content in their teaching methods and lesson plans. This practice was also identified by many of the teachers who participated in the present study's online survey and focus group. For example, one focus participant stated that at the start of the year or semester they "[...] introduce walking excursion forums. [...] So, simple as that - just get outside. We [also] do video productions, [...] photo walking tours, and then a paperless classroom for 10 years". Another participant chimed in stating that they started a vermicomposting project at their school. "Before I just had a big huge composter and it kind of snowballed from there. But now, each semester, [the students] grow their own soil, then they grow their own food" and some of that food goes into the lunchtime salad bar. With each year, the program is "expanding, and it's getting bigger, and one thing I'm finding is that the students are really shocked at how long it takes for food to grow, so they have a little more respect for it".

Overall, participants in the online survey and focus group described a variety of ways they include environmental content in their formal teaching. They included the use of media, the internet and apps, reading materials, nature excursions and field trips. As well as ways in which environmental education is included into their daily classroom (or school) activities, such as role modelling sustainable practices (e.g., re-useable mugs; re-purposing materials; reducing paper use, or going paperless), proper waste management, informative posters and graphics, and EcoSchool activities. The teachers or other staff members actions and habits regarding green or sustainable behaviours, or lack thereof, provides students with a sort of 'accidental education', was how one focus group participant described modelling behaviors to students as being equally important as formal education. It is important for students to not only be taught about environmentally conscious behaviours, but to be shown through daily actions, that they are attainable. 
During the focus group, the theme of education 'about the environment' was most prominent; it was the NVivo node with the highest frequency (expressed 72 times). Its use was especially prominent when participants discussed what subject areas they teach, and where they are able to easily emphasize content about the environment in their teaching. Subject areas included the sciences, especially ecology and biology, to some degree math, and certain themes within geography such as livable communities. These findings are not surprising as environmental education has explicit connections to science and geography (Fien, 1993; Mannion \& Adey, 2011; Fazio \& Karrow, 2015).

In addition to the low hanging fruit of teaching about the environment in science, math and geography to include environmental education into regular lesson planning, the practice of bringing students outdoors was also a prominent theme. Research has shown that there is a strong association between student experiences outdoors, and in nature, and successful environmental education, from the perspectives of student engagement and information retention (Sobel, 2004; Gruenewald, 2008; Mannion \& Adey, 2011; Pedretti \& Nazir, 2014). The present study found that a statistically significant positive relationship exists between the frequency study participants took their classes outdoors for instruction, and the amount of environmental content they included in their lessons. This important finding, also supported by comments made in the focus group discussion, highlights that study participants view the opportunity to hold lessons outdoors, through field trips and nature excursions, as a method to teach about the environment, while in the environment. And, can be viewed as participants placing a high value on place-based learning. The pedagogical approach of delivering environmental education through (or in) the environment proposes that being outdoors creates opportunities for positive student experiences in the natural environment (Gruenewald, 2008; Pedretti \& Nazir, 2014). 
It is widely understood that urban city centres have less access to green space than their rural or wilderness counterparts as a result of impermeable surfaces and densification (Swannick et al., 2003; Wolsink, 2016); so, one could argue that schools located in these urban and peri-urban environments are viewed to be deficient in their natural surroundings and, therefore, unsuitable for delivering outdoor environmental education. This view has often translated into the perceived requirement to leave the urban centre to experience the environment. And, as was made clear by participants in the present study, organizing and running field trips is complex and faces many hurdles.

While pristine natural environments are less common within or close to cities, urban ecosystems can still provide rich experiences for students to learn about the environment, and especially how it is impacted by humans. Urban environments are not devoid of nature; it just looks a little different. Cities are filled with natural systems, and exploring nature in the city is about recognizing that street trees, parks, schoolyards and backyards are all part of urban ecosystems. Additionally, rather than leaving the urban environment, it is just as important, if not more, to teach students to understand and connect to their immediate spaces. This directly relates to the theory of place-based education; and how fostering experiences for students in the space they occupy on daily basis can help them understand (and appreciate) how they impact their environment (Sobel, 2004; Gruenewald, 2008). Nevertheless, it should be noted that having a variety of outdoor experiences (e.g., urban, rural, wilderness), where possible, is beneficial to receiving a holistic environmental education. In Ontario, at the time of this writing, provincial level budget cuts to education have made resourcing outdoor nature centres less feasible and, similarly has made organizing field trips and other outdoor excursions increasingly difficult. 
The current political climate surrounding education in the Province of Ontario (2019-2020) is tense; in March 2019, the Conservative government released their plan to cut millions of dollars from public education (Government of Ontario, 2019b). Government directives to deal with these cuts have been for schools to increase the class size for grades four to 12 , reduce special education funding, and require all high school students to take four online courses as a replacement for inclass lesson (Jeffords, 2019; The Canadian Press, 2019; Ontario Federation of Labour, 2020; Ontario Secondary School Teachers' Federation, 2020). Increased class sizes and mandatory elearning will result in fewer teachers and less support staff in schools. It is easy then to make the leap to the likely outcome of fewer extracurricular activities, limited course options in secondary school, and less one-on-one teacher-student interaction.

In particular, larger class sizes will increase teachers' time spent marking and lesson planning and, effectively limit the time and resources required to organize and run field trips and outdoor excursions (OSSTF, 2019). Moreover, the reduction in TDSB 2019-2020 operating budget of $\$ 68.7$ million will not only result in changes to daily operations within Ontario schools, as approximately 300 staff may be laid off, there is a plan to close between two and four outdoor education centres (Canadian Union of Public Employees, 2019; CBC News, 2019; Sam, 2019). Prior to the 2019-2020 budget, TDSD operated 10 outdoor education centres (TDSB, n.d).

Participants in the present study believe that the provincial government should not make delivering formal environmental education more difficult. In fact, some believe that providing environmental education opportunities is perhaps more necessary today than it was in the past. Broadly, investment in education is a necessity to support development of a future generation of leaders and decision makers, and more specifically, with reference the 2009 Acting Today, Shaping Tomorrow policy document, will ensure students have the necessary knowledge and skills to 
protect and enhance the planet's ecosystems. One study participant expressed that "[...] it takes a lot of paperwork and planning. I think that's a huge barrier for a lot of people. Even if you're just doing something in the city, there's certain [activities] you can't do. And that's getting tighter and tighter" let alone reducing funding for schools and programming.

Therefore, in a political climate where formal environmental education is under threat, ensuring its continued delivery requires bottom-up approaches that are easily integrated into existing teaching formats, provide a strong complement to mandated curriculum, and make use of local outdoor spaces (e.g., schoolyards and local parks). Moreover, closures of outdoor education centres further necessitate the need to leverage outdoor spaces already accessible to schools. Shifting the spotlight to environmental issues experienced in the 'backyards' of many students may, in fact, assist teachers to make more immediate connections for students to their role and responsibility as a human within an ecosystem, and how, collectively, humans are shaping many ecological processes for good and for ill. Understanding the environment from a systems approach has become a popular and important pedagogical approach to teaching environmental education. Systems are interconnected and interdependent networks; exploring and experiencing urban or peri-urban ecosystems is essential to teaching from a place-based perspective, one that can deliver tangible and transformative opportunities for environmental learning.

Emphasizing this requirement to better leverage outdoor spaces teachers have access to, focus group participants discussed examples of simple approaches to outdoor environmental education that they conduct on their school grounds. Examples included bringing their students out for walks that included a focus such as exercise (e.g., health and wellbeing), engaging in plant and animal identification (e.g., biodiversity), providing inspiration for art (e.g. photography, visual art, writing), as well as simply conducting lessons in the schoolyard (whether or not subject matter 
was environment focused). The TDSB has approximately 30,000 trees growing on its 500 properties, and many suitable schoolyards that can be utilized as outdoor classrooms for any and all subjects. In fact, some TDSB schools have formal outdoor classrooms that are comprised of natural seating, often surrounded by vegetation, and can be used by teachers during class time (TDSB, 2014c). This is a great opportunity for teachers to provide a change of scenery for their students and to increase their students' exposure to nature.

One focus group participant in the present study made an insightful observation about how often teachers can get preoccupied with trying to plan field trips, when the schoolyard and surrounding community is readily available. They said, "I think at times we forget how easy it is to just go outside and do something [...] take some binoculars, look up in the trees, take pictures, pick leaves, see the animals and insects. [...] We make it more difficult than it is a lot of time".

Unfortunately, not all school grounds or communities have equal access to the natural environment; therefore, investing in schoolyard green space and removing hardscape is an important step toward facilitating the potential for increased place-based environmental education. In addition to using outdoor classrooms and schoolyards in general, focus group participants talked about classroom and school-wide projects, such as pollinator or vegetable gardens, green houses, vermicomposting, and aquaponics. Each of these projects can be engaged in different ways and by different grades to provide environmental education across subjects and inter-annually among grades. Multi-year environmental projects can encourage collaboration among students as well as require them to think beyond the short-term outcomes of their individual (and societal) actions. Moreover, multi-year collaborative school projects can facilitate teaching responsibility, and develop tangible skills that can empower students with agency to become stewards of the natural environment. 


\subsection{Environmental Education: Frequency of Classroom Inclusion}

To achieve desired learning outcomes, the many valuable teaching approaches described by teachers require implementation. The frequency with which online survey participants in the present study delivered formal environmentally-themed education was high, with $54 \%$ indicating daily, and $26 \%$ at least weekly. Moreover, when considering both formal and informal interaction with students, $57 \%$ of respondents indicated that they always talk about the environment, while an additional 30\% say the talk about it very often. A small number of teachers (13\%) said they talk about the environment with their students only sometimes. In contrast, the study by Pedretti and Nazir (2014) reported that $47 \%$ of respondents include formal environmental education in their classes on a weekly basis. While the present study may have targeted additional online survey respondents whose teaching subjects are more closely aligned with environmental education, there does appear to have been an increase in the frequency with which environmental education is occurring in TDSB classrooms.

However, this finding contrasts' with respondent views on whether their broader school is doing an adequate job with support for, and inclusion of, formal environmental education; only $44 \%$ of online survey participants either strongly agreed or somewhat agreed that their school was doing an adequate job at supporting formal environmental education across subjects, and interannually. Thus, it can be argued that, while teachers participating in the online survey, perceive they are delivering on objectives of the 2009 policy, Acting Today, Shaping Tomorrow, they view their broader school community is often lagging. In fact, participant comments arising in the focus group go further to indicate that teaching environmental education is still viewed as a marginal activity, and there was a lack of support from other staff members. Lack of support came from many directions, and included other teachers, the school administration, building caretakers and 
grounds keepers, the school board, and (at present) the provincial government. One focus group participant expressed that the lack of support or 'buy-in' from other staff members is an issue, and that "There's always those debates of 'is climate change, real', 'is recycling one sheet of paper going to make a difference' $[\ldots]$ it's something that I always have to fight for in the school".

\subsection{Environmental Education: Formal and Informal Educator Experience}

Participants in the online survey conducted as part of the present research were more likely to include formal environmental education in their teaching the greater the number years they had of teaching experience. This statistically significant finding is supported by comments that arose during the focus group, where participants who were newer to the teaching profession felt that their teaching style and inclusion of content was more heavily influenced by other teachers in their school delivering the same or similar courses. A focus group participant with less than two years of teaching experience stated that they are having difficulties with keeping up with the curriculum expectations and pace of more experienced teachers. They continued to say that "I know I'm new, so it'll come in time. But I'm not at the point where I can curate the course to be my own".

In contrast, experienced teacher participants in the focus group ( $>10$ years teaching experience) conveyed that, although the curriculum is massive, dense, and often overwhelming with expectations, the teacher must remember that as long as they are meeting the curriculum requirements, they are in charge of how the course material is curated and delivered. Thus, the ability to curate lesson plans comes with experience, which further places the spotlight on the potential to integrate environmental education in to the classroom in meaningful and effective ways. If formal environmental education were, therefore, intentionally imbedded into the curriculum with adequate supportive resources, and all teachers had proper training to deliver it, newer teachers could focus more on pedagogy (honing their style and content delivery creativity) 
than focusing on content. It is worth pointing out that the policy document Acting Today, Shaping Tomorrow (2009a) mandates much of this intentionality and requirement for resources.

The need to have teachers properly trained to implement environmental education throughout all subject areas, and inter-annually across $\mathrm{K}-12$, is imperative to the successful implementation of Acting Today, Shaping Tomorrow (2009a). Nevertheless, findings reported by Pedretti and Nazir (2014) demonstrated that there was unequal knowledge and understanding of environmental education, from the perspective of content and delivery methods, among Ontario teachers. One particular issue identified by these authors was the sources of teacher environmental education. They reported that only $10.4 \%$ of their study participants received environmental education from pre-service courses (i.e., teacher's college). And, perhaps even more surprising, only $11.7 \%$ of the teachers they studied cited additional qualifications, which are typically courses taken by teachers to add to their list of teachable qualifications (often taken in the summer). Pedretti and Nazir (2014) go on to report that the most prominent sources of environmental education their study group reported was from personal (non-professional) studies (75.6\%), and from their undergraduate degrees $(49.5 \%)$.

Similarly, the present study, through its online survey, determined that $13 \%$ of participants acquired their training to teach about the environment in pre-service courses at teacher's college. However, in modest contrast to Pedretti and Nazir's (2014) findings, just over one quarter (28\%) of participants in the present study obtained environmental teaching knowledge from the pursuit of additional qualifications. It should be noted that pre-service learning has a greater focus on 'how to teach' (e.g., delivery, engagement), whereas the category of additional qualifications is more heavily focused to further develop (or update) their teaching skills, as well as to specialize in different subject areas (Ontario College of Teachers, 2020b; University of Toronto, n.d). Similar 
to numbers reported by Pedretti and Nazir (2014), the most prominent answers given by respondents in the present study to where they obtained their environmental knowledge was for personal studies (63\%), and from undergraduate degrees (37\%). The majority of participants in the present study (76\%) began their teaching careers before Acting Today, Shaping Tomorrow (2009a) was released and, therefore, had also completed their formal teaching studies. Of the participants in the online survey who identified as having taught for fewer than 10 years $(n=13 ; 24 \%), 62 \%$ indicated learning about the environment came from personal studies, followed by community courses/events at $46 \%$.

Despite updates to Ontario Teachers College requirements for graduation, it still does not appear that a pedagogical focus on the delivery of environmental education is adequate during preservice training. Yet, teachers are expected to deliver this content to their students as reflected in Acting Today, Shaping Tomorrow (2009a) policy. Even if environmental education was mandated through all pre-service education immediately, it would be two years before teachers with these new requirements to graduate from Teacher's College, and additional time for them to be hired, and to settle into a career. While this training requirement would go far to support delivery of formal environmental education, as it is envisioned in Acting Today, Shaping Tomorrow, the timeline to meaningfully manifest in teaching outcomes could be as much as half a decade. Therefore, new and innovative bottom-up approaches must be encouraged to help the complement existing delivery of environmental education into Ontario classrooms.

The present study proposes that information and communications technologies (ITCs) can be used as an opportunity to bridge the gap between of rhetoric and practice, while not adding to the already heavy burden of crowded and dense, mandated curriculum. 


\subsection{Technology \& Environmental Education}

The use of technology in the classroom, as a teaching tool, has been shown to benefit both teachers and students (Jimoyiannis \& Komis, 2007; Buabeng-Andoh, 2012; McKnight et al., 2016). Benefits include increased student interest and engagement, improved access to up-to-date information, and better time management (Glassett \& Schrum, 2009; Jimoyiannis \& Komis, 2007; Buabeng-Andoh, 2012; Levin \& Schrum, 2013; McKnight et al., 2016). Findings from the present study align well with those reported in the literature. Moreover, these benefits have been positively associated with the frequency a teacher will use technology as a teaching tool (Wozney et al., 2006; Ottenbreit-Leftwich et al., 2010; Buabeng-Andoh, 2012). Specifically, the present study determined that there was a significant and positive association between teachers who perceive technology to be a beneficial learning tool, and how much they use it to facilitate learning in K-12 teaching. However, perhaps more importantly, study participants indicated that student information retention was also statistically significantly positively associated with the use of technology as a teaching tool. This finding is relevant in an era where technology has become ubiquitous in society. Teaching students how technology can be effectively used as an active tool, rather than simply a passive vessel promoting consumption, is especially relevant to contemporary environmental education.

Teaching students about the environment with a variety of digital tools may, in fact, bolster their interest in learning about the environment, and allow them to see points of meaningful intersection between their skills and solutions to environmental problems (Buchanan et al., 2018). Although it may seem to some that the use of technology ("screen time") is at odds with environmental education (e.g., outdoor learning), many authors (Wells, 2000; Mooij, 2004; Jimoyiannis \& Komis, 2007; Faber-Taylor \& Kuo, 2009) indicate that technology (tools and the 
information they deliver) is essential to contemporary exploration of different themes, ideas, and experiences that are very applicable to formal environmental education.

In the present study, the majority of respondents to the online survey indicated that they agreed technology can help facilitate environmental education and, moreover, that they used the Internet and apps as a method of delivering environmental education to their students. This finding was reiterated during the focus group, when participants discussed how they leverage media and online resources (e.g., news, documentaries, films), webinars, digital photography, mapping platforms such as Google Earth, and software such as Geographic Information Systems (GIS) to engage and educate their students about the environment. This finding highlights that teachers are open to the notion of using ICTs in their lesson plans to help facilitate environmental education and, that in many cases, they are already doing so, which is supported by research (Chen et al., 2014; Kalagiannakis \& Papadakis, 2017; Buchanan et al., 2018).

To return to the value of place-based learning in the delivery of formal environmental education, increased access to mobile technologies has created new opportunities for students to explore their schoolyard or local community through a new lens (Kalagiannakis \& Papadakis, 2017). Not only can mobile technologies provide new opportunities to connect to the surrounding environment, teachers and students can now become active participants in describing and measuring environment-related attributes in their local communities through voluntary data contributions in the form of citizen science (Gruenewald, 2008; Mannion \& Adey, 2011; Greenwood \& Hougham, 2015; Buchanan et al., 2018). Thus, coupling the use of technology with placed-based education, by utilizing the school grounds and the local community, could go far to reduce the barriers of organizing and running field trips, while providing environmental education 
across the subjects and through K-12 in support of Acting Today, Shaping Tomorrow (2009a) policy.

\subsection{Gender Identity, Teaching \& Learning}

It is interesting to note that, while not the primary focus of this research, there was a very large representation of participants who identified as female in both the online survey (83\%) and semistructured focus group (89\%). Although this might appear, at first glance, to not be representative of the broader demographic of Ontario teachers, the 2018 Annual Report from the Ontario College of Teachers' and the 2016 census from Statistics Canada revealed that the dominant female participant demographic may actually come close to mirroring the broader Ontario teaching profession. Ontario College of Teachers' 2018 Annual Report stated that $74.43 \%$ of members identified as female, $25.55 \%$ as male, and $0.02 \%$ identified as transgendered, non-binary, two spirited or binary, or chose not to disclose. Similarly, according to the 2016 federal census, of 451,405 teachers, $75.1 \%$ identified as female, and $24.9 \%$ as male (Statistics Canada, 2018). This evidence of a gender imbalance in the teaching profession is also supported by research, not only in Canada but globally, especially in primary and elementary schooling (see Basten, 1997; Drudy, 2008; Skelton, 2012; Warin \& Gannrud, 2014; Moosa \& Bhana, 2017).

In fact, the absence of male teachers in environmental education became a discussion within the focus group. In particular, participants discussed the overall interest of their students in environmentally themed content and activities, and whether the demographics of the focus group were indicative of student engagement. The focus group participants, however, felt the level of student engagement really depended on the environmental activities presented. Some participants articulated that their female students were more involved in not only the environmental clubs (such as TDSB's EcoSchools), but student council and other extra-curricular (non-sport related) school 
activities as a whole. In contrast, when opportunities were presented to students such as aquaponics and urban farming, there was a higher interest from male students. One participant stated that "if you can get the boys to take a course [such as green industries], they actually really like it. They like to get dirty, they like to grow stuff". Another participant echoed this observation at their school with their aquaponics club, that "the farming aspect for city kids was really, really cool. And so that engage the males". They continued to express that perhaps "[...] we're just not advertising [environmental activities] the right way", and critiqued the EcoSchools model as it is "very scripted, and it's not necessarily getting out and doing environmental things". There is a heavy focus in EcoSchools on "trying to make recycling and waste management interesting" and "waste management is not the same as environmental education, it's only a component of it, yet it's a large component in EcoSchools". 


\section{CHAPTER SIX: Limitations and Recommendations}

\subsection{Limitations}

Limitations to this study include that the online survey and focus group participants were only drawn from TDSB schools (largest school board in Canada). The TDSB has unique characteristics in terms of teacher and student diversity, expansive facilities, location within a heavily urbanized area, and comparatively strong funding for programming and professional development. Despite these differences, many of the views expressed by the TDSB teachers, and reported on in this study, are applicable to the broader Province of Ontario as (i) the curriculum is set at the provincial level, (ii) the majority of Ontario's population resides in urban centres, and (iii) the TDSB is the largest school board within the province. It should also be recognized that although most TDSB school grounds have access to some form of greenspace, it is not equal in quality or equitably distributed amongst all school facilities. Because this research investigated teacher perceptions concerning leveraging existing greenspaces on school grounds for environmental education, soliciting input from only TDSB teachers may not have adequately captured the perspective held be teachers at schools in peri-urban or rural locations.

Other limitations included that study participants were not explicitly asked about all of the technologies they use with their students or to prepare and delivery lessons. During the online survey, there was the option for participants to add in any additional technologies; however, not all participants opted to add to the predetermined list. As well as, during the focus group, the question of all technologies used was never directly asked. This is a limitation as this research may

not have captured the breadth of technology used within the classroom to support the delivery of lessons. Additionally, the focus group was approximately three times as large as recommended, with a total of 18 participants. This is a direct result of the socio-political climate of impending 
labour-action at the time the focus group was held (September 12,2019). This is a limitation to the study as the larger focus group has the potential to impede the ability of all participants verbalizing their ideas, thoughts, and experiences for each question posed to the group. This was mitigated by the participants being given paper and writing utensils to record their responses, as outlined in the methodology and results sections.

\subsection{Recommendations}

This research has identified tangible avenues that teachers, and school boards alike, can pursue in order to bridge the gap between environmental rhetoric and action-oriented practice. Many of these avenues capitalize on bottom-up approaches that embrace simple and innovative methods to deliver environmental education that include using the schoolyard and the local community to undertake place-based and outdoor teaching that exposes students to many immediate and tangible human-environment conflicts. Moreover, curation of ICTs to complement and enhance mandated environmental curriculum is one recommended approach that teachers can take to engage students in the real-world collection of data, its analysis, and its interpretation.

Several ICTs exist that can be leveraged in this way, both of which encourage volunteered data in the form of citizen science. At the time of this writing, iNaturalist (www.inaturalist.org) is one of the most well-known international citizen science platforms, while the Citytrees Suite of tools (www.citytrees.ca; Ryerson University) is a locally developed ICT geared toward raising awareness about the urban forest and its many environmental, social and economic benefits. Citytrees Schoolyard, one of the suite's apps is being developed for teachers with curated lesson plans that link Ontario curriculum learning objectives to the urban forest found in the schoolyard and surrounding neighbourhood. Using ICTs in this manner may serve to bolster teacher 
knowledge and confidence in environmental topics, making such an approach educational for both the teacher and the students. 


\section{CHAPTER SEVEN: Conclusion}

Overall, the findings from this research study add to the growing literature concerning environmental education practices. They serve to benchmark current teachers' perceptions of environmental education as a priority in Ontario, and identify barriers to its delivery across all subjects, and inter-annually, as mandated by the 2009 policy framework, Acting Today, Shaping Tomorrow. Despite the Ontario Ministry of Education's policy on environmental education being in place for more than a decade, teachers who include environmentally-themed content in their lesson plans still feel they are treated like a minority, and report both lack of school and board resources, as well as limitations to their own knowledge and confidence, as it relates to the effective delivery of environmental education.

The inclusion of environmental education in school curriculum is increasingly important as human society is progressively feeling the negative effects of environmental degradation. Environmental education not only creates environmentally literate citizens, it can also foster (re)connection with nature in positive and meaningful ways that develop personal qualities of empathy and responsibility. There are many different top-down avenues to further support teachers in the delivery of environmental education, which include mandating environmental education courses during pre-service training (teachers' college), increasing professional development opportunities and workshops, and sustained financial support for outdoor education centres. At the same time, bottom-up initiatives are required immediately to bridge the gap between government rhetoric and classroom practice. As is stated in Acting Today, Shaping Tomorrow (2009a, p. 7), "More than ever, it is vitally important that our education system not only prepare students academically but also provide them with the skills, perspectives, and practices they will need to meet the social and environmental challenges of the future". Until there is transformative top-down 
action from the provincial government to support the policy framework, Acting Today, Shaping Tomorrow (2009), bottom up approaches such as leveraging environmentally themed ICTs to support teachers in their delivery if environmental education will necessary to foster the next generation of environmentally aware and action-oriented members of society. 


\section{Appendix A: Ethics and Research Permissions}

In order to conduct research where there are interactions with humans, the study design needed to be approved by the Ryerson Ethic's Board. In order to submit the ethics application, the primary researcher completed the Tri-Council Policy Statement: Ethical Conduct for Research Involving Humans - TCPS 2 (https://tcps2core.ca/) (Figure A1). Ethics was obtained through Ryerson Ethic's Board on Wednesday, March 8, 2019, approval file REB-2019-003 (Figure A2). Subsequently, additional permissions from the TDSB's External Research Review Committee (ERRC) was needed to conduct research within the board, and granted June 13, 2019 (Figure A3).

As part of the condition for approval were consent forms for the participants for both the online survey and participation in the semi-structured focus group. Please see below for a copy of the consent form approved by REB and ERRC, and that was used for the semi-structured focus group. The templates for both consent forms were the same, although the semi-structured focus group included information about audio recording, which did not pertain to the online survey. It should be noted that at the time of the focus group, Thursday September 12, 2019, there was still the intention of including a case-study using a web-based application, Citytrees Schoolyard, with a select number of semi-structured focus group participants. Due to time constraints and unforeseen circumstances, this was removed from the study design.

\section{PANEL ON}

RESEARCH ETHICS

Navigating the ethics of human research

\section{TCPS 2: CORE}

\section{Certificate of Completion}

This document certifies that

Courtney Carrier

has completed the Tri-Council Policy Statement:

Ethical Conduct for Research Involving Humans

Course on Research Ethics (TCPS 2: CORE)

Date of Issue:

7 January, 2019

Figure A1: Certificate of completion, for Courtney Carrier, of the Tri-Council Policy Statement: Ethical Conduct for Research Involving Humans Course on Research Ethics. 


\section{$\begin{array}{ll}\text { Research } \\ \text { Ryerson } & \text { Ethics Board }\end{array}$}

To: Andrew Millward

Geography and Environmental Studies

Re: REB 2019-003: Using Information Communication Technologies to Enhance Environmental Education Delivery by Ontario High School Teachers

Date: March 8, 2019

Dear Andrew Millward,

The review of your protocol REB File REB 2019-003 is now complete. The project has been approved for a one year period. Please note that before proceeding with your project, compliance with other required University approvals/certifications, institutional requirements, or governmental authorizations may be required.

This approval may be extended after one year upon request. Please be advised that if the project is not renewed, approval will expire and no more research involving humans may take place. If this is a funded project, access to research funds may also be affected.

Please note that REB approval policies require that you adhere strictly to the protocol as last reviewed by the REB and that any modifications must be approved by the Board before they can be implemented. Adverse or unexpected events must be reported to the REB as soon as possible with an indication from the Principal Investigator as to how, in the view of the Principal Investigator, these events affect the continuation of the protocol.

Finally, if research subjects are in the care of a health facility, at a school, or other institution or community organization, it is the responsibility of the Principal Investigator to ensure that the ethical guidelines and approvals of those facilities or institutions are obtained and filed with the REB prior to the initiation of any research.

Please quote your REB file number (REB 2019-003) on future correspondence.

Congratulations and best of luck in conducting your research.

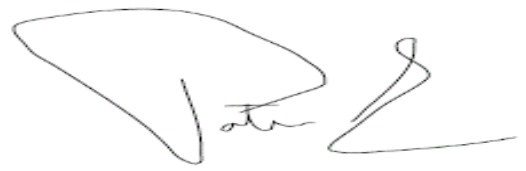

Dr. Patrizia Albanese, $\mathrm{PhD}$

Chair, Ryerson University Research Ethics Board

The Following protocol attachments have been reviewed and approved.

\section{Figure A2:}

Letter from the Ryerson Ethics Board, approving the research project as of March 8, 2019. 
June 13, 2019

Dear Courtney Carrier \& Dr. Andrew Millward,

Re: Using Information and Communication Technologies to Support Ontario Teachers in their Delivery of Environmental Education

On behalf of the External Research Review Committee (ERRC) of the Toronto District School Board I reviewed and accepted your follow-up responses to our earlier feedback (Feb $15^{\text {th }}$ ) for final ERRC approval. Thank you for submitting the Ryerson REB approval letter, a Principal Invitation and Information package outlining the Teacher commitments, a revised Parent Letter, survey edits, and updated timelines for the data collection and the Citytrees Schoolyard pilot project. I'd suggest you also communicate that release time would be provided for participation in the first focus group and workshop being conducted off-site.

We understand that you are collaborating with the Sustainability Office and the Green Project Team Leader and that they will help facilitate the initial recruitment of potential participants.

Please note that this ERRC approval does not obligate anyone to participate and the invited Principals and teachers may make the final decision about their own involvement. For ERRC's internal recordkeeping, please forward the final list of schools agreeing to participate in the project once that has been confirmed.

As a condition of this approval, ERRC will also look forward to receiving a copy of your research findings and summary report upon completion. The original application indicated a final report would be available by September 2019 however with the delay in scheduling we realize that due date will need to be updated. Please let us know what the expected reporting date would be now so that we can update our records.

Sincerely,

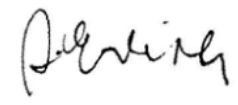

Sally Erling, Chair, External Research Review Committee, TDSB

E-mail: ERRC@tdsb.on.ca

c.c. Richard Christie, Senior Manager, Sustainability Office

Karen Dobrucki, Green Project Team Leader

2018-2019-46

\section{Figure A3:}

Letter from the TDSB's External Research Review Committee, approving the research project as of June 13, 2019. 


\section{TEACHER CONSENT AGREEMENT FOR FOCUS GROUP}

You're invited to participate in a research study. Please read this consent form so that you understand what their participation will involve. Before you consent to their participation, please do not hesitate to ask questions to clarify any concerns you may have.

STUDY: Using Information and Communication Technologies to Support Ontario Teachers in Their Delivery of Environmental Education

INVESTIGATORS: This research study is being conducted by Courtney Carrier (Masters of Applied Science Candidate) and Dr. Andrew Millward from the Department of Geography and Environmental Studies at Ryerson University.

If you have any questions about this research, please do not hesitate to contact Courtney Carrier (courtney.carrier@ryerson.ca) or Dr. Andrew Millward (millward@geography.ryerson.ca or 416979-5000 ext. 2673).

The dissemination of information gathered by this study will include the Masters of Applied Science thesis dissertation for Courtney Carrier. If you wish to review the results of this study please see the Ryerson Digital Depository: https://digital.library.ryerson.ca/. A direct link will be provided to your child's teacher and school once the study has been completed. We will also aim to publish a minimum of one journal publication that would target urban forestry related journals and/or environmental education journals (e.g. Urban Forestry \& Urban Greening, Canadian Journal of Environmental Education). Copies of any related publications stemming from this study may also be provided in full in PDF format.

Preliminary results of this study will be presented at the American Association of Geographers conference at the beginning of April, 2019. Additional reports will be written to be provided to share with the TDSB and TD Friends of the Environment.

PURPOSE OF THE STUDY: This study conducted by Ryerson University is in collaboration with the Toronto District School Board. The Ontario Ministry of Education's policy framework, Acting Today, Shaping Tomorrow (2007) outlines that environmental education should be included throughout all subject areas in the Ontario curriculum. This study seeks to determine if using technology can support teachers in their delivery and inclusion of environmental education in their classroom. The case study technology is a web-based application, Citytrees Schoolyard, that frames environmental education through an urban forestry lens.

WHAT YOU WILL BE ASKED TO DO: We are looking for 10-20 TDSB teacher's to participate in a focus group. In this focus group you will be a facilitated discussion exploring themes of environmental education and technology in the classroom. The focus group will include questions that intend to examine teachers' comfort with and inclusion of environmental education curriculum across a range of subjects including science, geography/social sciences, and mathematics, and invites discussion that addresses insight into existing effective strategies. The workshop component will take place in the latter half of the time allotted, where participants will learn about the web-based application, Citytrees Schoolyard, and have a chance to use it and 
provide feedback to the researchers. To participate in the focus group you must be a teacher within Ontario within the TDSB. A separate consent form will be provided for the workshop component. For more information about the Citytrees Project, check out: www.citytrees.ca.

If you do not wish to participate in the workshop component your time commitment will be approximately 1.5 hours. If you wish to participate in both the focus group and work shop, your time commitment will be approximately 3 hours and 15 minutes ( 1.5 hour focus group, 15 minute break, followed by 1.5 hour workshop). The focus group and workshop will be held [DATE, TIME, LOCATION].

If you cannot attend the focus group, but still wish to participate, please get in contact with either: Courtney Carrier (courtney.carrier@ryerson.ca) or Dr. Andrew Millward (millward@geography.ryerson.ca or 416-979-5000 ext. 2673) to arrange an in-depth interview.

POTENTIAL BENEFITS: This study will generate ideas and synthesize best practices regarding environmental education, which will help teachers reflect and recognize opportunities to possibly improve their engagement with the environmental curriculum that meets the Ontario Ministry of Education curriculum goals. Through the pilot project, which will utilize the web-based application Citytrees Schoolyard, teachers will be supported to facilitate students to learn about local trees, and their environmental and social benefits, in a meaningful way.

Our role as facilitators is aimed at creating and providing a tool to help students effectively and meaningfully learn about the local environmental in their classrooms, especially within the realm of urban fores try. We also assert that this project will help to increase environmental awareness and stewardship, specifically urban forestry and understanding of ecological value (socially, economically, and environmentally). Social benefits for this pilot project include learning about and working towards the long-term goal of creating a sustainable future for Canada.

Additionally, the implementation of the TDSB tree database (approximately 30,000 trees) into the Citytrees project database will provide the school community and also broader community with access to urban forestry data and knowledge of the benefits the trees produce. This information will also be beneficial in updating and managing urban forestry within the property of TDSB.

WHAT ARE THE POTENTIAL RISKS TO YOU AS A PARTICIPANT: The potential risks for your participation in this study are very low, however you may feel elements of discomfort when asked value or knowledge based questions. Participants could also possibly experience a low social risk in the form of a sense of discomfort or fear of criticism from others during group discussions due to the things that they say, or due to their unique learning pace.

If you do not want to participate in this study, there will be no negative effects to your job as an education with the TDSB. If consent is given and at the time of the pilot project you feel uncomfortable at any time, you are most welcome to skip such questions or activities, stop participation temporarily (e.g., take a break, and come back when you are ready to participate again), or choose to end your participation. 
CONFIDENTIALITY: Your participation is entirely voluntary, and you may decline to participate at any time. Your decision regarding whether or not you wish to participate will in no way jeopardize your position with the TDSB. Furthermore, you may decide to withdraw from this study at any time without any consequences by advising the researchers. If you withdraw, any feedback you have provided will be destroyed. With respect to the study, no identifying information will be given about the participants.

In regards to a publication that may arise out of this research, in the consent form that follows please indicate your preference regarding attribution. If you indicate that you can be quoted, you will have the opportunity to review and approve any quotations that would be attributed to you (or your general position/expertise) prior to any publication of research findings. Or, if you indicate that you wish to remain anonymous, your personal identity will not be disclosed and no direct quotes will be linked back to you.

With your consent, the focus group will be audio-recorded in order to allow the researchers full attention to facilitate discussion. The audio-recordings will be transcribed at a later date, verified, and then destroyed.

All data relating to this study, including the transcripts, will be password protected and stored on Ryerson University's Shared Google Drive. Any hard (paper) data that is related to this study will be kept in the secure faculty office of one of the researchers, Dr. Andrew Millward, at Ryerson University. Data will be stored for a period of three years at the end of this study after which time it will all be destroyed.

VOLUNTARY PARTICIPATION AND WITHDRAWAL: Please note that your participation is completely voluntary. You can choose whether or not to be in this study. You may stop participating at any time. If you choose to stop participating, you may also choose to not have their data included in the study.

QUESTIONS ABOUT THE STUDY: If you have any questions regarding this study, including the types of activities that will take place, anticipated benefits that will result from its findings, or any additional information that might assist in your decision about participating, please do not hesitate to contact either:

\section{Courtney Carrier at courtney.carrier@ryerson.ca}

or

Dr. Andrew Millward at millward@geography.ryerson.ca or 416-979-5000 ext. 2673

Please notify us as to whether you are interested in participating in this research study, that would be greatly appreciated. We look forward to hearing from you!

This study has been reviewed by the Ryerson University Research Ethics Board. If you have questions regarding your rights as a participant in this study please contact:

Research Ethics Board

c/o Office of the Vice President, Research and Innovation

Ryerson University

350 Victoria Street 
Toronto, ON M5B 2K3

416-979-5042

rebchair@ryerson.ca

Study: Using Information and Communication Technologies to Support Ontario Teachers in Their Delivery of Environmental Education

\section{CONFIRMATION OF AGREEMENT:}

Your signature below indicates that you have read the information in this agreement and have had a chance to ask any questions you have about the study. Your signature also indicates that you agree to your child's participation in the study and you have both been told that you can withdraw consent and refuse to participate at any time. You have been given a copy of this agreement. You have been told that by signing this consent agreement you are not giving up any of your legal rights.

Name of Participant (please print)

Date

Signature of Participant

Date

I agree to be audio-recorded for the purposes of this study. I understand how these recordings will be stored and destroyed.

Signature of Participant

Date 


\section{Appendix B: Online Survey Questions and Format}

The online survey, titled Using information and communication technologies to support Ontario teachers in their delivery of environmental education, was distributed through Google Forms. Section One and Two included the background information and consent form information prior to gaining access to the survey. If a participant clicked "no" to consent, the survey brought them to Section 9 - "Thank You", and the survey concluded. Please see Appendix A for the consent form. Please note that Appendix A is the consent form from the focus group, however, the templates were the same and the only major difference was the use of audio recording in the focus group, which is irrelevant to the online survey.

\section{Section 3}

Complete this survey to the best of your ability. If you do not feel comfortable answering the question, click the "No Answer" option. You are free to withdraw your consent to participate at any time. Withdrawal of your consent will have no impact on you or your employment at TDSB. The results of this survey will be used for the purpose of a Masters of Applied Science thesis dissertation. Participant responses to this survey will be kept confidential, and the identities of respondents will be anonymous.

\section{Section 4: Teacher Details}

Time to complete: approximately 3 minutes

1. Gender?

2. Your Age?
a. [short answer text]

a. Less than 30

b. 30 to less than 40

c. 40 to less than 50

d. 50 to less than 60

e. older than 60

f. No Answer

3. What is the name of your school?

a. [short answer text]

4. Select the option that best describes your employment
a. Full time
b. LTO/Supply
c. Retired
d. No Answer

5. What level of education do you teach?
a. Elementary (K-8)
b. High School (9-12)
c. No Answer

6. What are your teachables (select all that apply)?
a. The Arts (Fine Arts, Music, Dance, Drama)
b. Business
c. English
d. French or another language
e. Geography/History/Social Studies
f. Mathematics
g. Physical Education
h. Science
i. No answer 
7. How many years have been a teacher?
a. Less than 2
b. Between 2 and $<5$ years
c. Between 5 and $<10$ years
d. Between 10 and $<20$ years
e. Greater than 20 years
f. No Answer

8. Do you ever take summer courses to advance your teaching skills?
a. Yes, every year
b. Yes, every few years
c. Rarely
d. Never
e. No answer

\section{Section 5: Environmental Education}

Time to complete: approximately 12 minutes

1. The Ontario Ministry of Education mandates environmental education across the curriculum in all K-12 subject areas.
a. Yes
b. No
c. Don't Know
d. No Answer

2. You include environmentally themed education in your teaching.
a. Never
b. Once or Twice in a Course
c. Once a Month
d. Almost Weekly
e. Almost Daily
f. No Answer

3. You talk about the environment to your students.
a. Never
b. Rarely
c. Sometimes
d. Very Often
e. Always
f. No Answer

4. You take your students outside the classroom to learn about the environment (e.g., to the schoolyard or to a local park).
a. Never
b. Rarely
c. Sometimes
d. Very Often
e. Always
f. Not Applicable (environmental content is not discussed in my classes)
g. No Answer

5. Your classes use the internet or apps to learn about the environment.
a. Never
b. Rarely
c. Sometimes
d. Very Often
e. Always
f. Not Applicable (environmental content is not discussed in my classes)
g. No Answer 
6. You enjoy teaching about the environment.
a. Never
b. Rarely
c. Sometimes
d. Very Often
e. Always
f. Not Applicable (environmental content is not discussed in my classes)
g. No Answer

7. You feel confident teaching about the environment.
a. Never
b. Rarely
c. Sometimes
d. Very Often
e. Always
f. Not Applicable (environmental content is not discussed in my classes)
g. No Answer

8. Students are engaged when you teach about the environment.
a. Never
b. Rarely
c. Sometimes
d. Very Often
e. Always
f. Not Applicable (environmental content is not discussed in my classes)
g. No Answer

9. You teach about the environment in a local context (e.g. Toronto, Southern Ontario).
a. Never
b. Rarely
c. Sometimes
d. Very Often
e. Always
f. Not Applicable (environmental content is not discussed in my classes)
g. No Answer

10. Environmental education is important in $\mathrm{K}-12$.
a. Never
b. Rarely
c. Sometimes
d. Very Often
e. Always
f. Not Applicable (environmental content is not discussed in my classes)
g. No Answer

11. Environmental education is difficult to incorporate into K-12 teaching.
a. Never
b. Rarely
c. Sometimes
d. Very Often
e. Always
g. No Answer
a. Yes
b. Somewhat
c. No
d. Don't Know
e. No Answer

f. Not Applicable (environmental content is not discussed in my classes)

12. Environmental education is a difficult subject to teach. 
13. You are comfortable including environmental education in all subject areas that you teach.
a. Yes
b. Somewhat
c. No
d. Not Applicable (environmental content is not discussed in my classes)
e. No Answer

14. Environmental education outside of physical science is important.
a. Yes
b. Somewhat
c. No
d. Don't Know
e. No Answer

15. Environmental education is a priority in your classroom.
a. Yes
b. Somewhat
c. No
d. Not Applicable (environmental content is not discussed in my classes)
e. No Answer

16. Where did you obtain your knowledge to teach environmental education (select all that apply)?
a. Undergraduate Degree
b. Pre-service Education or Training (e.g., teacher's college)
c. Additional Qualification courses
d. Personal Learning (community events, additional resources, documentaries, etc.)
e. Not Applicable (environmental content is not discussed in my classes)
f. No Answer

17. You teach about the environment in a global context (e.g., United Nations materials, world news, etc.).
a. Never
b. Rarely
c. Sometimes
d. Very Often
e. Always
f. Not Applicable (environmental content is not discussed in my classes)
g. No Answer

18. You are familiar with the Ontario Ministry of Education's environmental education goals.
a. Yes
b. Somewhat
c. No
d. Don't Know
e. No Answer

19. Teachers are given adequate training in order to implement environmental education in their classrooms.
a. Strongly Disagree
b. Somewhat Disagree
c. Neutral
d. Somewhat Agree
e. Strongly Agree
f. No Answer

20. Teaching about the environment with hands-on assignments (e.g., data collection, field observations, experiments) helps students to understand complicated subject matter.
a. Strongly Disagree
b. Somewhat Disagree
c. Neutral
d. Somewhat Agree
e. Strongly Agree
f. No Answer 
21. Cities are part of the natural environment.
a. Strongly Disagree
b. Somewhat Disagree
c. Neutral
d. Somewhat Agree
e. Strongly Agree
f. No Answer

22. It is possible to include environmental education curriculum adequately without leaving the classroom.
a. Strongly Disagree
b. Somewhat Disagree
c. Neutral
d. Somewhat Agree
e. Strongly Agree
f. No Answer

23. You observe positive changes in your students behaviour attributable to environmental education (e.g., empathy, patience, focus, curiosity).
a. Strongly Disagree
b. Somewhat Disagree
c. Neutral
d. Somewhat Agree
e. Strongly Agree
f. Not Applicable (environmental content is not discussed in my classes)
g. No Answer

24. The quality of environmental education you are teaching is adequate.
a. Strongly Disagree
b. Somewhat Disagree
c. Neutral
d. Somewhat Agree
e. Strongly Agree
f. Not Applicable (environmental content is not discussed in my classes)
g. No Answer

25. The quality of environmental education your school is implementing is adequate.
a. Strongly Disagree
b. Somewhat Disagree
c. Neutral
d. Somewhat Agree
e. Strongly Agree
f. No Answer

26. You are knowledgeable about the EcoSchool's Program.
a. Yes
b. Somewhat
c. No
d. No Answer

27. You are employed at an EcoSchool.
a. Yes
b. Don't Know
c. No
d. No Answer 
28. How do you include environmental education in your classroom? (select all that apply)

a. Readings (e.g., textbooks, papers and other educational resources)

b. Media (e.g., daily news, documentaries, etc.)

c. Field Trips to Environmental Organizations (e.g., High Park Nature Centre, Evergreen Brickworks)

d. Nature Excursions (e.g., local park, schoolyard)

e. Through EcoSchool Activities

f. Not Applicable (environmental content is not discussed in my classes)

g. No Answer

29. Your school outsources environmental education to an outdoor education centre (e.g., High Park Nature Centre, Evergreen Brickworks).
a. Yes
b. Sometimes
c. No
d. Don't Know
e. No Answer

30. Your outdoor schoolyard/grounds is adequate to use for environmental education.
a. Yes
b. Sometimes
c. No
d. Don't Know
e. No Answer

31. Organizing field trips to take students off school property is straightforward.
a. Strongly Disagree
b. Somewhat Disagree
c. Neutral
d. Somewhat Agree
e. Strongly Agree
f. No Answer

32. You have received formal training in environmental science or studies (e.g., through university/college or professional certification).
a. Yes
b. No
c. No Answer

33. What have been sources of your environmental training (select all the apply)?

a. Undergraduate Degree

b. Graduate Degree (Masters/PhD)

c. Pre-service Education or Training (e.g., teacher's college)

d. Additional Qualification courses

e. College Diploma or Certificate

f. Other Certificate Programs

g. Personal Studies

h. Community Events

i. Not Applicable (I do not have any environmental training)

j. No Answer

34. More environmental training would better equip you to teach about the environment in the classroom.
a. Yes
b. No
c. Don't Know
d. No Answer

35. There are barriers to including environmental education in your classroom/lesson plans.
a. Yes
b. No
c. Don't Know
d. No Answer 
36. Identify barriers that you think may be preventing environmental education from being included in K-12 education. Select all that apply.
a. Lack of Knowledge
b. Lack of Confidence
c. Overcrowded Curriculum
d. Inadequate Planning Time
e. Lack of Resources
f. Difficulty Running Field Trips
g. Lack of Accessibility to Nature
h. There Are No Barriers
i. No Answer

37. Environmental education in all subject areas is realistic for $\mathrm{K}-12$.
a. Strongly Disagree
b. Somewhat Disagree
c. Neutral
d. Somewhat Agree
e. Strongly Agree
f. No Answer

38. Environmental education should be its own subject.
a. Strongly Disagree
b. Somewhat Disagree
c. Neutral
d. Somewhat Agree
e. Strongly Agree
f. No Answer

39. Environmental concepts are best taught in science or geography.
a. Strongly Disagree
b. Somewhat Disagree
c. Neutral
d. Somewhat Agree
e. Strongly Agree
f. No Answer

40. Environmental education is an afterthought in curriculum requirements.
a. Strongly Disagree
b. Somewhat Disagree
c. Neutral
d. Somewhat Agree
e. Strongly Agree
f. No Answer

\section{Section 6: Technology in the Classroom}

Time to complete: approximately 4 minutes

1. Your school uses technology in its classrooms (e.g., laptops, tablets, smart devices).
a. Always
b. Very Often
c. Sometimes
d. Rarely
e. Never
f. No Answer 
2. You use technology in your classroom (e.g., laptops, tablets, smart devices).
a. Always
b. Very Often
c. Sometimes
d. Rarely
e. Never
f. No Answer

3. Technology is helpful to teaching K-12 subjects.
a. Always
b. Very Often
c. Sometimes
d. Rarely
e. Never
f. No Answer

4. Teaching technology is reliable in your school.
a. Always
b. Very Often
c. Sometimes
d. Rarely
e. Never
f. No Answer

5. Teaching using technology as an educational tool is frustrating.
a. Always
b. Very Often
c. Sometimes
d. Rarely
e. Never
f. No Answer

6. Students enjoy using technology in the classroom.
a. Strongly Disagree
b. Somewhat Disagree
c. Neutral
d. Somewhat Agree
e. Strongly Agree
f. No Answer

7. Students expect technology as a teaching tool in the classroom.
a. Strongly Disagree
b. Somewhat Disagree
c. Neutral
d. Somewhat Agree
e. Strongly Agree
f. No Answer

8. Students are more engaged when taught using technology in the classroom.
a. Strongly Disagree
b. Somewhat Disagree
c. Neutral
d. Somewhat Agree
e. Strongly Agree
f. No Answer

9. Students retain more information when using learning-focused technology.
a. Strongly Disagree
b. Somewhat Disagree
c. Neutral
d. Somewhat Agree
e. Strongly Agree
f. No Answer 
10. Students are distracted when learning-focused technology is used in the classroom.
a. Strongly Disagree
b. Somewhat Disagree
c. Neutral
d. Somewhat Agree
e. Strongly Agree
f. No Answer

11. Your school is receptive to technology in the classroom for education purposes.
a. Strongly Disagree
b. Somewhat Disagree
c. Neutral
d. Somewhat Agree
e. Strongly Agree
f. No Answer

12. You are receptive to technology in the classroom when used for educational purposes.
a. Strongly Disagree
b. Somewhat Disagree
c. Neutral
d. Somewhat Agree
e. Strongly Agree
f. No Answer

13. What are barriers for teachers to including technology in the classroom and in lesson plans? Select all that apply.
a. Lack of Knowledge
b. Lack of Confidence
c. Overcrowded Curriculum
d. Inadequate Planning Time
e. Lack of Resources
f. Lack of Accessibility to Nature
g. There Are No Barriers
h. No Answer

14. Teaching students with current technology is a priority in your classroom.
a. Strongly Disagree
b. Somewhat Disagree
c. Neutral
d. Somewhat Agree
e. Strongly Agree
f. No Answer

15. What teaching technologies are available to you as an instructor? Select all that apply.
a. Laptops
b. Tablets
c. Desktop Computers
d. Smartboard (with internet connection)
e. None (I don't have access to teaching technologies)
f. No Answer

16. Students are capable of effectively using technology as a learning tool.
a. Strongly Disagree
b. Somewhat Disagree
c. Neutral
d. Somewhat Agree
e. Strongly Agree
f. No Answer 
17. Students are mandated by your school to bring a personal form of technology to the classroom for use as a learning tool (e.g., laptop, tablet).
a. Yes
b. No
c. Don't Know
d. No Answer

18. Your school is WIFI enabled, and this WIFI network can be accessed by teachers and students for learning and teaching purposes.
a. Yes
b. No
c. Teacher Only WIFI Enabled

\section{Section 7: Environmental Education \& Technology in the Classroom}

Time to complete: approximately 1 minute

1. Environmental education and technology are at odds with each other.
a. Yes
b. Somewhat
c. No
d. Don't Know
e. No Answer

2. Technology can facilitate teaching environmental education in K-12.
a. Yes
b. Somewhat
c. No
d. Don't Know
e. No Answer

3. You are interested in learning more about how technology can be used to support teaching environmental educational to K-12 students.
a. Yes
b. Somewhat
c. No
d. Don’t Know

\section{Section 8: Stay Informed}

If you're interested in learning how technology could help with environmental education in the classroom there are opportunities for you to continue your participation in the form of a focus group and in-class pilot project! If you have any questions about this study, please email Courtney Carrier at courtney.carrier@ ryerson.ca or Dr. Andrew Millward at millward@ ryerson.ca

Are you interested in participating in our focus group and would like more information?
a. Yes
b. No
c. No Answer

\section{Section 9: Thank You!}

Thank you for participating in our online survey! Your contribution is greatly appreciated. 


\section{Appendix C: Semi-Structured Focus Group Questions and Format}

Date: Thursday September 12, 2019

Time: 1:00 PM - 3:00 PM

Location: Jorgensen Hall 8th Floor, Room 802, Ryerson University, Toronto, Ontario

Each participant will have a section of paper covering the table in front of them, and writing utensils (e.g. pens and markers). The researcher will instruct the participants to refrain from initially speaking once the question is asked and to write their answers on the sticky notes provided, to limit repetitive answers. Once everyone has written down an answer (or exercises their right not to), the researcher will ask participants to read out what they wrote and let the discussion ensue.

Question One: What comes to mind when you hear "environmental education"?

Prompts: Do you think environmental education in all subject's areas is unrealistic?

Do you believe that environmental education should be its own subject, such as environmental science?

Do you think it's hard to bring in environmental concepts into other course than science or geography?

Do you feel like your school or school board provides opportunities enough for environmental education?

Do you feel like environmental education is an afterthought for curriculum requirements?

Question Two: How do you include environmental education into your classroom?

Prompts: Movies/shows/documentaries, news/recent events, community activities (tree planting, trash pick-ups, community gardening, etc.)

Do you think the schoolyard/grounds is "natural" enough to use it as the context for environmental education?

Field trips (e.g High Park Nature Centre, Evergreen Brickworks, etc.),

Do you find it hard to organize a field trip to outdoor education centres such as High Park Nature Centre, Evergreen

Brickworks, (etc.)?

Question Three: Are there barriers to incorporating environmental education into the classroom?

Prompts: Lack of confidence/education, time in planning, resources, support from the school/board

Question Four: Do you or your school use technology in the classrooms?

Prompts: Do you find technology helpful in the classroom?

Do you find technology unreliable in the classroom?

Do you get frustrated trying to use technology as an educational tool?

Do you think you're receptive to technology as an educational tool?

Do you feel supported by the school when you want to incorporate a new technology into your classroom?

Do you and your class have sufficient access to technology provided by the school?

Is the technology you have access adequate?

Question Five: Do you think your students enjoy using technology in the classroom?

Prompt: Do you think your students have come to expect technology in the classroom?

Do you think your students are more engaged when you use technological tools?

Do you think your students retain more information when using technology?

Do you think your students are more distracted when using technology?

Question Six: What barriers do teachers perceive to using technology as an educational tool?

Prompts: Does your school have access to computers/tablets, etc.? If so, are they adequate?

Is there a reliable WiFi connection?

Question Seven: Do you think technology and environmental education, or spending time outside, are at odds with each other? Why or why not?

Prompts: Do you feel that in order for environmental education to be effective you need to be outdoors, and this poses a barrier to including technology?

Do you think screen time is too prevalent, and therefore environmental education should be screen free?

Do you think technology can aid in your students understanding of environmental processes and relationships? 


\section{REFERENCES}

Agresti, A. (2013). Categorical data analysis (3rd ed.). Hoboken, NJ: Wiley.

Anderson, A. (2012). Climate change education for mitigation and adaption. SAGE Publications, 6(2), 191-206.

Andrews, B. (2003). Accountability in outdoor education. Toronto, ON: Andrews Education Services.

Appleton, J.V (1995). Analysing qualitative interview data: addressing issues of validity and reliability. Journal of Advanced Nursing, 22,993-997.

Ardoin, N.M., Bowers, A.W., Wyman Roth N., \& Holthuis, N. (2018). Environmental education and K-12 student outcomes: A review and analysis of research. The Journal of Environmental Education, 49(1), 1-17.

Ardoin, N. M., Clark, C., \& Kelsey, E. (2013). An exploration of future trends in environmental education research. Environmental Education Research, 19(4), 499-520.

Athman, J. \& Bates, T. (1998). Technology and environmental education: Friend or foe? Legacy $9(3), 12-15$.

Bangay, C., \& Blum, N. (2009). Education responses to climate change and quality: Two parts of the same agenda? International Journal of Education Development, 30, 359-368.

Basten, C. (1997). A feminised profession: Women in the teaching profession. Educational Studies 23(1), 55-62.

Blatt, E. (2013). Local tree mapping: A collaborative, place-based activity integrating science, technology, math, and geography. Science Activities: Classroom Projects and Curriculum Ideas, 50(3), 99-109.

Bolund, P. \& Hunhammar, S. (1999). Ecosystem service in urban areas. Ecological Economics, 29, 293-301.

Borland, J. (2009). A demonstration of craft: An outdoor educator's autoethnography.

Unpublished master's thesis, Brock University, Ontario, Canada. Retrieved from http://bit.ly/hFsoS9

Borland, J. (2011). Provoking dialogue: A short history of outdoor education in Ontario. The Ontario Journal of Outdoor Education, 23(2), 32-33.

Bowie, G. D., Millward, A. A., \& Bhagat, N. N. (2014). Interactive mapping of urban tree benefits using Google Fusion Tables and API technologies. Urban Forestry \& Urban Greening, 13(4), 742-755 
Blurton, C. (2002). "New directions of ICT-use in education" [pdf]. Retrieved June 14, 2018 from: http://www.unesco.org/education/lwf/dl/edict.pdf

Buabeng-Andoh, C. (2012). Factors influencing teachers' adoption and integration of information communication technology into teaching: A review of the literature. International Journal of Education and Development using Information and Communication Technology, 8(1), 136-155.

Buchanan, J., Pressick-Kilborn, K., \& Maher, D. (2018). Promoting environmental education for primary-aged students using digital technologies. EURASIA Journal of Mathematics, Science and Technology Education, 15(2), 1-15.

Calvani, A., Cartelli, A., Fini, A., \& Ranieri, M. (2008). Models and instruments for assessing digital competence at school. Journal of E-Learning and Knowledge Society, 4(3), 183-193.

Canadian Environmental Grantmakers' Network (2006, October). Environmental education in Canada [pdf]. Retrieved April 12, 2018 from: http://www.cegn.org/wpcontent/uploads/2013/10/EEBrief_Eng.pdf

Canadian Union of Public Education. (2019, June 5). TDSB trustees urged to save students' outdoor education from Ford government's cuts. Retrieved December 5, 2019 from: https://cupe.ca/tdsb-trustees-urged-save-students-outdoor-education-ford-governments-cuts

CBC News. (2019, May 22). Low income students to be hardest hit as TDSB looks to trim outdoor education programs, some warn [CBC News]. Retrieved December 20, 2019 from: https://www.cbc.ca/news/canada/toronto/tdsb-outdoor-education-budget-1.5145523

Chen, B., Gallagher-McKay, K., \& Kidder, A. (2014). Digital learning in Ontario schools: The 'new normal'. People for Education [pdf]. Retrieved Jan 15, 2020.

Citytrees (n/d). What is this? Retrieved February 22, 2018 from: https://citytrees.ca/overview/what-is-this\#content-1

Costanza, R., d'Arge, R., de Groot, R., Farber, S., Grasso, M., Hannon, B., Limburg, K., Naeem, S., O’Neill, R.V., Paruelo, J., Raskin, R.G., Sutton, P., \& van den Belt, M. (1997). The value of the world's ecosystem services and natural capital. Nature, 387, 253-260.

Cundiff, B. (1989). Reading, writing and the environment. Seasons, 29(3), 16-19.

Davey, I. E. (2003). The rhythm of work and the rhythm of school. In N. Janoviček \& J. Parr (Eds.), Histories of Canadian children and youth (pp. 108-121). Don Mills, ON: Oxford University Press.

Drudy, S. (2008). Gender balance/gender bias: the teaching profession and the impact of feminization. Gender and Education, 20(4), 309-323. 
Eickelmann, B. (2011). Supportive and hindering factors to a sustainable implementation of ICT in schools. Journal for Educational Research Online, 3(1), 75-103.

Eshach, H. (2007). Bridging in-school and out-of-school learning: Formal, non-formal, and informal education. Journal of Science Education and Technology, 16(2), 171-190.

Faber-Taylor, A., \& Kuo, F. E. (2009). Children with attention deficits concentrate better after walk in the park. Journal of Attention Disorders, 12(5), 402-409.

Fazio, X., \& Karrow, D.D. (2013). Negotiating the constraints of schools: Environmental education practices within a school district. Environmental Education Research, 19(5), 639-655.

Fazio, X., \& Karrow, D.D. (2015). Curricular critique of an environmental education policy: Implications for practice. Brock Education Journal, 24 (2), 88-108.

Fien, J. (1993). Education for the environment: Critical curriculum theorising and environmental education. Melbourne, Australia: Deakin University Press.

Gerber, B. L., Marek, E. A., \& Cavallo, A. M. L. (2001). Development of an informal learning opportunities assay. International Journal of Science Education, 23(6), 569-583.

Gilster P. (1997). Digital Literacy. New York, John Wiley.

Glassett, K., \& Schrum, L. (2009). Teacher beliefs and student achievement in technology-rich classroom environments. International Journal of Technology in Teaching and Learning, 5(2), $138-153$.

Government of Canada. (2002). A framework for environmental learning and sustainability in Canada [pdf]. Retrieved April 13, 2018 from:

http://www.emsb.qc.ca/en/greenplan/pages/resources/pdf/govDocs/EnvironCda_Framework.pdf

Government of Canada. (2017, July 24). Education in Canada: Elementary and secondary education. Retrieved January 30, 2020 from: https:/www.canada.ca/en/immigration-refugeescitizenship/services/new-immigrants/new-life-canada/enrol-school/elementary-secondary.html

Government of Ontario. (2019a, August 21). K-12 education: The kindergarten program 2016. Retrieved January 30, 2020 from: https://www.ontario.ca/document/kindergarten-program-2016

Government of Ontario. (2019b). 2019 Ontario budget: Protecting what matters [pdf]. Retrieved December 5, 2019 from: https://budget.ontario.ca/pdf/2019/2019-ontario-budget-en.pdf

Gruenewald, D.A. (2008). The best of both worlds: A critical pedagogy of place. Environmental Education Research, 14(3), 308-324. 
Gruenewald, D.A., \& Smith, G.A. (2008). Place-based education in the global age. New York: Routledge.

Greenwood, D.A, \& Hougham, R.J. (2015). Mitigation and adaptation: Critical perspectives toward digital technologies in place-conscious environmental education. Policy Futures in Education, 13(1), 97-116.

Hew, K. F., \& Brush, T. (2007). Integrating technology into K-12 teaching and learning: current knowledge gaps and recommendations for future research. Educational Technology Research and Development, 55, 223-253.

Higgins, S., Xiao, Z., \& Katsipataki, M. (2012). The impact of digital technology on learning: A summary for the education endowment foundation. Durham, UK: Education Endowment Foundation and Durham University.

Hsi, S., Pinkard, N., \& Woolsey, K. (2005). Creating equity spaces for digitally fluent kids. Retrieved June 5, 2019 from: https://www.exploratorium.edu/files/research/digitalkids/Digital_equity_paper.pdf

Jeffords, S. (2019, March 15). Ontario announces revamped sex-ed curriculum, increase in class sizes for high school [Global News]. Retrieved December 5, 2019 from: https://globalnews.ca/news/5059062/ontario-education-class-size/

Jickling, B. (2001). Climate change, global warming, and education with uncertainties. Canadian Journal of Environmental Education, 6(1), 5-7.

Jimoyiannis, A., \& Komis, V. (2007). Examining teachers' beliefs about ICT in education: Implications of a teacher preparation programme. Teacher Development, 11(2), 149-173.

John, P.D., \& Sutherland, R. (2004). Teaching and Learning with ICT: new technology, new pedagogy? Education, Communication \& Information, 4(1), 101-107.

Kalogiannakis, M., \& Papdakis, S. (2017). Combining mobile technologies in environmental education: A Greek case study. International Journal of Mobile Learning and Organisation, 11(2), 108-130.

Keengwe, J., \& Onchwari, G. (2008). Computer technology integration and student learning: Barriers and promise. Journal of Science Education and Technology, 17, 560- 565.

Kahn, R., \& Kellner, D. (2007). Paulo Freire and Ivan Illich: Technology, politics and the reconstruction of education. Policy Futures in Education, 5(4), 431-448.

Kidd, P.S., \& Parshall, M.B. (2000). Getting the focus and the group: Enhancing analytical rigor in focus group research. Qualitative Health Research, 10(3), 293-308. 
Kitzinger, J. (1995). Introducing focus groups. BMJ: British Medical Journal 311(7000), 299302.

Levin, B., \& Schrum, L. (2013). Using systems thinking to leverage technology for school improvement: Lessons learned from award-winning secondary schools/districts. Journal of Research on Technology in Education, 46(1), 29-51.

Louv R. (2005). Last Child in the Woods: Saving our children from Nature-deficit Disorder. Chapel HillNC: Algonquin Books of Chapel Hill.

Lowenstein, E. (2010). Navigating teaching tensions for civic learning. Learning and Teaching, $3(1), 32-50$.

Majoka, M. I., Fazal, S., \& Muhammad, S. K. (2013). Implementation of information and communication technologies (ICTs) in education course: A case from teacher education institutions in Pakistan. Bulletin of Education and Research, 35(2), 37-55.

Mannion, G., \& Adey, C. (2011). Place-based education is an intergenerational practice. Children, Youth and Environments, 21(1), 35-58.

Marshall, C. \& Rossman, G.B. (1989). Designing Qualitative Research. Sage, London.

Mårtensson, F., Boldemann, C., Söderström, M., Blennow, M., Englund, J.E., \& Grahn, P. (2009). Outdoor environmental assessment of attention promoting settings for preschool children. Health \& Place, 15(4), 1149-1157.

McKnight, K., O'Malley, K., Ruzic, R., Horsley, M.K., Franey, J.J., \& Bassett, K. (2016). Teaching in a digital age: How educators use technology to improve student learning. Journal of Research on Technology in Education 48(3), 194-211.

Merriam, S. B., \& Tisdell, E. J. (2015). Qualitative research: A guide to design and implementation. John Wiley \& Sons.

Miles, M.B., \& Huherman, A. (1984). Qualitative data analysis: A sourcebook of new methods. SAGE, London.

Millward, A.A, \& Sabir, S. (2011). Benefits of a forested urban park: what is the value of Allan Gardens to the City of Toronto, Canada? Landscape and Urban Planning, 100(3), 177-188.

Mnyusiwalla, L., Bentley, C., Ho, E., \& McCarthy, L. (2016). Education experts' workshop: Implementation of the Bondar Report (2007) [White Paper]. Ryerson University, Toronto Ontario.

Mnyusiwalla, L., \& Bardecki, M. (2017). Place-based education in the Ontario secondary school system. Canadian Journal of Environmental Education, 22, 116-135. 
Mooij, T. (2004). Optimising ICT effectiveness in instruction and learning: multilevel transformation theory and a pilot project in secondary education. Computers \& Education, 42(1), $25-44$.

Moosa, S., \& Bhana, D. (2017). Men managing, not teaching Foundation Phase: Teachers, masculinity and the early years of primary schooling. Educational Review, 69(3), 366-387.

Nasah, A., DaCosta, B., Kinsell, C., \& Seok, S. (2010). The digital literacy debate: An investigation of digital propensity and information and communication technology. Education Technology Research Development, 58, 531-555.

Neyland, E. (2011). Integrating online learning in NSW secondary schools: Three schools perspectives on ICT adoption. Australia Journal of Educational Technology, 27(1), 152-173

Ontario College of Teachers. (2018). 2018 Annual report: Statistics - Membership demographics. Retrieved April 16, 2020 from: https://reports2018.oct.ca/en/Statistics/Membership-Demographics

Ontario College of Teachers. (2020a). Becoming a teacher. Retrieved February 17, 2020 from: https://www.oct.ca/becoming-a-teacher

Ontario College of Teachers. (2020b). Types of teaching certificates. Retrieved February 18, 2020 from: https://www.oct.ca/public/professional-standards/how-teachers-arecertified/certificates

Ontario EcoSchools. (2018a). Mission and vision. Retrieved February 22, 2018 from: https://www.ontarioecoschools.org/about-us/mission-and-vision/

Ontario EcoSchools. (2018b). About us: Supporters. Retrieved March 10, 2018 from: https://www.ontarioecoschools.org/about-us/our-supporters/

Ontario Federation of Labour. (2020, January 20). Ford tracker: PC actions to date. Retrieved January 25, 2020 from: http://ofl.ca/power-of-many-ford-tracker-pc-cuts-and-privatization-todatel

Ontario Ministry of Education. (2007). Shaping our schools, shaping our future [pdf]. Retrieved February 22, 2018 from: http://www.edu.gov.on.ca/curriculumcouncil/shapingSchools.pdf

Ontario Ministry of Education. (2009a). Acting today, shaping tomorrow [pdf]. Retrieved February 22, 2018 from: http://www.edu.gov.on.ca/eng/teachers/enviroed/ShapeTomorrow.pdf

Ontario Ministry of Education. (2017a). Environmental education: Scope and sequence of expectations, 2017 edition. The Ontario curriculum grades 1-8 and the kindergarten program [pdf]. Retrieved March 14, 2018 from:

http://www.edu.gov.on.ca/eng/curriculum/elementary/environmental_ed_kto8_eng.pdf 
Ontario Ministry of Education. (2017b). Environmental education: Scope and sequence of expectations, 2017 edition. The Ontario curriculum grades 9-12 [pdf]. Retrieved March 14, 2018 from: http://www.edu.gov.on.ca/eng/curriculum/secondary/environmental_ed_9to12_eng.pdf

Ontario Ministry of Education. (2019a, August 22). School year calendar. Retrieved January 30, 2020 from: http://www.edu.gov.on.ca/eng/general/list/calendar/holidaye.html

Ontario Ministry of Education. (2019b, November 29). Ministry of Education. Retrieved January 30, 2020 from: https://www.ontario.ca/page/ministry-education

Ontario Secondary School Teachers' Federation. (2020). No cuts to education. Retrieved December 18, 2019 from: https://www.osstf.on.ca/en-CA/public-education/no-cuts-toeducation.aspx

Ontario Secondary School Teachers' Federation. (2019, May 22). Impact of class size increase: Modelling the effects on school programs - Full report [pdf]. Retrieved December 18, 2019 from: https://www.osstf.on.ca/public-education/no-cuts-to-education/research-and-reports-oneducation.aspx

Ontario Teachers' Pension Plan. (2018). 2018 annual report: All the right elements. [pdf]. Retrieved February 17, 2020 from: https://www.otpp.com/documents/10179/803025/Ontario+Teachers\%27\%20Pension+Plan+2018 +Annual+Report/3cf8ee83-e3d0-40a6-a3d7-954ff32695c9

Ottenbreit-Leftwich, A.T., Glazewski, K.D., Newby, T.J., \& Ertmer, P.A. (2010). Teacher value beliefs associated with using technology: Addressing professional and student needs. Computers \& Education, 55, 1321-1335.

Passmore, J. (1972). Outdoor education in Canada - 1972. Toronto, ON: Canadian Education Association.

Patton, M.Q. (1990). Qualitative evaluation and research methods. SAGE Publications, London

Pedretti, E., \& Nazir, J. (2014). Tensions and opportunities: A baseline study of teachers' views of environmental education. International Journal of Environmental \& Science Education, 9, 265-283.

Petko, D. (2012). Teachers' pedagogical beliefs and their use of digital media in classrooms: Sharpening the focus of the 'will, skill, tool' model and integrating teachers' constructivist. Computers \& Education, 58(4), 1351-1359.

Puk, T., \& Behm, D. (2003). The diluted curriculum: The role of government in developing ecological literacy as the first imperative in Ontario secondary schools. Canadian Journal of Environmental Education, 8, 217-232.

Pyle, R. M. (2001). The rise and fall of natural history. Orion, 20(4), 16-23. 
Resnick, M. (2002). Rethinking learning in the digital age. In The Global Information Technology Report” Readiness for the Networked World, edited by G. Kirkman. Oxford University Press.

Rickinson, M. (2001). Learners and learning in environmental education: A critical review of the evidence. Environmental Education Research, 7(3), 207-320.

Sam, P. (2019, August 28). TDSB to make hundreds of job cuts 2019-2020 school year [Global News]. Retrieved December 18, 2019 from: https://globalnews.ca/video/5825149/tdsb-to-makehundreds-of-job-cuts-for-2019-2020-school-year

Schaal, S., \& Lude, A. (2015). Using mobile devices in environmental education and education for sustainable development - Comparing theory and practice in a nation wide survey. Sustainability, 7, 10153-10170.

Selwyn, N. (2009). The digital native - myth and reality. Aslib Journal of Information Management, 61(4), 364-379.

Shepardson, D.P., Niyogi, D., Roychoudhury, A., \& Hirsch, A. (2012). Conceptualizing climate change in the context of a climate system: implications for climate and environmental education. Environmental Education Research, 18(3), 323-352

Skelton, C. (2012). Men teachers and the "feminised" primary school: A review of the literature. Educational Review 64(1), 1-19.

Smith, G.A., \& Sobel, D. (2010). Place - and community - based education in schools. New York, NY: Routledge, Taylor \& Francis Group.

Sinay, E., Ryan, T., \& Nahornick, A. (2016). Unpacking TDSB's vision for learning: research brief on digital fluency. (Research Report No. 15/16-18). Toronto, Ontario, Canada: Toronto District School Board.

Sobel, D. (1993). Children's special places. Tucson, AZ: Zephry Press.

Sobel, D. (1996). Beyond ecophobia: Reclaiming the heart in nature education. Great Barrington, MA: The Orion Society and The Myrin Institute.

Sobel, D. (1998). Mapmaking with children. Portsmouth, NH: Heinemann.

Sobel, D. (2004). Place-based education: Connecting classroom and community. Nature and Listening, 4, 1-7.

Statistics Canada. (2018, September 7). Back to school... by the numbers: 2018. Retrieved April 20, 2020 from: https://www.statcan.gc.ca/eng/dai/smr08/2018/smr08_220_2018\#a8 
Stevenson, R.B. (2007). Schooling and environmental education: Contradiction in purpose and practice. Environmental Education Research, 12(2), 139-159.

Swanwick, C., Dunnett, N., and Wooley, H. (2003). Naturel, role and value of green space in towns and cities: An overview. Built Environment 29(2), 94-106.

The Canadian Press. (2019, December 9). A list of cuts and program changes the Ford government has reversed [The Star]. Retrieved December 18, 2019 from:

http://www.edu.gov.on.ca/eng/funding/1920/Education_Funding_Sector_Engagement_Guide_20 $19 \_20$ en.pdf

Toronto District School Board. (n.d.). Toronto outdoor education centres. Retrieved December 5, 2019 from: https://schoolweb.tdsb.on.ca/toes/

Toronto District School Board. (2014a). EcoSchools: About us. Retrieved February 22, 2018 from: http://www.tdsb.on.ca/ecoschools/Home/About-Us

Toronto District School Board. (2014b). About us. Retrieved June 18, 2019 from: https://www.tdsb.on.ca/About-Us

Towner, T., \& Lego Munoz, C. (2016). Boomers versus millennials: Online media influence on media performance and candidate evaluations. Social Science, 5, 1-20.

University of Waterloo (n.d). Future workforce survey and management guide. Retrieved January 30, 2020 from: https://uwaterloo.ca/hire/how-to-recruit-motivate-and-retain-gen-z-atwork-future-workforce-survey-and-managementguide?gclid=EAIaIQobChMIIMCDhoe75wIVFWKGCh27jAqCEAAYASAAEgJBzPD_BwE

van Rijnsoever, F.J. (2017). (I can't get no) Saturation: A simulation and guidelines for sample sizes in qualitative research. PLoS ONE, 12(7), 1-17.

Vongkulluksn, V.W., Xie, K., \& Bowmana, M.A. (2018). The role of value on teachers' internalization of external barriers and externalization of personal beliefs for classroom technology integration. Computers \& Education, 118, 70-81. DOI:

https://doi.org/10.1016/j.compedu.2017.11.009

Wang, R., Wiesemes, R., \& Gibbons, C. (2012). Developing digital fluency through ubiquitous mobile devices: Findings from a small-scale study. Computers and Education, 58, 570-578.

Warin, J., \& Gannerud, E. (2014). Gender, teaching and care: A comparative global conversation. Gender and Education 26(3), 193-199.

Wee, M.C., \& Bakar, Z.A. (2006). Obstacles towards the use of ICT tools in teaching and learning of information systems in Malaysian Universities. The International Arab Journal of Information Technology, 3(3), 203-209. 
Wells, N.M. (2000). At home with nature: Effects of "greenness" on children's cognitive functioning. Environment and Behavior, 32(6), 775-795.

Wolsink, M. (2016). Environmental education excursions and proximity to green space densification in a 'compact city'. Environmental Education Research 22(7), 1049-1071.

Wozney, L., Venkatesh, V., \& Abrami, P. C. (2006). Implementing computer technologies:

Teachers' perceptions and practices. Journal of Technology and Teacher Education, 14(1), 173207.

\section{Acts and Laws}

Education Act, R.S.O. 1990, c. E.2, s 21 https://www.ontario.ca/laws/statute/90e02\#BK30 